\title{
HERMANNSTADT UND DIE STADTARCHÄOLOGIE
}

\author{
MARIA CRÎNGACI ȚIPLIC* ${ }^{*}$ IOAN MARIAN ȚIPLIC*** \\ * Institutul de Cercetări Socio-Umane Sibiu \\ Forschungsinstitut für Geisteswissenschaften Hermannstadt \\ 40, Bulevardul Victoriei, 550024 Sibiu, Rumänien \\ mariatiplic@icsusib.ro \\ ** Universitatea Lucian Blaga din Sibiu \\ Lucian-Blaga-Universität Hermannstadt \\ 10, Bulevardul Victoriei, 550024 Sibiu, Rumänien \\ ioan-marian.tiplic@ulbsibiu.ro
}

\begin{abstract}
Sibiu and the urban archaeology. During the last two-three decades the urban archaeology in Transylvania has pointed towards a visible progress. In the cities of Alba Iulia, Bistrița, Brașov, Baia Mare, Dej, Cluj-Napoca, Lugoj, Orăștie, Oradea, Sebeș, Sfântu Gheorghe, Sibiu, Sighișoara, Timișoara, Târgu Mureș and Turda archaeological investigations were carried out. In Sibiu, the first preemptive archaeological excavation took place in 1970 and focused upon the house and residence of the town's former mayor, Altemberger. Afterwards any archaeological campaign has been stopped for more than a decade. It was in 1983 that such endeavors have made a new start - once again in the respect to the same gothic historical civil monument. In Sibiu this was a year that is to be regarded as the beginning of scientific and salvage archaeological research, at an institutional level. Ever since then up until 2016 more than hundred archaeological interventions have taken place in Sibiu. After more than three decades of urban archaeological research and collecting information we must emphasize the need for centralizing, for developing a chronological repertoire, a mapping of archaeologically investigated objects, for listing the involved archaeologists, the results and various interpretations, the numerous papers, studies and monographs, as well as their abstracted interpretation.
\end{abstract}

Keywords: Sibiu, urban archaeology, medieval archaeology, medieval cities, Transylvania

Die Erforschung der Geschichte der mittelalterlichen Städte Siebenbürgens erlangte durch die von Paul Niedermaier in den 1970er Jahren initiierten wissenschaftlichen Untersuchungen der Geschichte mittelalterlicher Städte Siebenbürgens, des Banats und des Kreischgebietes eine neue Dimension, wie es im Verlauf von vier Jahrzehnten durch die Veröffentlichung mehrerer Bücher und Studien zu diesem Thema zum Ausdruck kam. ${ }^{1}$ Dabei beschränkte sich der Hermannstädter Architekt und Wissenschaftler nicht nur auf die Forschungsarbeit, deren Ergebnisse sowohl auf nationaler als auch internationaler Ebene Anerkennung fanden, ${ }^{2}$ sondern er begründete in Rumänien auch eine neue Forschungsrichtung, die sich im Juli 1991 mit der Gründung der Kommission für Städtegeschichte Rumäniens im Rahmen der Rumänischen Akademie (CIOR) mit Sitz in Hermannstadt konkretisierte. ${ }^{3}$

${ }^{1}$ Vorliegender Beitrag ist die deutsche Übersetzung des veröffentlichten Artikels M. CRîngaCI ȚIPLIC-I. M. ȚIPLIC: Sibiul și arheologia urbană. In: CiовANU-IACов 2017, 542-593. Der Artikel wurde von Nora Căpățână ins Deutsche übersetzt.

P. NIEDERMAIER: Siebenbürgische Städte. Forschungen zur städtebaulichen und architektonischen Entwicklung von Handwerksorten zwischen dem 12. und 16. Jahrhundert. București 1979; Ders.: Der mittelalterliche Städtebau in Siebenbürgen, im Banat und im Kreischgebiet. I. Die Entwicklung vom Anbeginn bis 1241. Heidelberg 1996; Ders.: Städtebau im Mittelalter. Siebenbürgen, Banat und Kreischgebiet. II. 1242-1347. Köln-Weimar-Wien 2002; Ders.: Städtebau im Spätmittelalter. Siebenbürgen, Banat und Kreischgebiet. III. 1348-1541. Köln-Weimar-Wien 2004; Ders.: Geneza orașelor me- dievale în Transilvania [Die Entstehung der mittelalterlichen Städte in Siebenbürgen]. Contribuţii privind istoria oraşelor 14. București 2016.

${ }^{2}$ Die Ergebnisse seiner Forschungen und die Bedeutung seiner Beiträge für die mittelalterliche Stadtgeschichte führten $1988 \mathrm{zu}$ seiner Aufnahme in die Internationale Kommission für Städtegeschichte (International Commission for the History of Towns), zur Verleihung verschiedener Ehrungen (1998 „Mihail Kogălniceanu“-Preis der Rumänischen Akademie und „Pro civitate Austriae“) und seiner Ernennung zum korrespondierenden Mitglied der Rumänischen Akademie (Abteilung Geschichtswissenschaft und Archäologie) im Jahr 2001.

${ }^{3}$ Beschluss des Präsidialbüros der Rumänischen Akademie vom 25. Juli 1991 (Informații privind istoria orașelor, Sibiu (1992) Nr. 1); P. NiEderMAIER: Comisia de Istorie a Orașelor - un 
Er war der Präsident dieser Kommission bis $2008 .{ }^{4}$ Durch die Gründung der CIOR gelang ihm die Schaffung von Forschungsstrukturen, d. h. einer Forschungsabteilung innerhalb des Forschungsinstituts für Geisteswissenschaften in Hermannstadt. Von da initiierte, begründete und/oder verfasste er eine Reihe editorischer Projekte, ${ }^{5}$ unter anderen Izvoare privind istoria timpurie a orașelor din România (Quellen zur frühen Geschichte der Städte Rumäniens), ${ }^{6}$ in dem ein Kapitel den wichtigsten archäologischen Entdeckungen gewidmet ist, „die ein konkludentes Bild der Anfänge mittelalterlichen städtischen Lebens auf dem Gebiet Rumäniens umreißen können“. ${ }^{7}$ Das Kapitel Repere arheologice privind orașele medievale ale diferitelor zone. Transilvania (Archäologische Anhaltspunkte zu den mittelalterlichen Städten der verschiedenen Gegenden. Siebenbürgen) stammt von dem Archäologen Zeno Karl Pinter, Wissenschaftler am Forschungsinstitut für Geisteswissenschaften Hermannstadt und Professor an der dortigen Lucian-Blaga-Universität. Zum ersten Mal werden hier die grundlegenden archäologischen Forschungen zusammengefasst, die in den siebenbürgischen Städten - in Karlsburg, Arad, Bistritz, Kronstadt, Karansebesch, Klausenburg, Diemrich, Lugosch, Mediasch, Großwardein, Broos, Mühlbach-Alba, Hermannstadt, Schässburg, Sankt Georgen, Neumarkt und Temeswar ${ }^{8}$ - durchgeführt wurden. Professor Paul Niedermaier ist die Einführung einer Vorlesung zur Geschichte mittelalterlicher Städte an der Lucian-Blaga-Universität Hermannstadt am Lehrstuhl für antike und mittelalterliche Geschichte zu verdanken, die von Kollegen der Abteilung mit archäologischen Lehrgrabungen an Baudenkmälern und mittelalterlichen Stätten in Broos, Hermannstadt und Karlsburg ergänzt wurde.

Seit zehn Jahren lässt sich eine Zunahme der archäologischen Rettungsgrabungen in den Zentren mittelalterlicher Städte beobachten, wobei die Forschungen nicht immer von mediävistischen Archäologen durchgeführt werden. Das liegt womöglich auch daran, dass es bisher kein Einverständnis auf theoretischer Ebene darüber gibt, was die Archäologie des Mittelalters in Rumänien bedeutet - was sich unserer Meinung nach aus dem Fehlen einer nachhaltigen Konzentration einer oder mehrerer Schulen der Mittelalterarchäologie ergibt.

Ein weiteres gemeinsames Problem der Mittelalterarchäologie und der Archäologie wurde von Harvey anschaulich umrissen, als er behauptete, dass ,es nicht ausreicht, Archäologe zu sein. Wir müssen in gleichem Maße auch Historiker sein“. ${ }^{9}$ D. Hinton unterstrich, dass die Aufgabe des Archäologen nicht darin bestehe, Belege zur Verfügung zu stellen, die dann von Historikern, die sich mit gesellschaftlichen oder wirtschaftlichen Aspekten beschäftigen, genutzt werden oder eben nicht, sondern die Bedeutung dieser Belege darzustellen, indem aufgezeigt wird, wie sie entstanden.

Die Tatsache, dass der Mittelalterarchäologe seinen Platz in der großen Familie der Archäologie noch nicht bestimmte, führt auch zu der Situation, dass Untersuchungen, die sich mit der sozialen, wirtschaftlichen oder demografischen mittelalterlichen Geschichte beschäftigen, die von der Archäologie hervorgebrachten Ergebnisse ignorieren, weil nicht alle, die sich mit Urkunden beschäftigen, das Potenzial der Mittelalterarchäologie verstanden oder verstehen.

Im Unterschied zur Situation der Archäologie in den Nachbarstaaten Rumäniens, in denen die wissenschaftliche und auch zahlenmäßige Gewichtung der mittelalterlichen Archäologie im Vergleich zu den anderen Spezialisierungen der archäologischen Wissenschaft ständig wuchs, sank das Interesse für die Erforschung mittelalterlicher Archäologie gegen Ende der 1980er Jahre in Rumänien schnell, als die Untersuchung der dakischen und dako-rumänischen Periode vor allem unter aufmerksamen politischen Vorgaben nachdrücklich erzwungen wurde. Heute können wir nicht von der Existenz einer Fachrichtung sprechen, die deutliche Unterkategorien der Forschung nach deutschem Vorbild definiert (Burgenarchäologie, Gräber- und Kirchenarchäologie, Siedlungs- und Stadtarchäologie). ${ }^{10}$

Die Tatsache, wonach die Archäologie des Mittelalters einer der jüngsten Bereiche der Archäologie ist, führte dazu, dass sie recht spät in die Studienprogramme der Universitäten aufgenommen wurde. Auch heute gibt es wenige Universitäten in Rumänien, die einen Teil ihres Lehrplans auf die Beschäftigung mit der Archäologie des Mittelalters richten. Eine glücklichere Situation herrscht in einigen westeuropäischen Ländern, wo Zentren gegrün-

deceniu de activitate [10 Jahre Tätigkeit der Städtegeschichtekommission]. Historia Urbana 10 (2002) 4. Am 8. Mai 1992 Sitzung für die Zusammenstellung der Kommission, Festsetzung des Kommissionsstatutes und Wahl der Kommissionsleitung: Paul Niedermaier - Präsident, Victor Spinei und Gheorghe Cantacuzino - Vizepräsidenten. Informații privind istoria orașelor, Sibiu (1992) Nr. 1.

${ }^{4}$ Informații privind istoria orașelor, Sibiu (2008) Nr. 138. Seit 2008 Ehrenpräsident der CIOR.

${ }^{5}$ Siehe V. Ciobanu: Paul Niedermaier la 80 de ani [Paul Niedermaier ist 80]. In: Cı́BANU-IACOB 2017, 13-19; bzw. die Präsentation durch M. CRÎNGaCI ȚiPliC-I. M. T,iplic: Profesorul şi cercetătorul Paul Niedermaier la 80 de ani [Der Professor und Forscher Paul Niedermaier wurde 80]. Anuarul Institutului de Cercetări Socio-Umane din Sibiu 24 (2017) 9-17.

${ }^{6}$ NiEDERMAIER 2005.

${ }^{7}$ Ebenda, 11.

${ }^{8}$ Ebenda, 188-207.

${ }^{9}$ D. A. Hinton (ed.): 25 Years of Medieval Archaeology. Sheffield 1983, 8.

${ }^{10}$ G. P. FeHring: Archaeology of Medieval Germany: An Introduction. London-New York 1991. 
det wurden, die traditionsgemäß Fachleute in mittelalterlicher Archäologie und Geschichte ausbilden: Cambridge (Großbritannien), Dijon (Frankreich), Tübingen und Darmstadt (Deutschland).

In Rumänien war die Mittelalterarchäologie eine kaum erforschte Disziplin an den Universitätszentren von Jassy, Constanţa, Klausenburg oder Temeswar, da dies lange Zeit Vorrecht des Bukarester Universitätszentrums war, zumindest ungefähr bis 1998. Gegenwärtig ist die Hermannstädter Universität eines der bedeutendsten Zentren, in denen die Mittelalterarchäologie ein Fach darstellt, das durch ein vollständiges Studium nach dem Bologna-System vertieft werden kann (Bachelor, Master, Doktorat). ${ }^{11}$ Im Bereich der Mittelalterarchäologie ist das Studienprogramm der Hermannstädter Universität vor allem auf die Unterbereiche Grabarchäologie und archäologische Denkmalforschung orientiert, was sich aus den Beschäftigungen der Fakultätsdozenten ergibt. ${ }^{12}$

Die städtische Archäologie ist ein neuerer Bereich von großer Aktualität, der in direkter Verbindung mit dem Schutz und der Erforschung historischer Stätten zur Skizzierung der städtischen Geschichte und Identität beiträgt und der Informationen bieten kann, wo es an schriftlichen Quellen in Hinblick auf Entstehung, Entwicklung und materielle Kultur der Städte mangelt - auch wenn ein Teil dieser Folgerungen womöglich eine Vielzahl von Debatten und Diskussionen auslösen mag. In Siebenbürgen erlebte diese neue Disziplin während der letzten zwei bis drei Jahrzehnte einen sichtbaren Fortschritt, der nicht nur durch archäologische Rettungsgrabungen im Zusammenhang mit umfangreichen Rehabilitations- und Modernisierungsarbeiten in öffentlichen Räumen und an historischen Gebäuden in Städten zu erklären ist, sondern auch durch die Entwicklung dieses Fachs, dank des Einsatzes einer Gruppe von Forschern im Bereich der Mittelalterarchäologie - im institutionellen Rahmen, am sichtbarsten in Hermannstadt, wie auch im Privatsektor, vertreten durch die Kronstädter Firma S.C. Damasus SRL unter der Leitung von Daniela Marcu Istrate. So wurden bemerkenswerte Ergebnisse erzielt, die teils in Ausstellungen, Katalogen, Fach- und populärwissenschaftlichen Studien oder Monographien präsentiert wurden. Wenn wir uns auf die Städte Siebenbürgens, des Banats und des Kreischgebietes beschränken, sind die folgenden Ortschaften zu nennen, wo umfassende archäologische Untersuchungen durchgeführt wurden: Alba Iulia (Karlsburg), Bistrița (Bistritz), Brașov (Kronstadt), Baia Mare (Frauenbach), Dej (Desch/Burglos), Cluj (Klausenburg), Lugoj (Lugosch), Orăștie (Broos), Oradea (Großwardein), Sebeș (Mühlbach), Sfântu Gheorghe (Sankt Georgen), Sibiu (Hermannstadt), Sighișoara (Schässburg), Timișoara (Temeswar), Târgu Mureș (Neumarkt), Turda (Thorenburg). ${ }^{13}$

Im Fall von Hermannstadt begann die erste archäologische Rettungsgrabung im historischen Zentrum um das Jahr 1970, als das Haus und die Residenz des namhaften Bürgermeisters Altemberger, das als „Altes Rathaus von Hermannstadt" bekannt ist, untersucht wurde. Dies ist eines der wertvollsten profanen Gebäude der Gotik in

2017.). $\quad{ }^{11}$ Siehe http://istorie.ulbsibiu.ro/specializari.php (21. 8.
${ }^{12}$ Für Einzelheiten siehe http://istorie.ulbsibiu.ro/catedre. php und http://arheologie.ulbsibiu.ro (21. 8. 2017.).

${ }^{13}$ Wir möchten in vorliegender Untersuchung nicht die Geschichtsschreibung der Stadtarchäologie Siebenbürgens diskutieren, sondern beschränken uns auf einige kürzlich erschienene Studien, aus denen sich das Stadium der Forschungen in diesem Bereich ergibt: Munteanu Beșliu 1998a, 87-102; A. A. Rusu: Cetatea Oradea. Monografie arheologicâ. I.: Zona palatului episcopal [Die Großwardeiner Burg. Eine archäologische Monografie. I.: Der Bereich des Bischofspalais]. Oradea 2002; PINTER 2003, 263-286; Z. K. PINTER: Repere arheologice privind orașele medievale ale diferitelor zone. Transilvania [Archäologische Belege für die mittelalterlichen Städte verschiedener Gebiete. Siebenbürgen]. In: Niedermaier 2005, 188-207, 199-200; MARCU Istrate 2007; Istrate 2007; F. DraŞOVEAN et al.: Timişoara în amurgul Evului Mediu. Rezultatele cercetărilor arheologice preventive din centrul istoric [Timişoara at the Dusk of the Middle Ages. The Results of Rescue Excavation from Historical Centre]. Bibliotheca historica et archaeologica Banatica 43. Timișoara 2007; D. MARCU Istrate: Catedrala romano-catolică „Sfântul Mihail“ și palatul episcopal din Alba Iulia. Cercetări arheologice 2000-2002 (The Roman-Catholic Cathedral and the Bishop's Palace of Alba Iulia [Gyulafehérvár]. The 2000-2002 Archaeological Research). Alba Iulia 2008; D. IsAC (coord.): Contribuții arheologice la istoria orașului Dej [Archaeological Contributions to the History of the City of Dej].
Cluj-Napoca 2008; E. GÁlL-B. GERGELY: Kolozsvár születése. Régészeti adatok a város 10-13. századi történetéhez (The Birth of Cluj. Archaeological Data Related to the City's History from the 10th to the 13th Century). Cluj-Napoca 2013; UrduZia 2010; L.-P. PuPEZă: Arheologia urbană în România. De la orașul antic la orașul contemporan [Urban Archaeology in Romania. From the ancient to the contemporary city]. In: H. PoP et al. (eds): Identități culturale, locale și regionale în context european. Studii de arheologie și antropologie istoric. In memoriam Alexandri V. Matei - Local and Regional Cultural Identities in European Context. Archaeology and historical anthropology. To the memory of Alexandri V. Matei. Bibliotheca Musei Porolissensis 13. Cluj-Napoca 2010, 701-711; Cs. SzABó: Primul arheolog urban al Transilvaniei: Béla Cserni [Der erste Stadtarchäologe Siebenbürgens, Béla Cserni]. Magazin Istoric 49/10 (2015) 2426; D. Marcu Istrate: Arheologia urbană a Braşovului [The Urban Archaeology of Brașov]. Transsylvania Nostra 10/2 (2016) 2-12; Cs. SzABó: Histories of urban archaeology in Alba Iulia (1916-2016). Transsylvania Nostra 10/2 (2016) 30-40; C. URduZIA: Arheologia urbană transilvăneană și descoperirile medievale ale ultimelor decenii [Transylvanian Urban Archaeology and the Mediaeval Discoveries of the Late Decades]. Transsylvania Nostra 10/2 (2016) 22-29; F. Drașovean-C. I. Suciu-D. Diaconescu: Cercetările arheologice preventive din anul 2015 în Piaţa Sfântul Gheorghe a Timişoarei [The 2015 Rescue Excavation in Timișoara's Sfântul Gheorghe Square]. Patrimonium Banaticum 6 (2016) 139-160. 
Siebenbürgen, ${ }^{14}$ erbaut in den letzten Jahrzehnten des 15. Jahrhunderts und den ersten Jahrzehnten des folgenden. Die im kleinen Innenhof des Alten Rathauses durchgeführte archäologische Sondierung von beschränktem Umfang wurde vom Archäologen des Landesamtes für historische Denkmäler in Bukarest, Nicolae Pușcaș, koordiniert, wobei die Untersuchung durch die Initiierung eines umfangreichen Restaurierungsprojektes bedingt war, das fast zwanzig Jahre dauerte. ${ }^{15}$ Ein ganzes Jahrzehnt wurden keine anderen archäologischen Forschungen in Hermannstadt mehr durchgeführt, erst im Jahr 1983 wurden sie an derselben historischen Stätte gotischer ziviler Architektur wieder aufgenommen. Die Untersuchung wurde vom Archäologen Thomas Nägler vom Forschungsinstitut für Geisteswissenschaften Hermannstadt und von Martin Rill, Kustos am Brukenthalmuseum in Hermannstadt, im Zusammenhang mit Restaurierungsarbeiten initiiert. Die Grabung wurde im Inneren und in der unmittelbaren Nachbarschaft des Ende des 15. Jahrhunderts gebauten Patrizierturmes durchgeführt. ${ }^{16}$ Somit kann 1983 als das Jahr angesehen werden, als in Hermannstadt archäologische Fach- und Rettungsgrabungen im institutionellen Rahmen eingeleitet wurden. Seitdem und bis 2016 wurden über hundert archäologische Interventionen umgesetzt, die Mehrheit koordiniert von Hermannstädter Archäologen vom Brukenthal Nationalmuseum (BNM), durch die LucianBlaga-Universität in Sibiu/Hermannstadt (LBU Sibiu) und das Forschungsinstitut für Geisteswissenschaften Hermannstadt (Institutul de Cercetări Socio-Umane din Sibiu - ICSU Sibiu) (s. Tabelle 1 und Karte 1). Einige archäologische Untersuchungen, allerdings die von großem Umfang, wurden von den Kronstädter Archäologen der S.C. Damasus SRL durchgeführt. Durch die im Alten Rathaus Hermannstadts vorgenommenen archäologischen Forschungen leitete der Archäologe Thomas Nägler die Reihe stadtarchäologischer Rettungsgrabungen in Hermannstadt ein. Die im Jahre 1983 begonnenen Untersuchungen des Alten Rathauses wurden ab 1984 vom Hermannstädter Archäologen Petre Beșliu Munteanu übernommen, der am Nationalmuseum Brukenthal angestellt war und mehr als fünfzehn Jahre die schwierige Mission annahm, archäologische Untersuchungen - Rettungsforschungen sowie systematische Erkundungen - sowohl am Alten Rathaus als auch an verschiedenen anderen Stellen im historischen Stadtzentrum von Hermannstadt durchzuführen.

Ein weiteres bedeutendes Jahr für die Hermannstädter Stadtarchäologie ist 1999, als die Mittelalterarchäologen der Hermannstädter Lucian-Blaga-Universität und des Hermannstädter Forschungsinstituts für Geisteswissenschaften - Zeno Karl Pinter ${ }^{17}$ und Ioan Marian Țiplic - durch ihre Rettungsgrabungen, die sie im Inneren der Evangelischen Kirche von Hermannstadt, bei einem Haus am Huetplatz Nr. 17 und einem Haus auf der Färbergasse Nr. 13 durchführten, die Bühne der Hermannstädter Stadtarchäologie betraten. Von 1999 bis 2005 wurden die archäologischen Untersuchungen in Hermannstadt von den Archäologen des Brukenthalmuseums Hermannstadt und der Lucian-Blaga-Universität koordiniert (s. Tabelle 1).

Das Jahr 2005 könnte man als Orientierungsjahr für die Stadtarchäologie Hermannstadts und Rumäniens bezeichnen, da man in Hermannstadt „,die umfangreichste Rettungskampagne städtischer Archäologie“ in Rumänien bis zu jenem Zeitpunkt - mit Ausnahme von Bukarest - umsetzte. ${ }^{18}$ Die Arbeiten wurden im Rahmen von Restaurierungs-, Modernisierungs- und Rehabilitierungsprojekten öffentlicher Flächen im historischen Zentrum von Hermannstadt begonnen, die durch das Rathaus von Hermannstadt im Zusammenhang mit den Vorbereitungen der Stadt auf den Titel „Europäische Kulturhauptstadt 2007“ finanziert wurden. Zwischen 2005 und 2006 wurden 22 Rettungsgrabungen durchgeführt - einige davon auf sehr großen Flächen, wie auf dem Huetplatz, Großen Ring, Kleinen Ring, Hermannsplatz/Kasernplatz, Bahnhofsplatz, Fingerlingsplatz, in der Harteneckgasse, Wiesengasse usw. Da die Archäologen von Hermannstadt und die Hermannstädter Institute durch die große Anzahl der Anfragen nach Rettungsgrabungen, Aufsichten und Präventivgrabungen in dieser Zeit überfordert waren, wurden auch Archäologen aus verschiedenen anderen Städten (Kronstadt, Temeswar, Klausenburg) durch die private Firma S.C. Damasus

${ }^{14}$ P. NiEDERMAiER: Städte, Dörfer, Baudenkmäler. Studien zur Siedlungs- und Baugeschichte Siebenbürgens. Als Festgabe zum 70. Geburtstag herausgegeben vom Vorstand des Arbeitskreises für Siebenbürgische Landeskunde. Studia Transylvanica 36. KölnWeimar-Wien 2008, 205-211; FABINI 1997, 6-16.

${ }^{15}$ FABINI 1997, 6-16. Die Ergebnisse der von Nicolae Pușcaş durchgeführten archäologischen Sondierung wurden nie veröffentlicht, da sie verloren gingen. BEŞLIU 1997.
${ }^{17}$ Zeno Karl Pinter, seit 1991 Wissenschaftler und Archäologe am Forschungsinstitut für Geisteswissenschaften Hermannstadt, führte die ersten stadtarchäologischen Untersuchungen seit 1991 an der Burg in Broos durch Orăștie - cetate. PINTER 2003, 263-286; P. NIEDERMAIER (Hrsg.): Institutul de Cercetări Socio-Umane Sibiu / Forschungsinstitut für Geisteswissenschaften Hermannstadt. Semicentenar 1956-2006. Sibiu 2006, 193.

${ }^{18}$ S. NISTOR: Cuvânt înainte [Vorwort]. In: MARCU ISTRATE $2007,7$. 


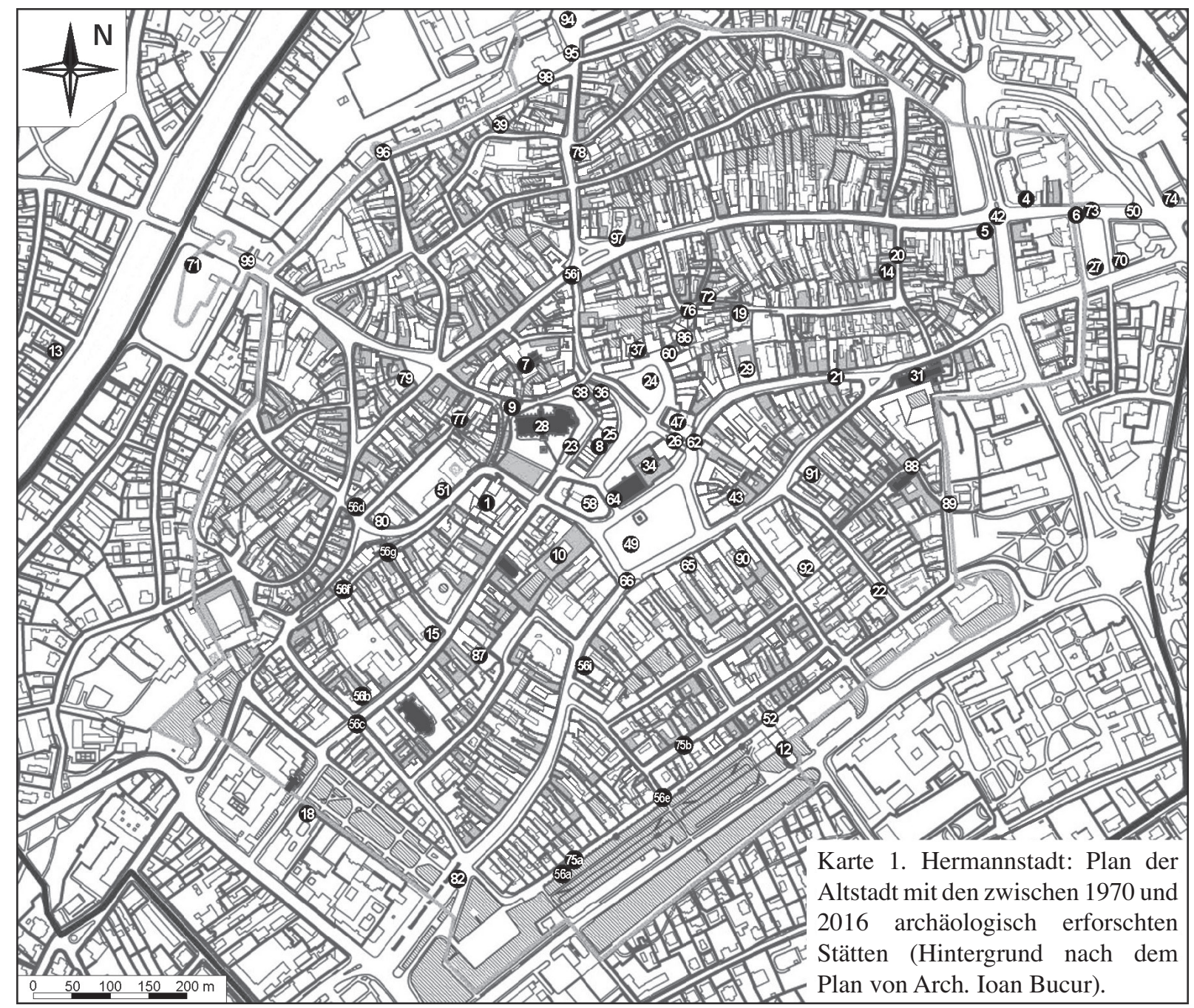

Karte 1. Hermannstadt: Plan der Altstadt mit den zwischen 1970 und 2016 archäologisch erforschten Stätten

(Hintergrund nach dem Plan von Arch. Ioan Bucur)

SRL unter der Leitung von Daniela Marcu Istrate und Angel Istrate herangezogen (s. Tabelle 1). Nach 2007 sank die Anzahl der Rettungsgrabungen in Menge und Umfang.

Nach mehr als drei Jahrzehnte andauernden stadtarchäologischen Forschungen und mithilfe der Sammlung von Daten können wir heute - trotz einiger bisher nicht oder nur teilweise veröffentlichter Untersuchungen und mancher Sanierungsarbeiten im historischen Zentrum Hermannstadts, die ohne archäologische Aufsicht und Rettungsgrabungen erfolgten - sagen, dass Hermannstadt die einzige Stadt in Siebenbürgen ist, die nicht nur von zahlreichen archäologischen Rettungsgrabungen profitierte, sondern die sich durch die Weitergabe archäologischer Ergebnisse, die in relativ großem Umfang veröffentlicht wurden, auszeichnet (s. Tabelle 1). Von Nachteil ist, dass nur ein kleiner Teil der erlangten Angaben in die allgemeine Geschichtsforschung, die dem Leser Informationen über die mittelalterliche Archäologie Hermannstadts und Siebenbürgens vermitteln kann, übernommen wurde, obwohl die Stadtarchäologie eine wichtige Rolle bei der Erforschung der Entstehung mittelalterlicher Städte, der Stadtentwicklung Siebenbürgens, der städtischen Zivilisation und der siebenbürgischen materiellen Kultur spielt. Bis in die Gegenwart gibt es keine Monographie, die die Stadtarchäologie einer mittelalterlichen Stadt Siebenbürgens darstellt. ${ }^{19}$ Im gegenwärtigen Forschungsstadium wäre Hermannstadt ein idealer Kandidat für ein solches Unterfangen. Deshalb begannen wir ein Projekt, das in einer ersten Phase der Zentralisierung, chronologischen Erfassung und Kartierung der archäologisch untersuchten Objekte gewidmet ist sowie der Erfassung der beteiligten Archäologen, erzielten 


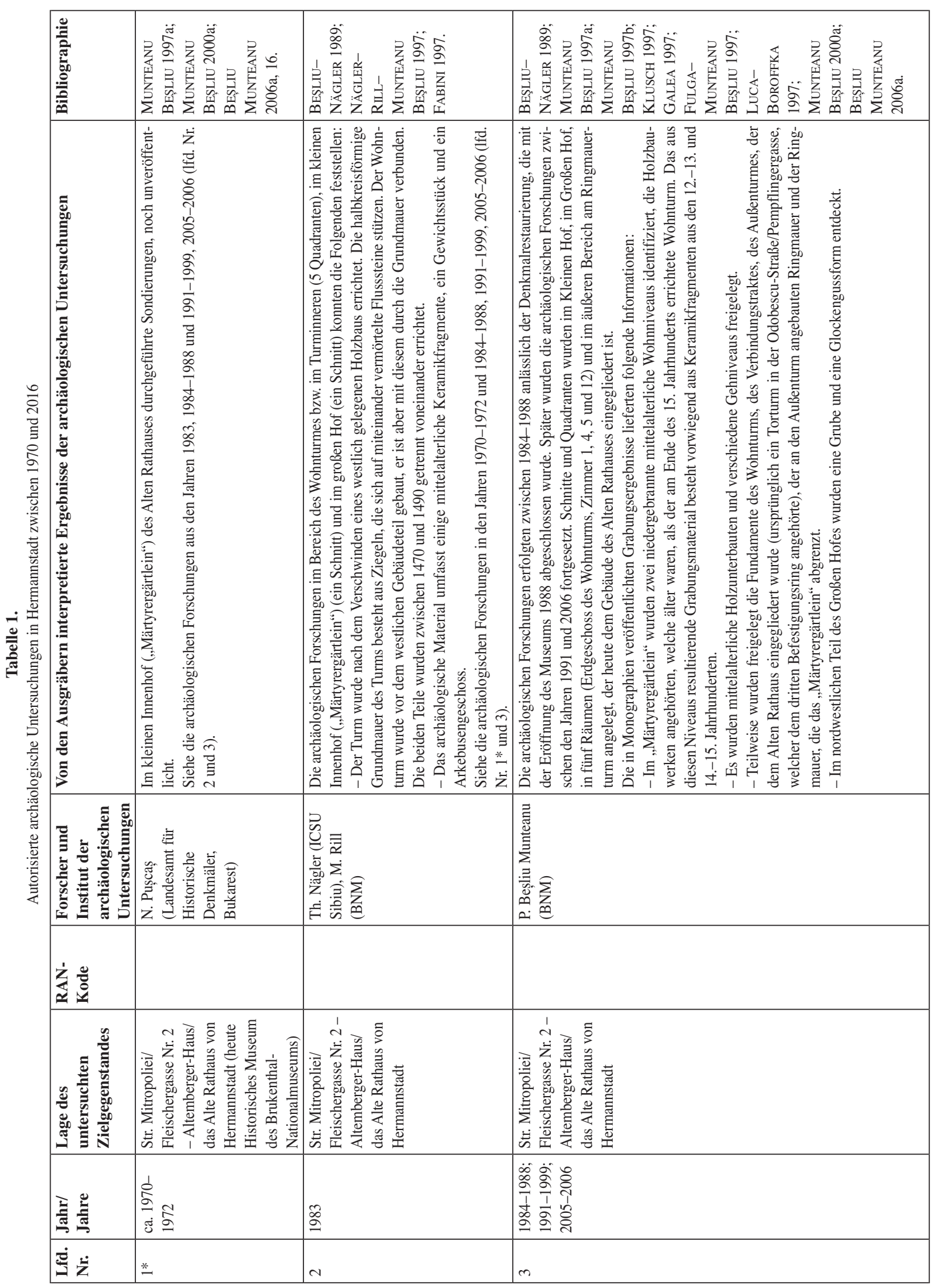

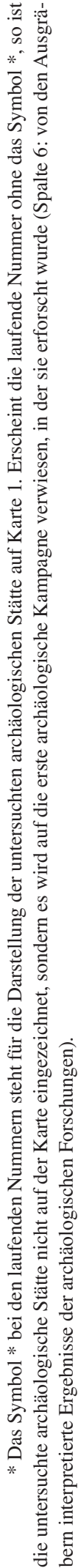




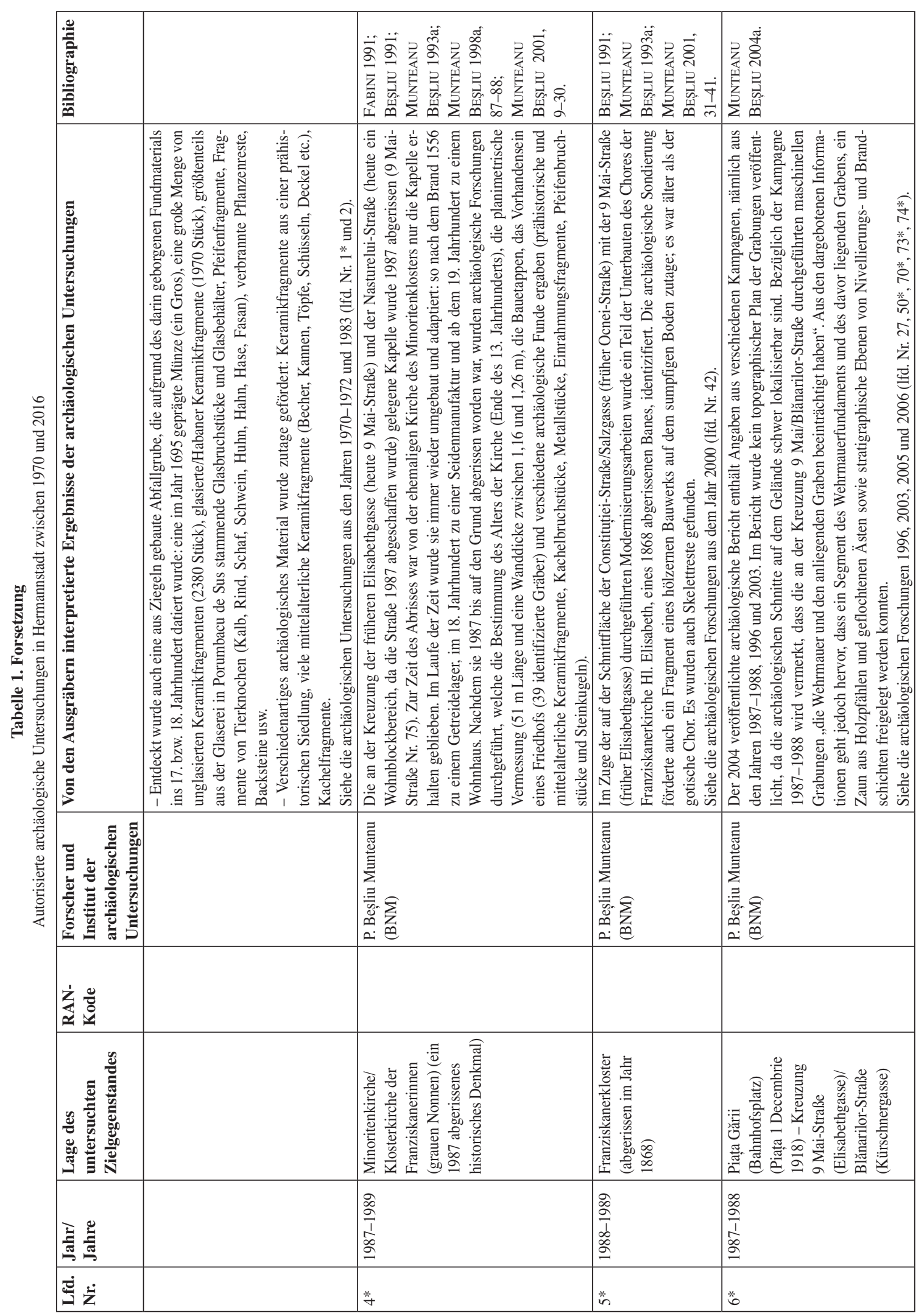

Acta Archaeologica Academiae Scientiarum Hungaricae 70, 2019 


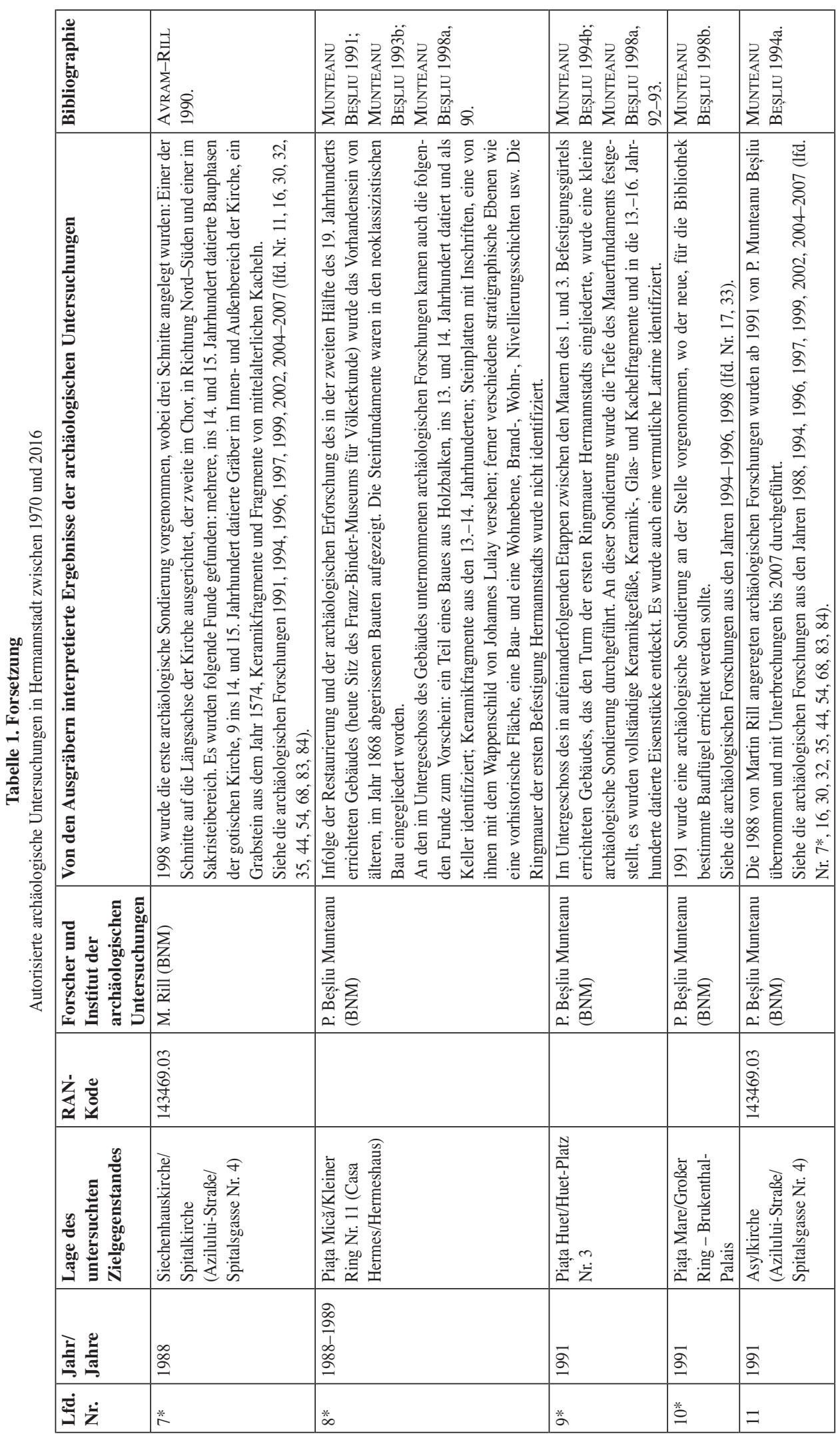

Acta Archaeologica Academiae Scientiarum Hungaricae 70, 2019 


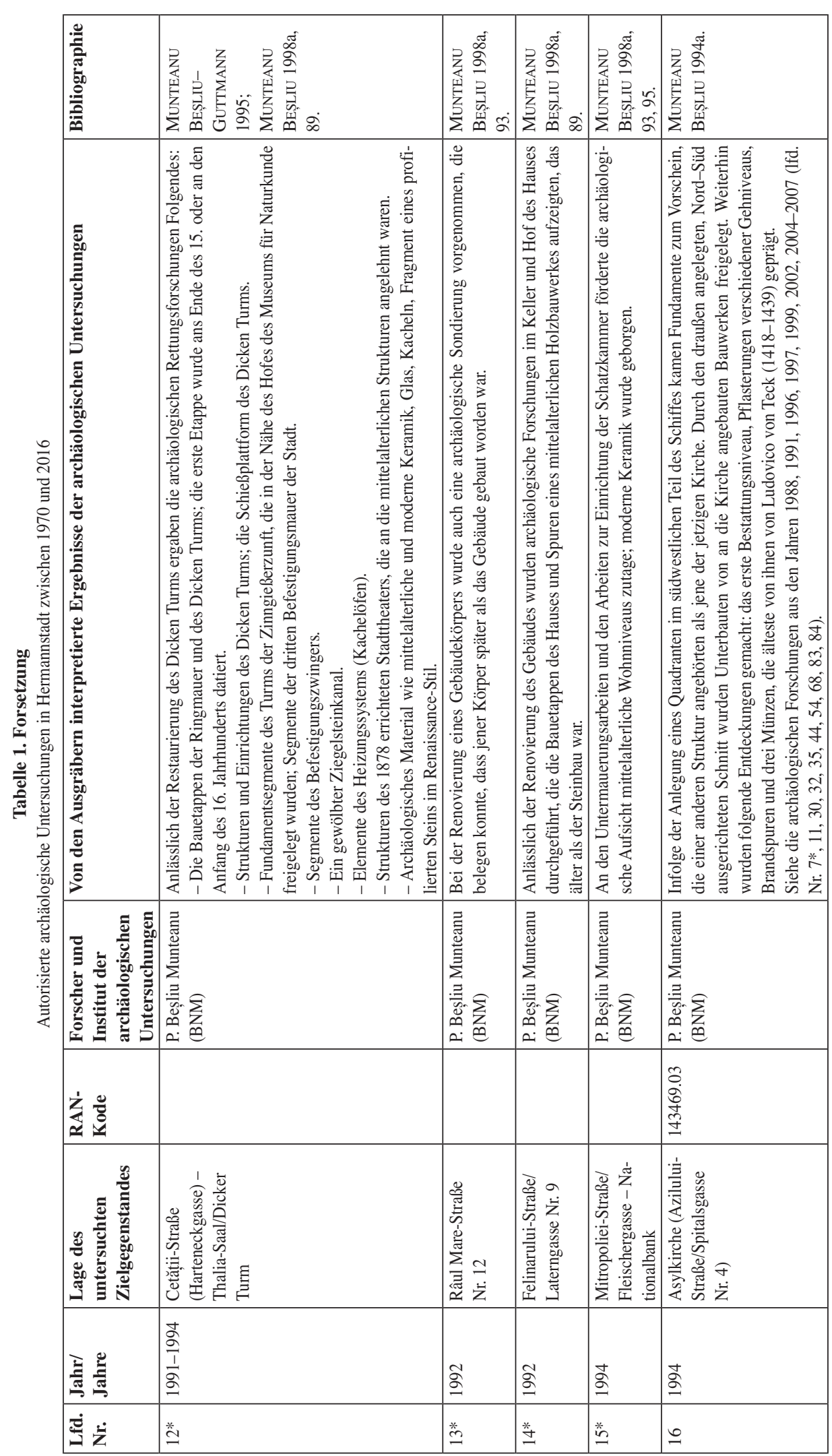

Acta Archaeologica Academiae Scientiarum Hungaricae 70, 2019 


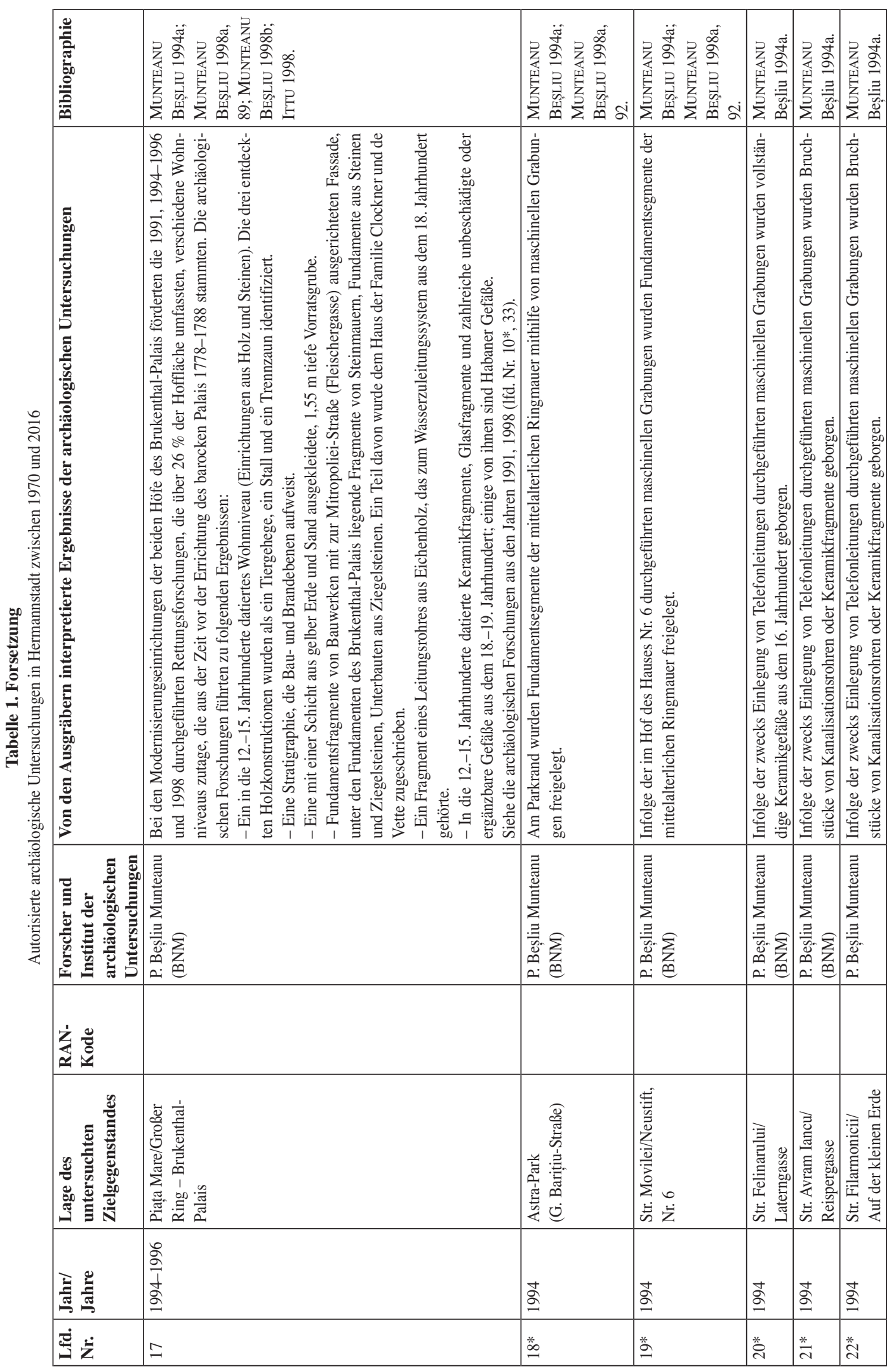

Acta Archaeologica Academiae Scientiarum Hungaricae 70, 2019 


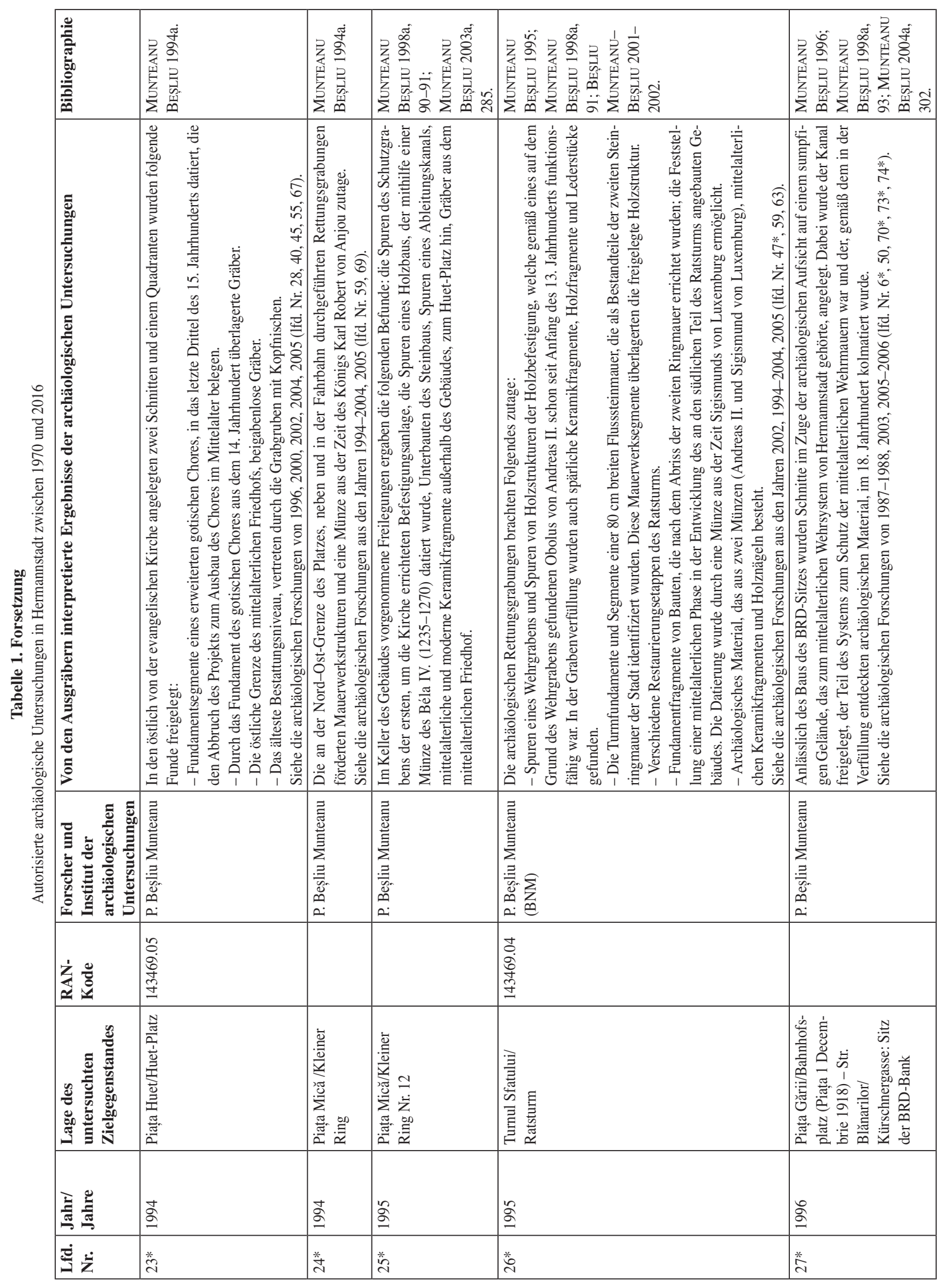

Acta Archaeologica Academiae Scientiarum Hungaricae 70, 2019 


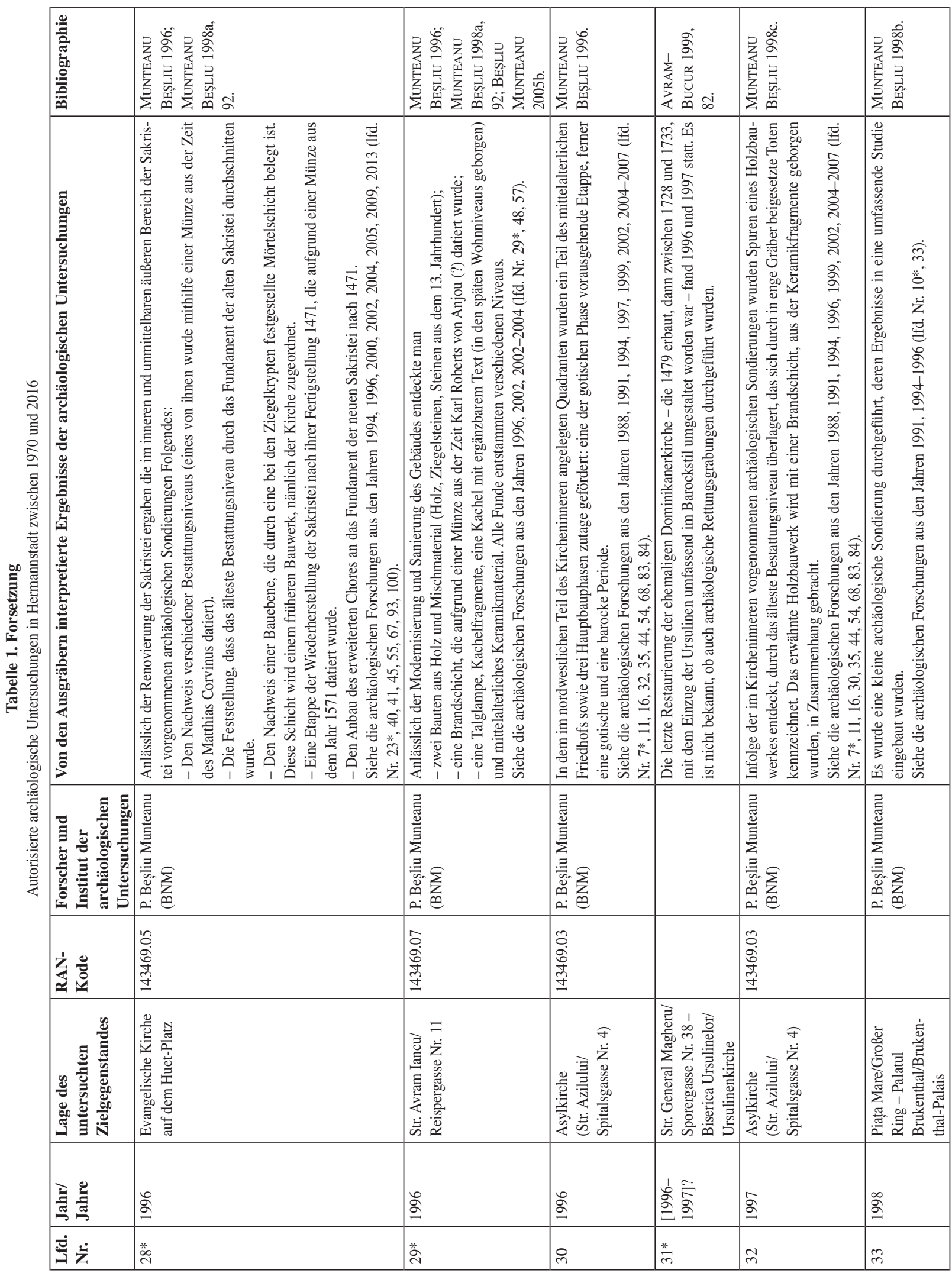




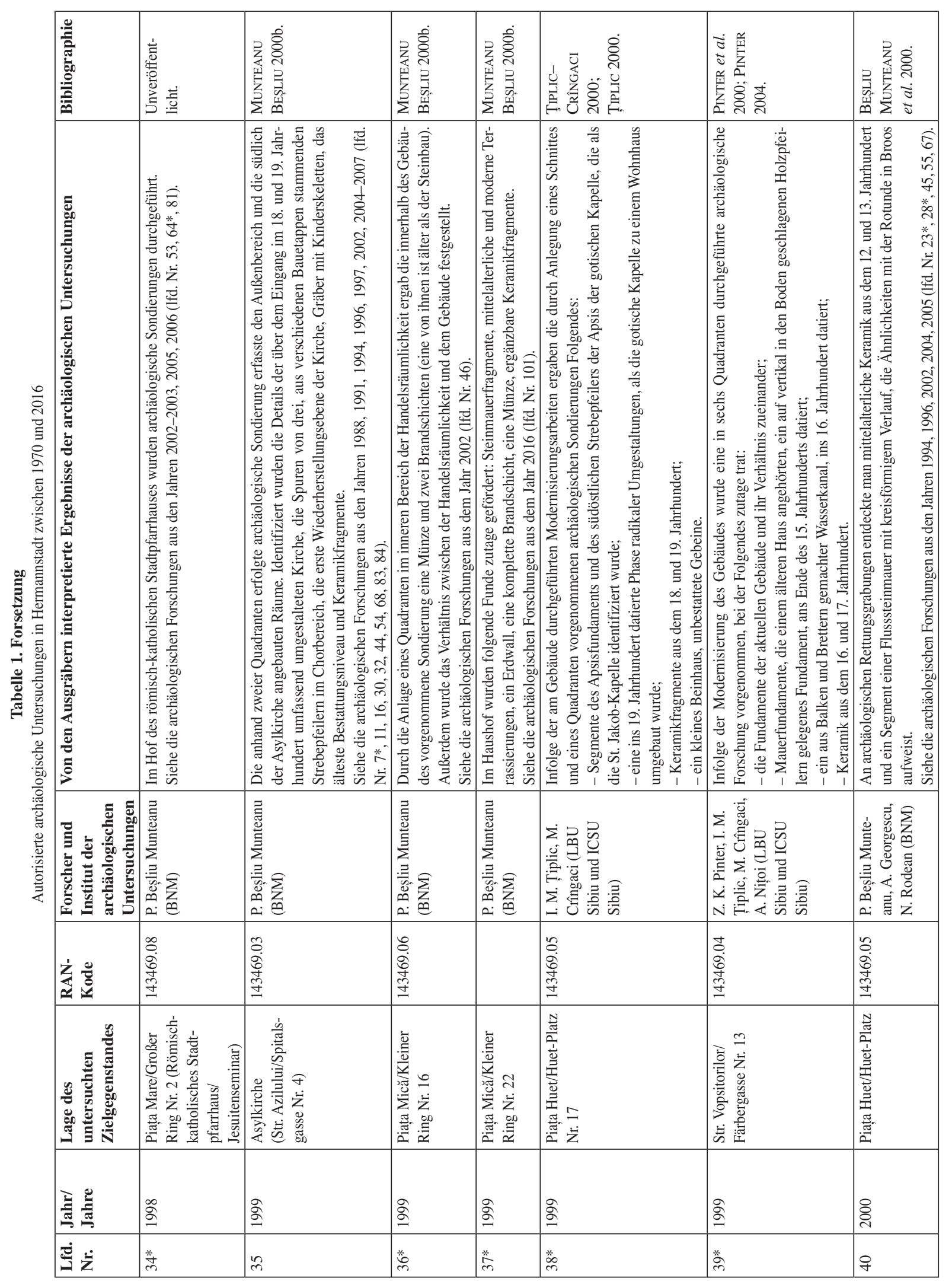

Acta Archaeologica Academiae Scientiarum Hungaricae 70, 2019 


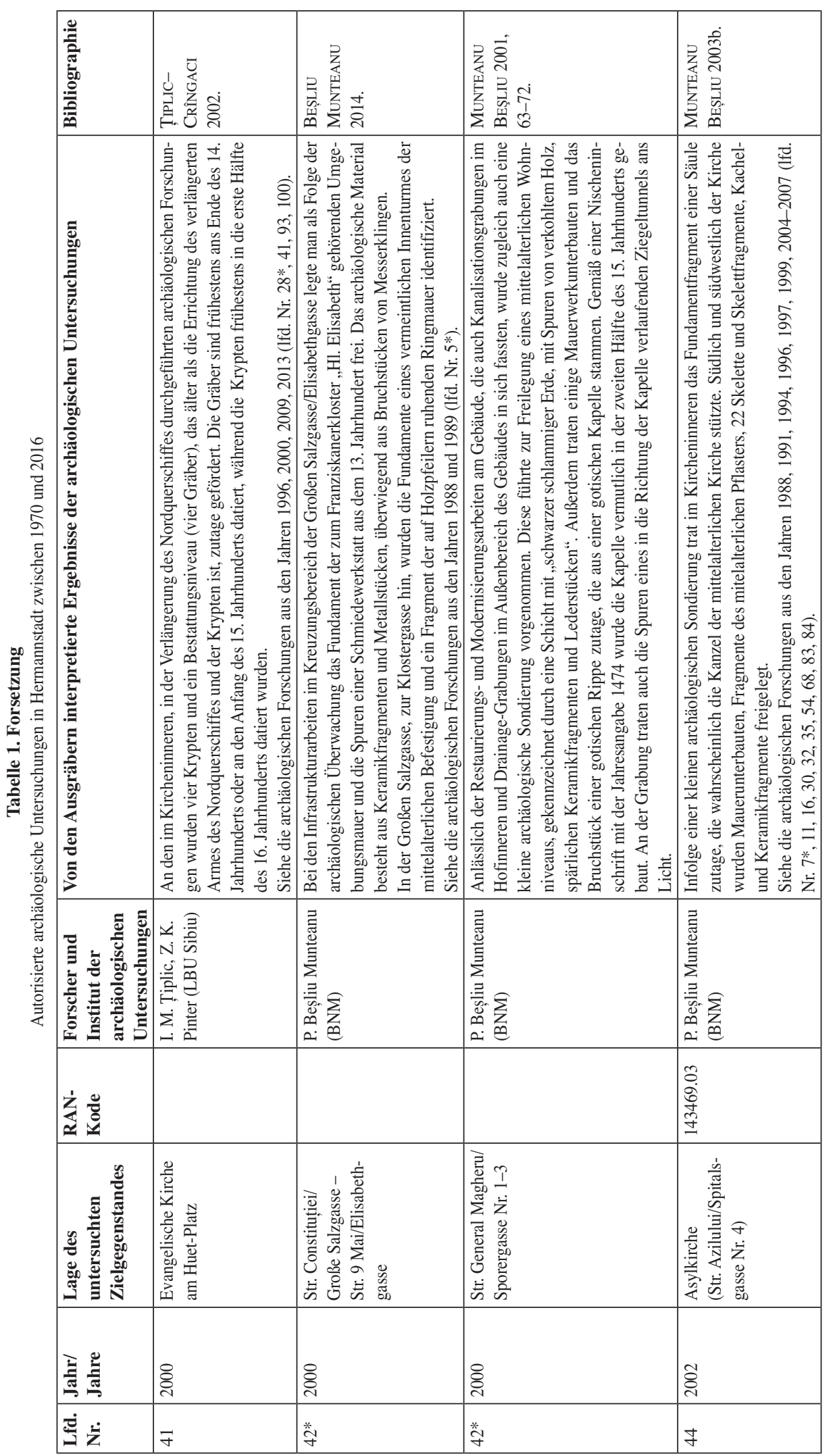

Acta Archaeologica Academiae Scientiarum Hungaricae 70, 2019 


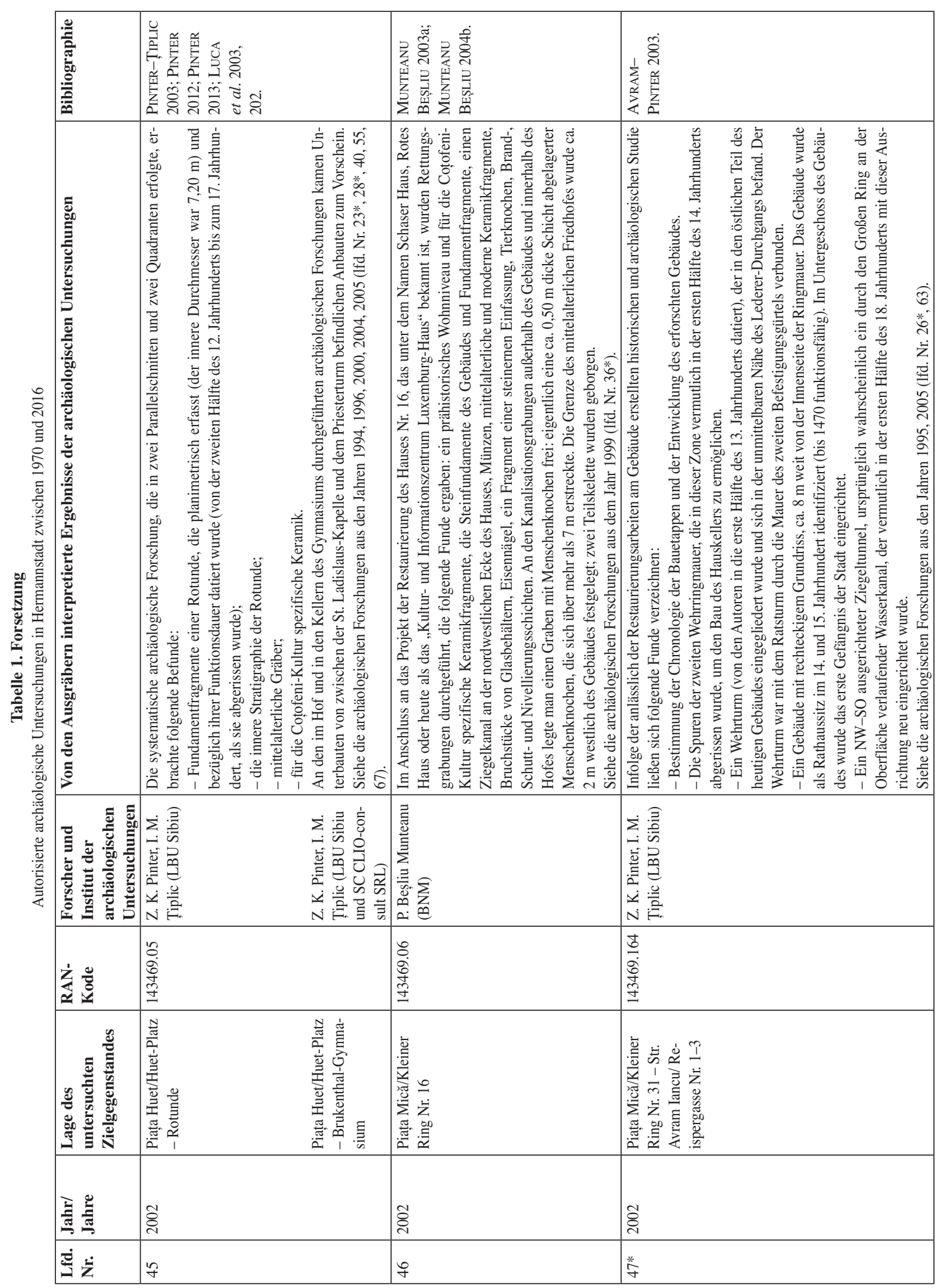

Acta Archaeologica Academiae Scientiarum Hungaricae 70, 2019 


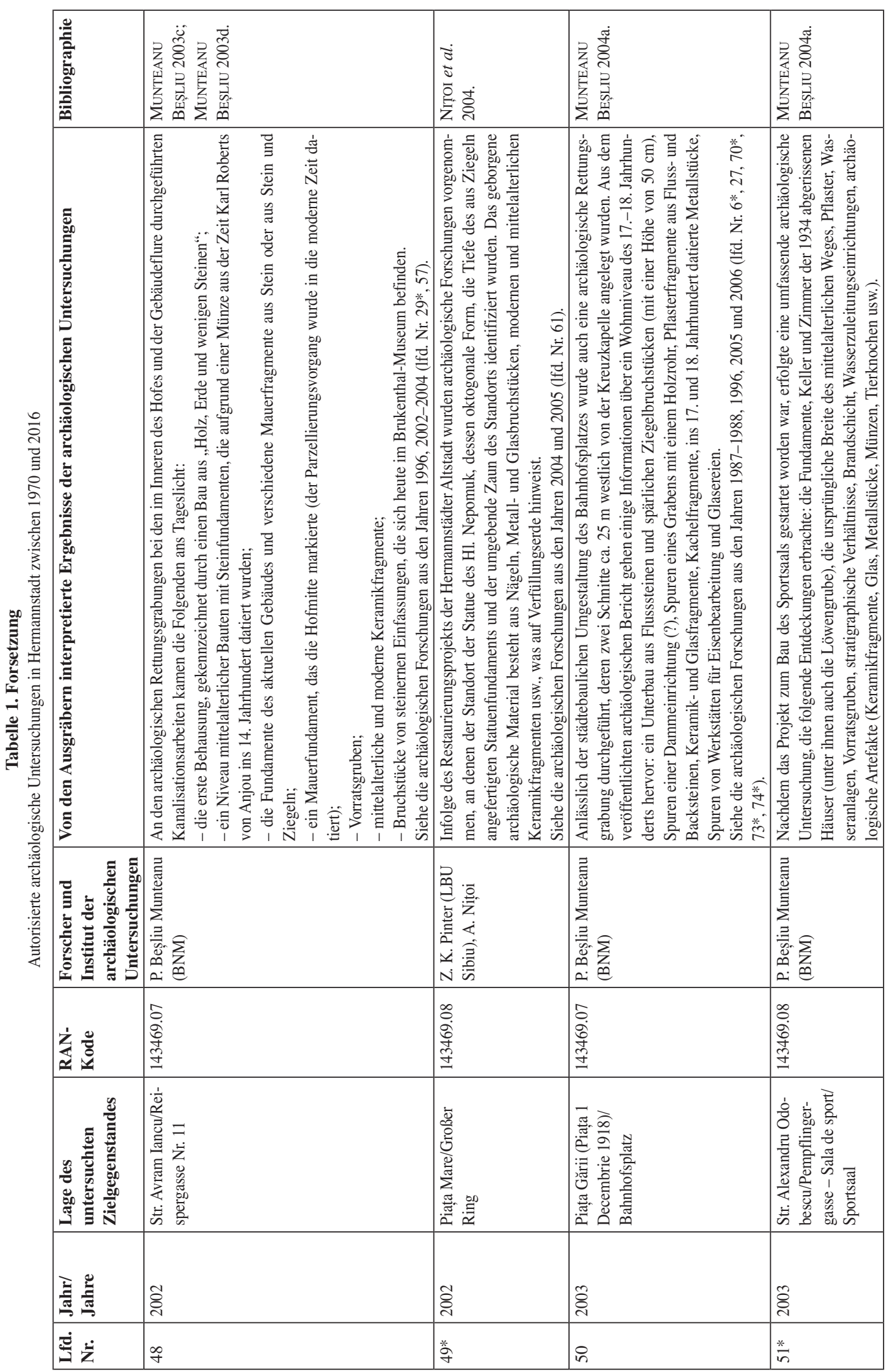

Acta Archaeologica Academiae Scientiarum Hungaricae 70, 2019 


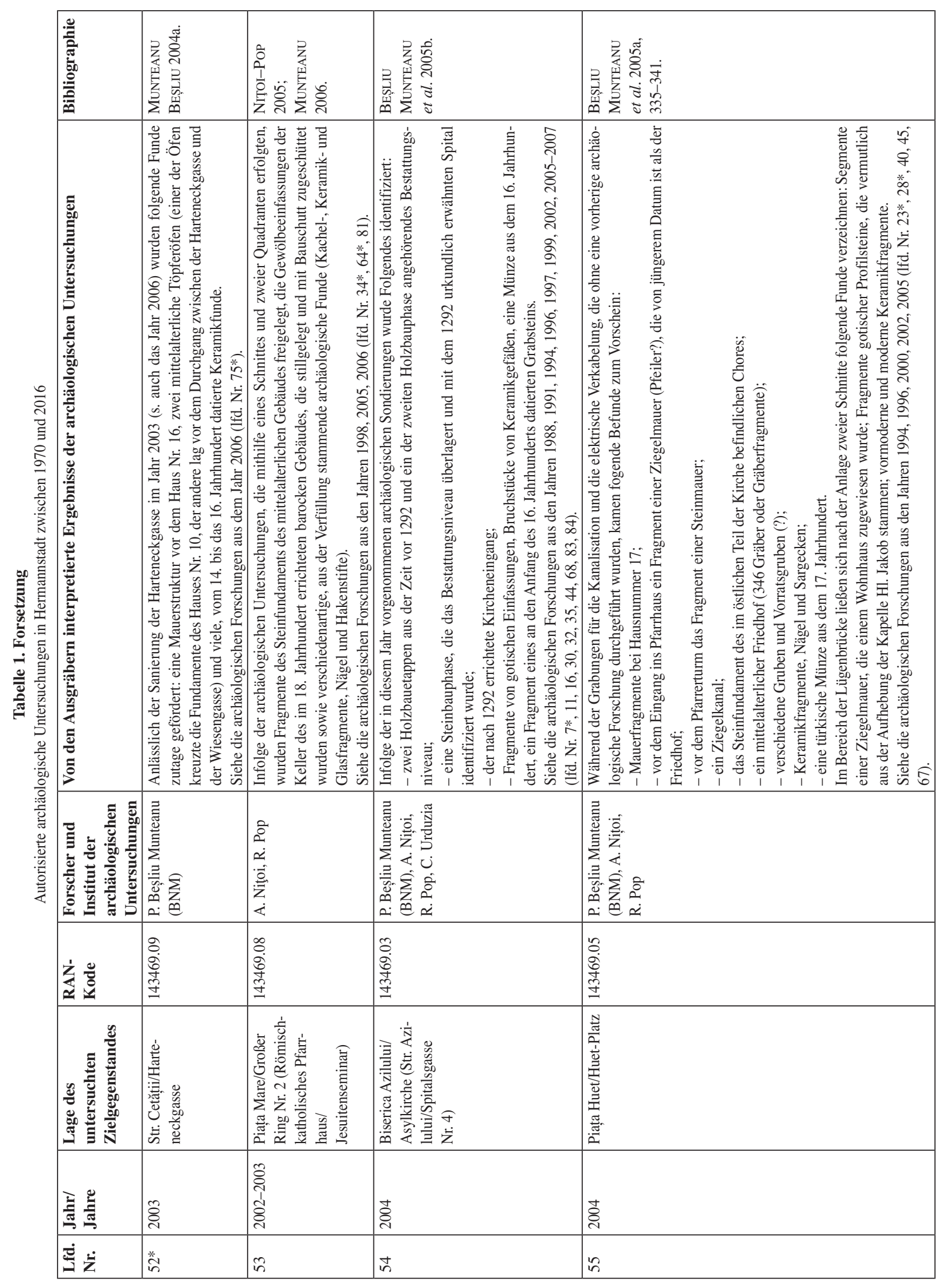

Acta Archaeologica Academiae Scientiarum Hungaricae 70, 2019 


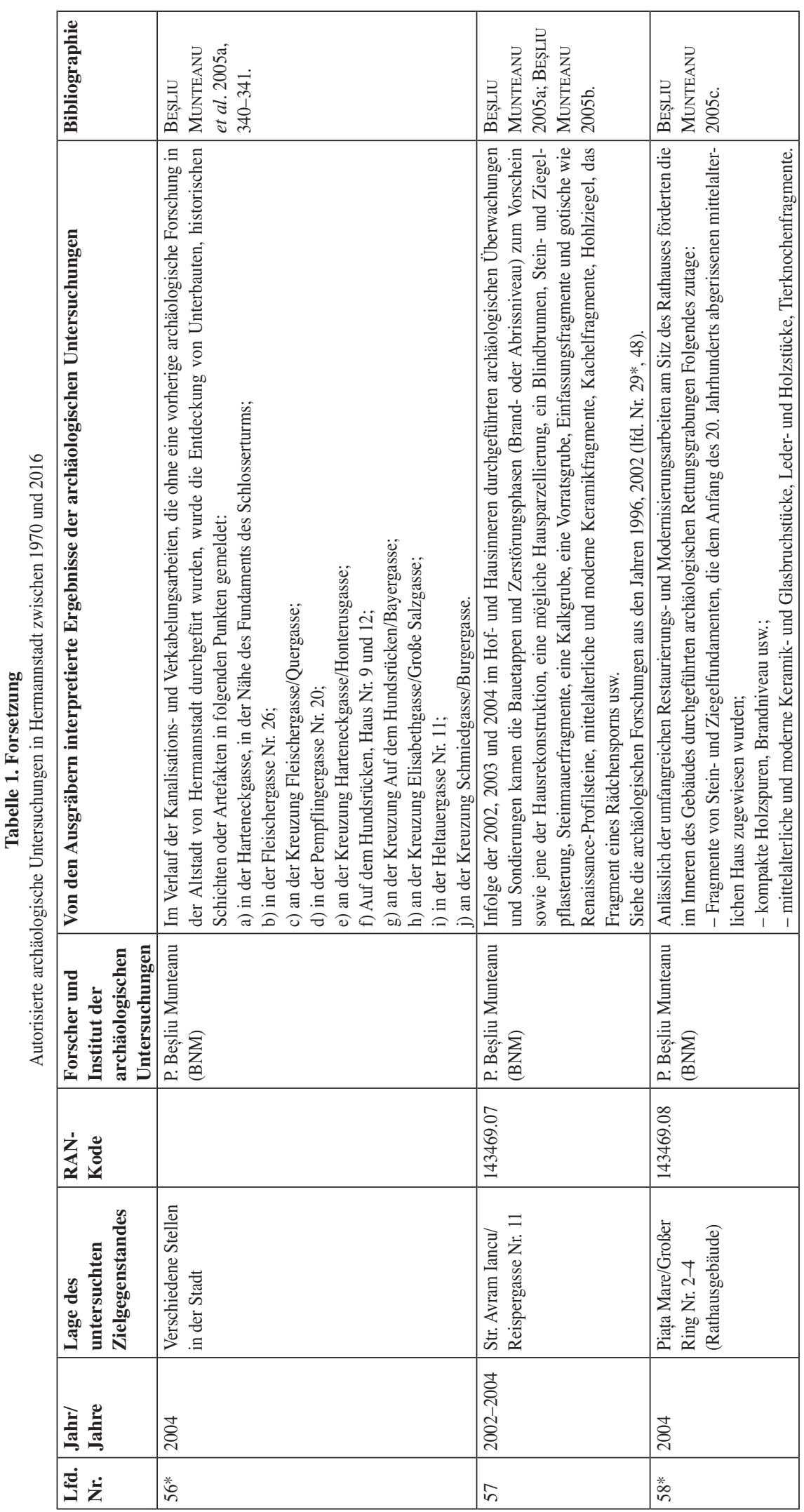

Acta Archaeologica Academiae Scientiarum Hungaricae 70, 2019 


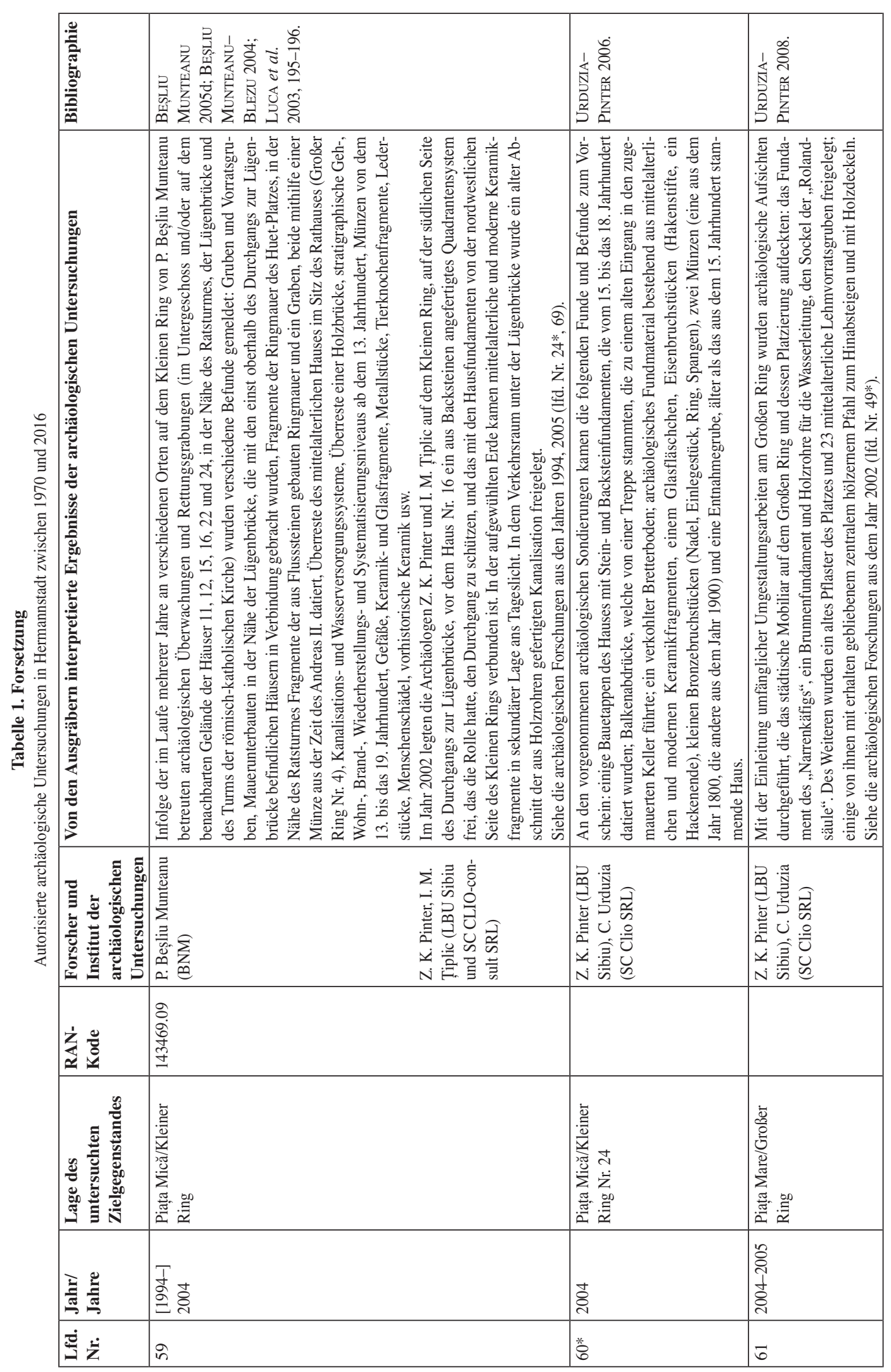

Acta Archaeologica Academiae Scientiarum Hungaricae 70, 2019 


\begin{tabular}{|c|c|c|c|c|c|}
\hline 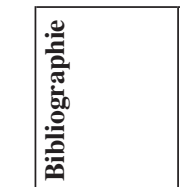 & 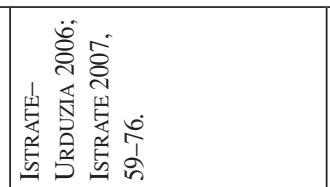 & 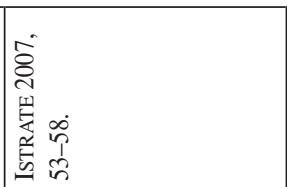 & 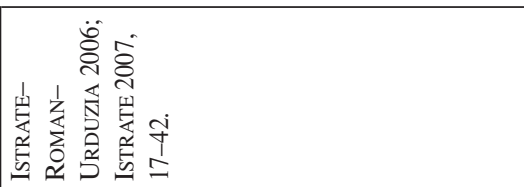 & 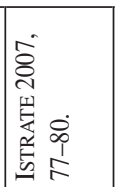 & 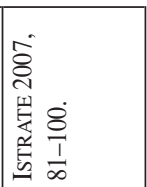 \\
\hline 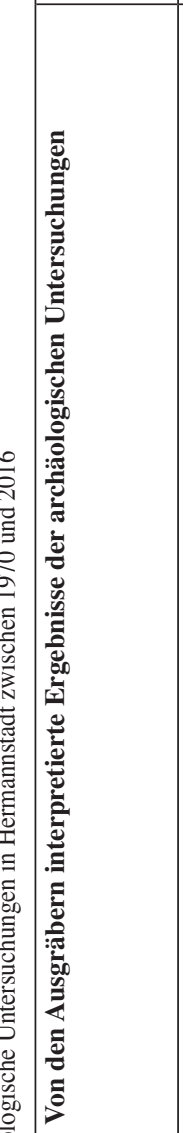 & 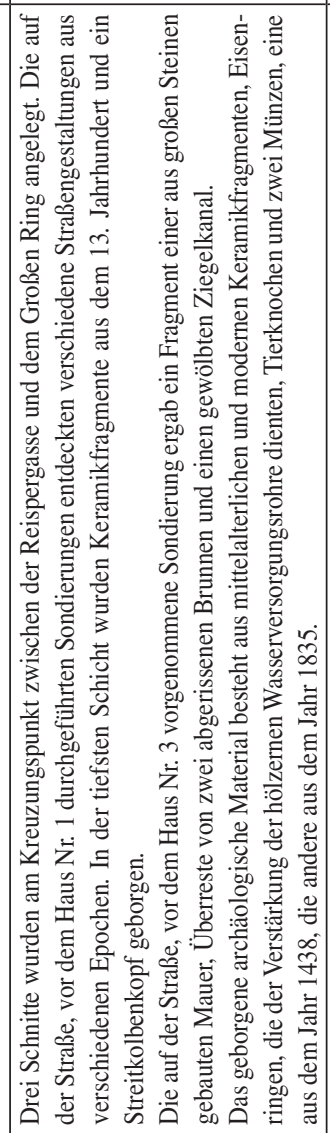 & 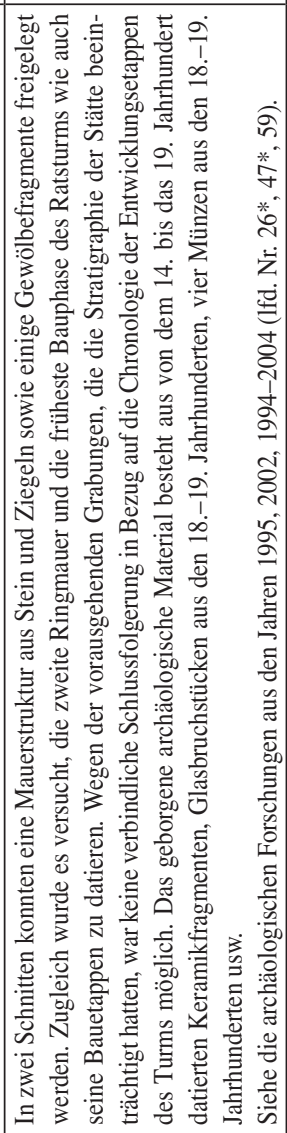 & 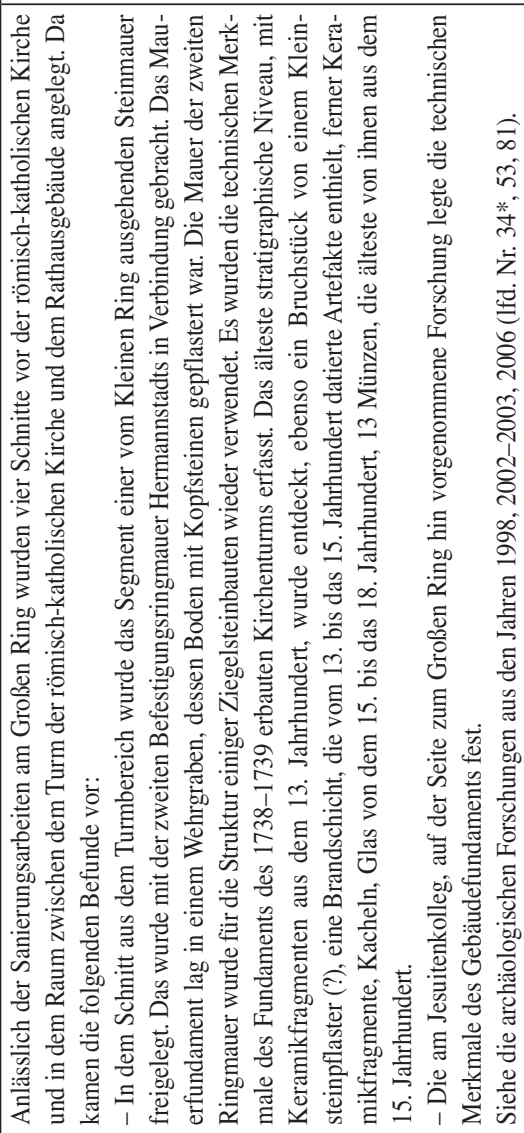 & 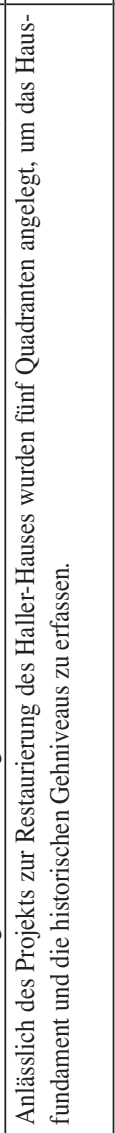 & 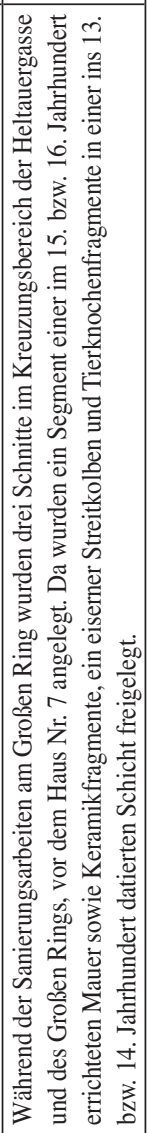 \\
\hline 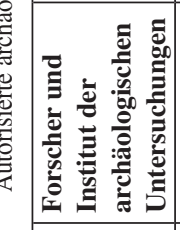 & 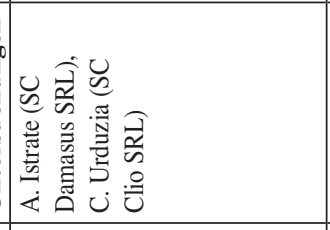 & 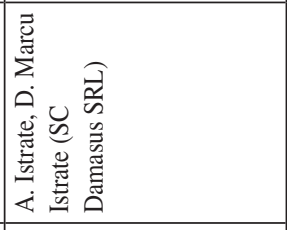 & 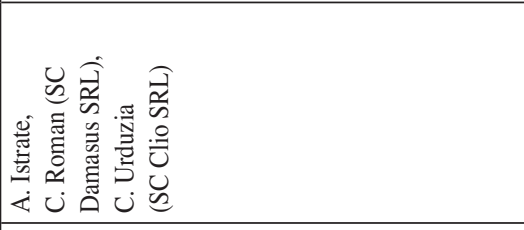 & 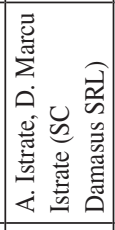 & 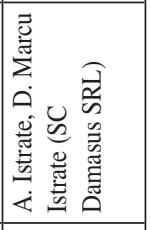 \\
\hline 妄忘 & 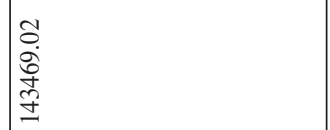 & & & & \\
\hline 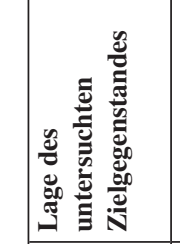 & 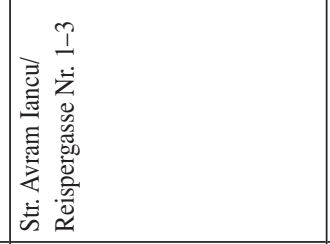 & 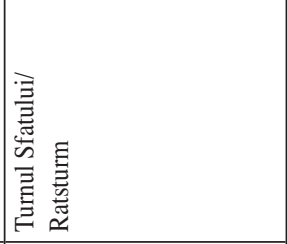 & 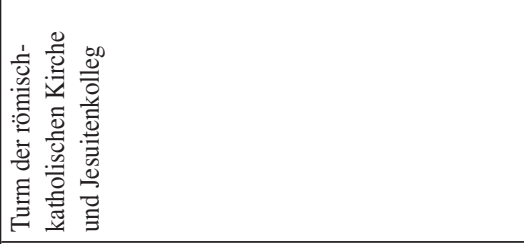 & 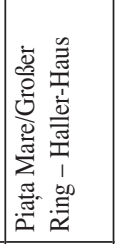 & 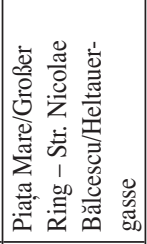 \\
\hline 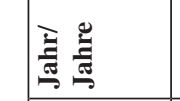 & 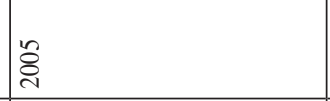 & 总 & 荢 & 哭 & 冬 \\
\hline 岕艺 & 苛 & 8 & 娄 & 菤 & 苞 \\
\hline
\end{tabular}




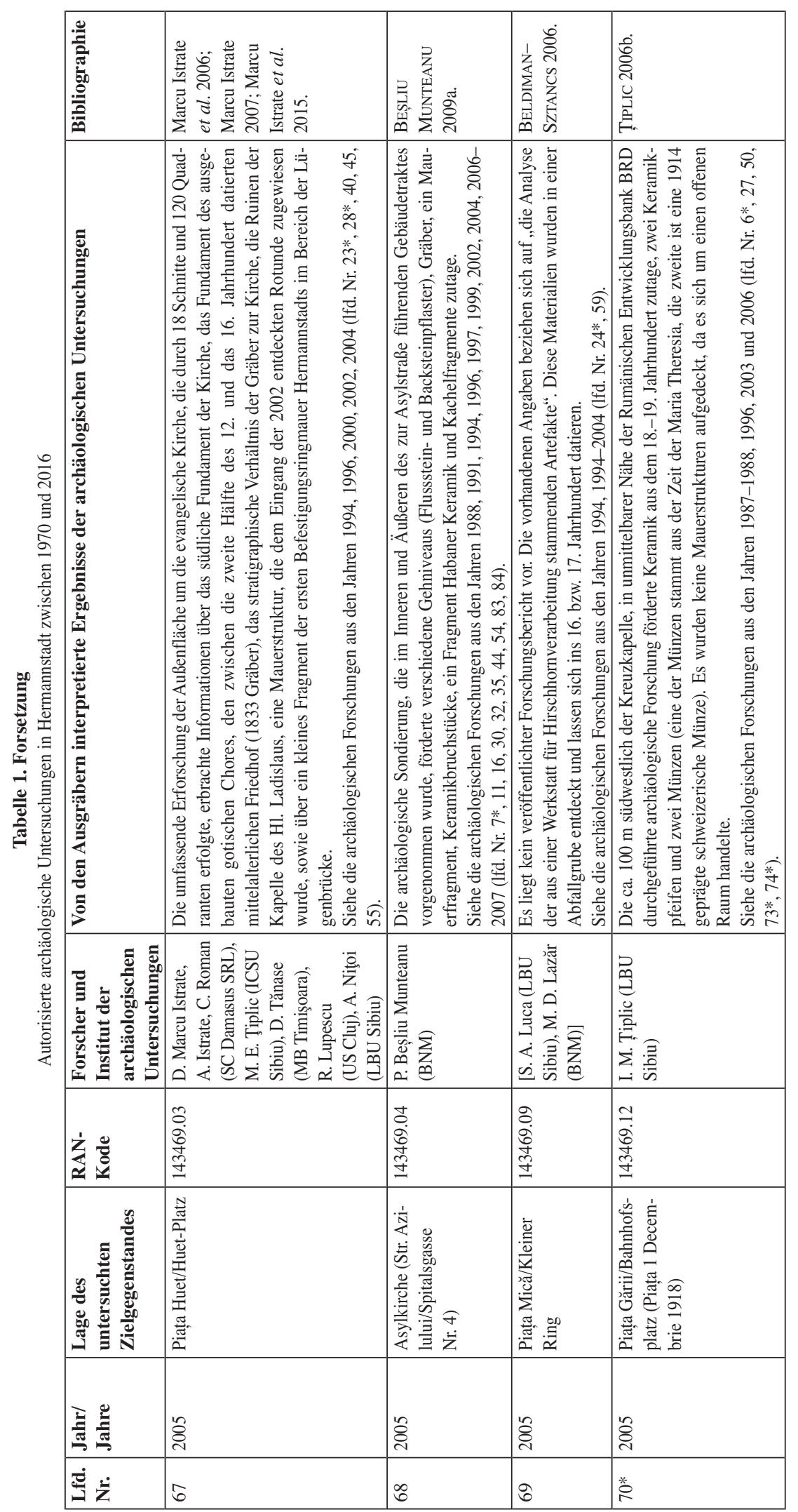

Acta Archaeologica Academiae Scientiarum Hungaricae 70, 2019 


\begin{tabular}{|c|c|c|c|}
\hline 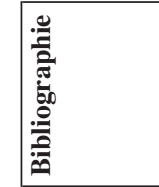 & & 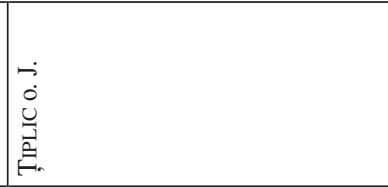 & 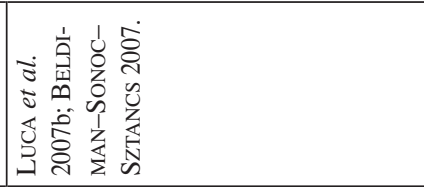 \\
\hline 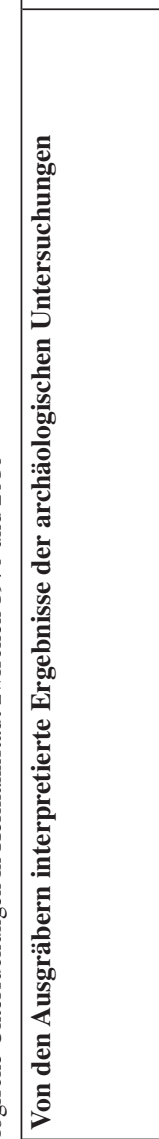 & 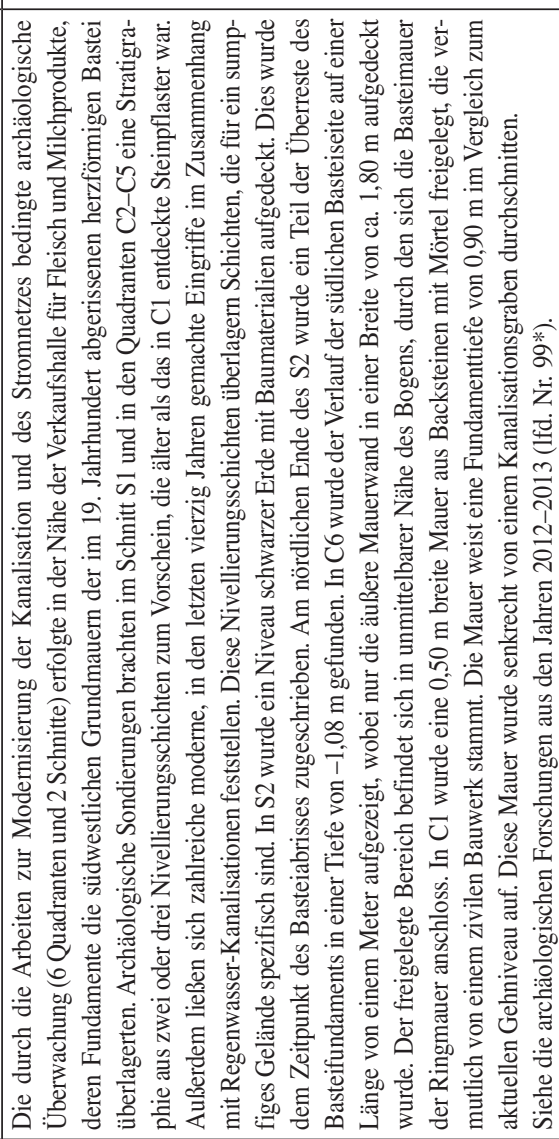 & 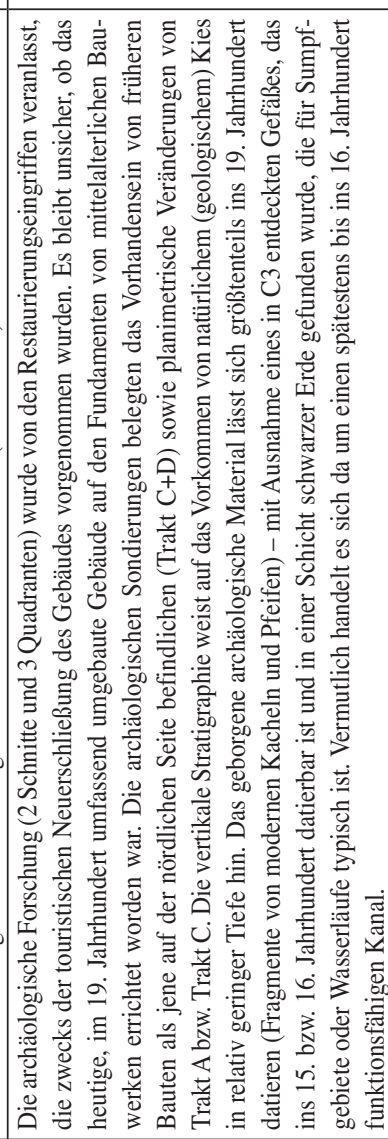 & 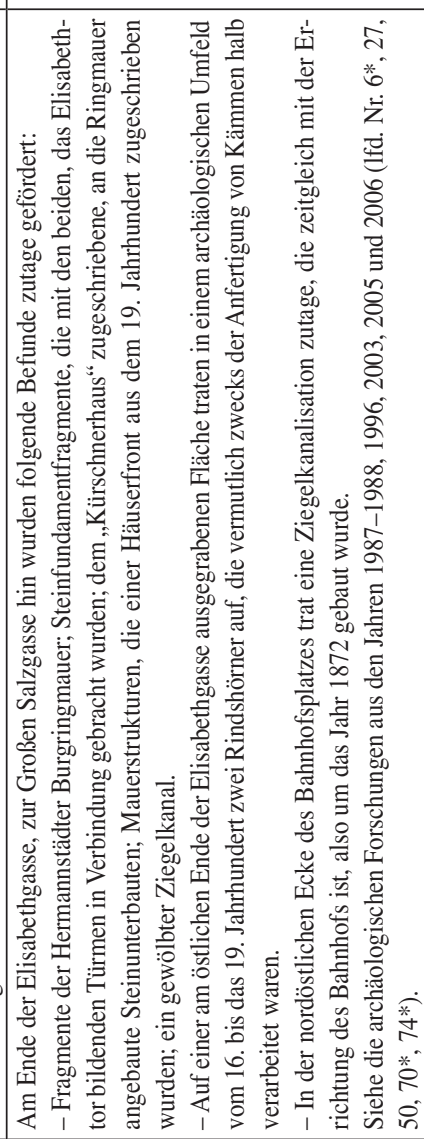 \\
\hline 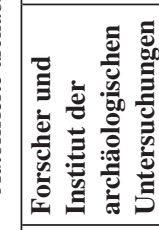 & 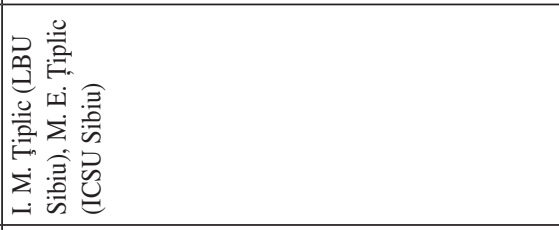 & 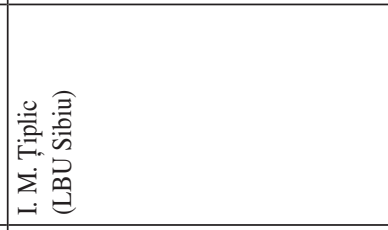 & 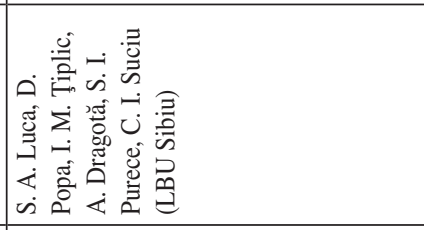 \\
\hline 案穿 & & & 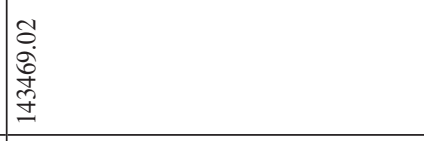 \\
\hline 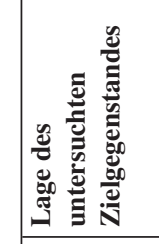 & 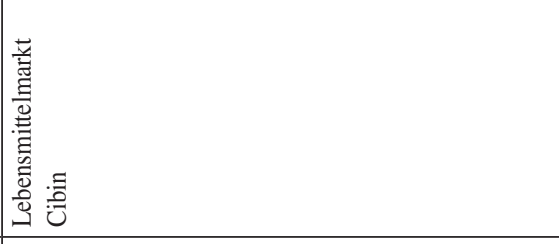 & 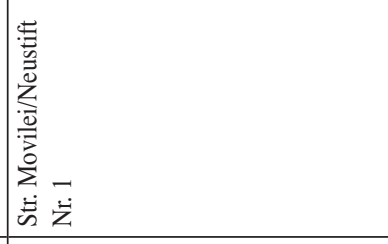 & 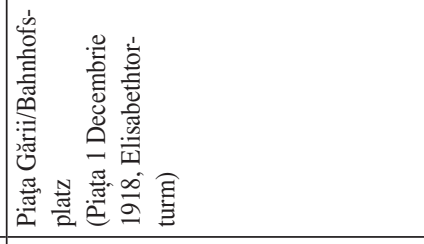 \\
\hline 音愛 & ఫั & ) & ¿્సి \\
\hline 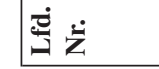 & $\stackrel{*}{\stackrel{*}{*}}$ & $\stackrel{*}{\stackrel{*}{i}}$ & 总 \\
\hline
\end{tabular}




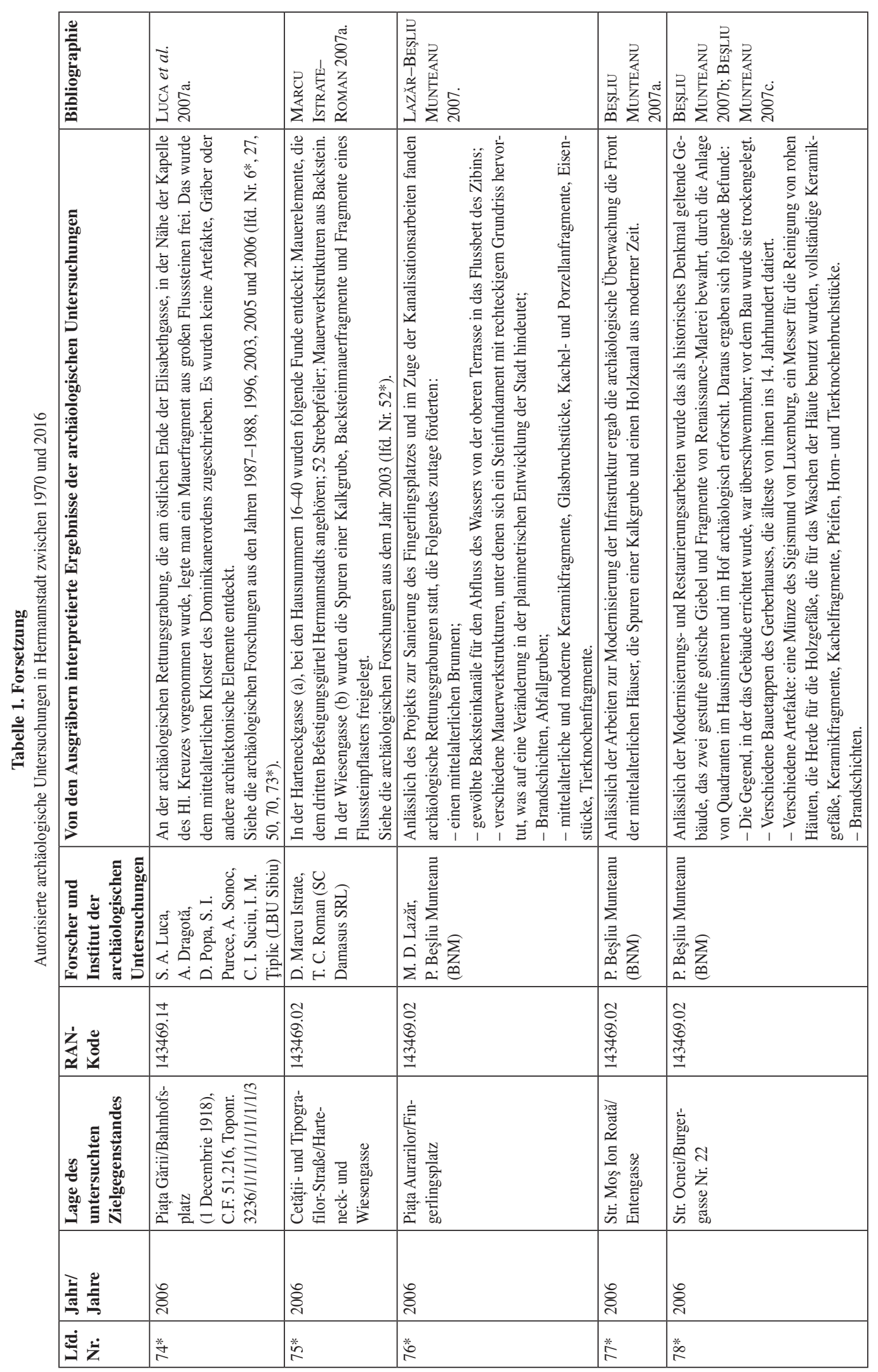

Acta Archaeologica Academiae Scientiarum Hungaricae 70, 2019 


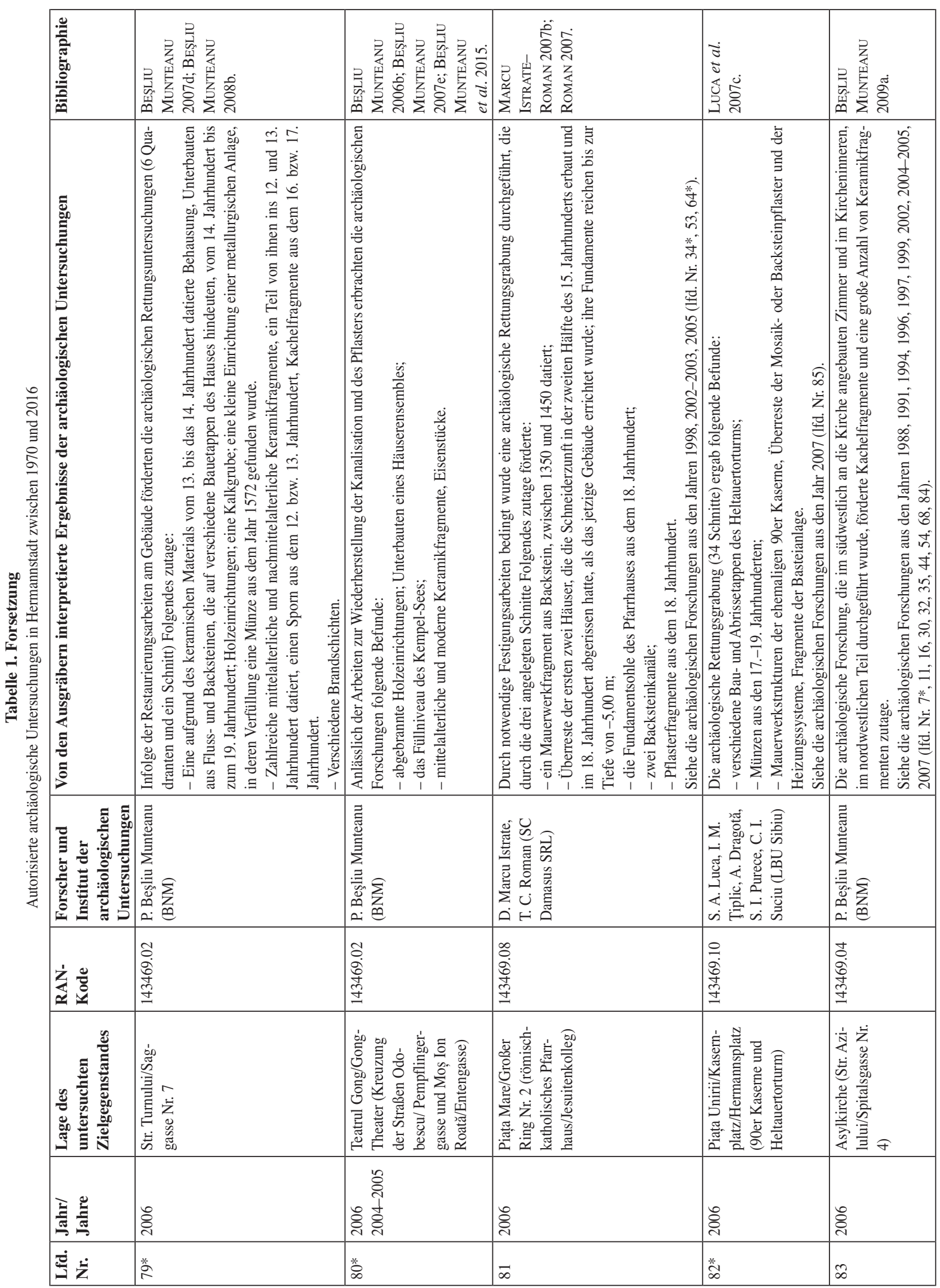




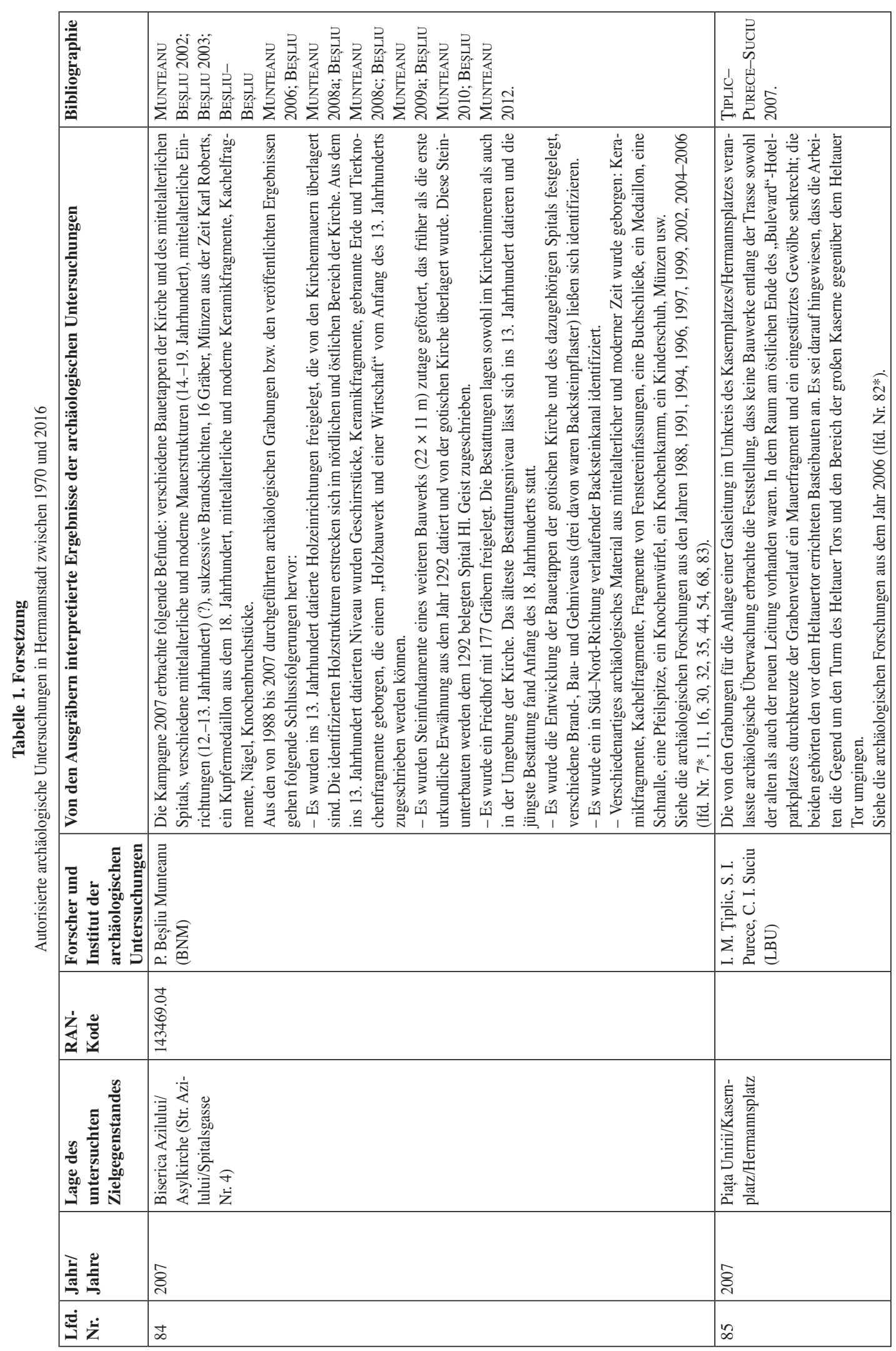

Acta Archaeologica Academiae Scientiarum Hungaricae 70, 2019 


\begin{tabular}{|c|c|c|c|c|c|c|c|}
\hline 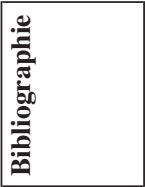 & 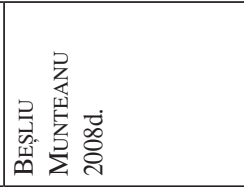 & 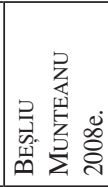 & 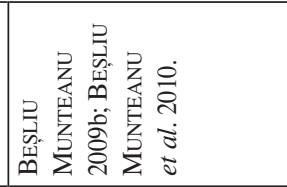 & 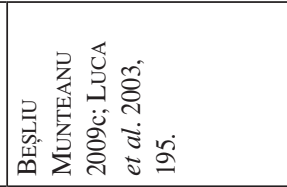 & 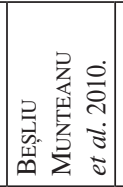 & 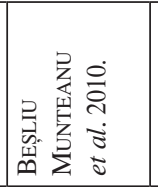 & 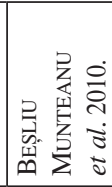 \\
\hline 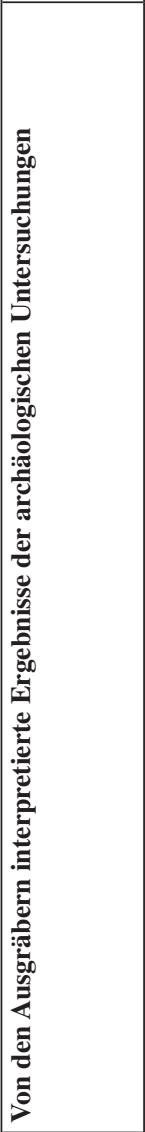 & 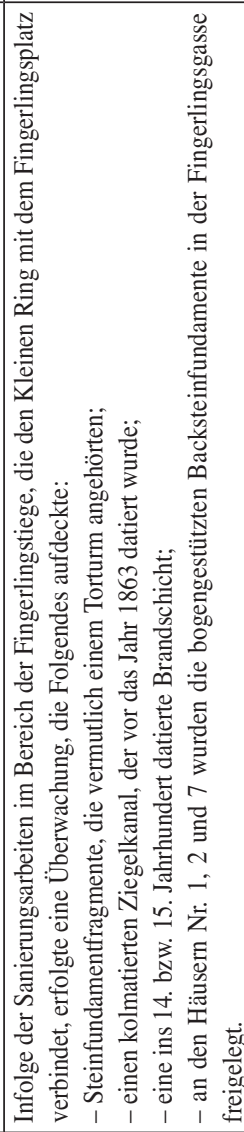 & 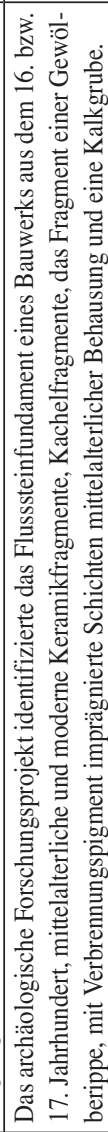 & 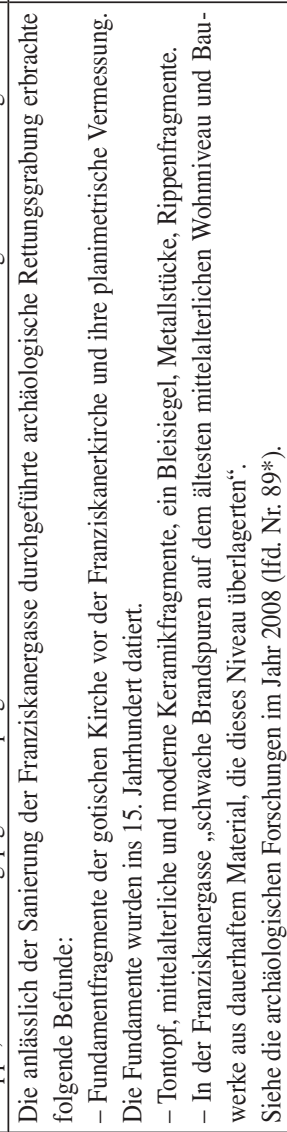 & 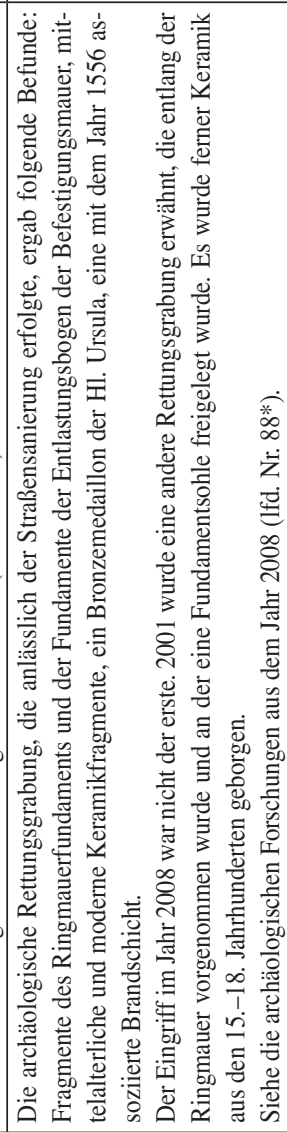 & 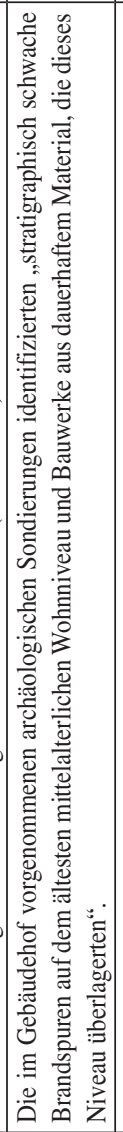 & 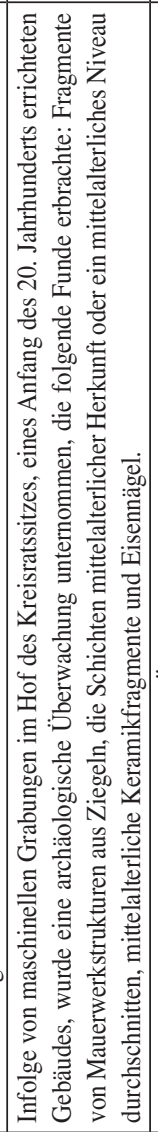 & 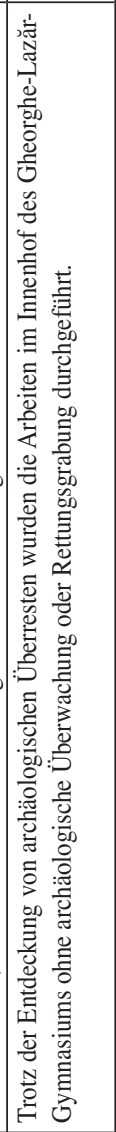 \\
\hline 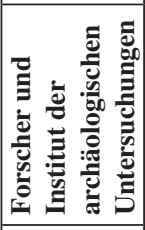 & 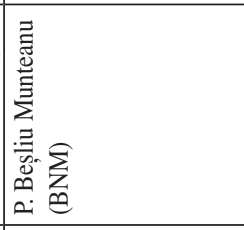 & 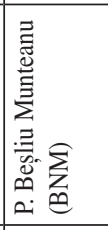 & 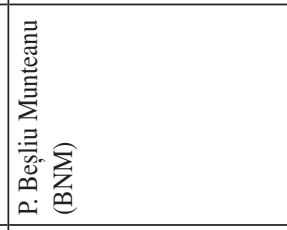 & 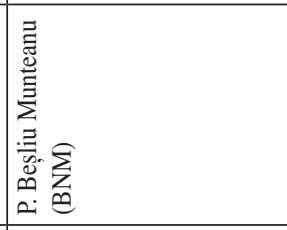 & & 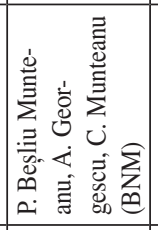 & \\
\hline 妄 & 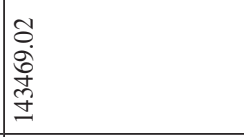 & 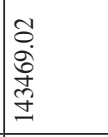 & 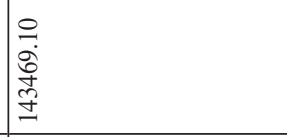 & $\mid \begin{array}{l}0 \\
0 \\
0 \\
0 \\
9 \\
9 \\
\end{array}$ & & \begin{tabular}{|l|} 
\\
0 \\
0 \\
0 \\
0 \\
9 \\
\end{tabular} & \\
\hline 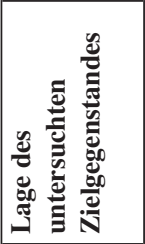 & 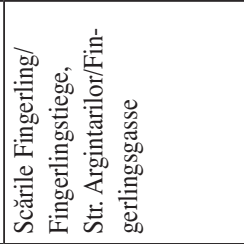 & 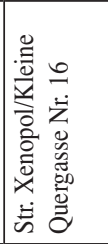 & 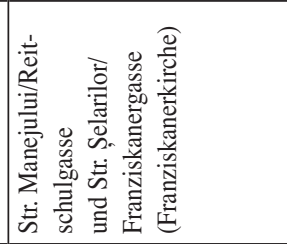 & 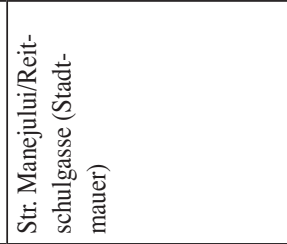 & 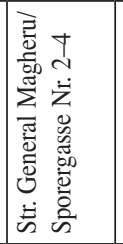 & 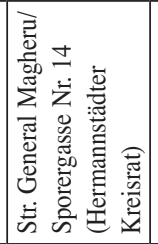 & 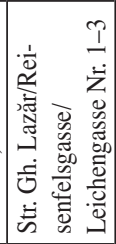 \\
\hline 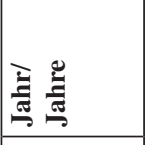 & 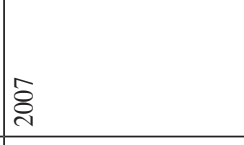 & 宫 & 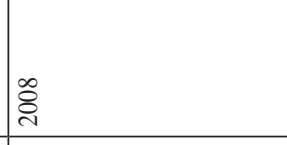 & 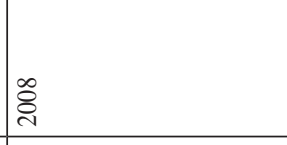 & 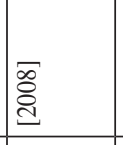 & ठ્ণે & 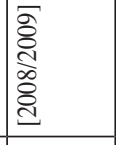 \\
\hline$\dot{\vec{Z}}$ & 密 & $\begin{array}{l}* \\
\vdots \\
\infty\end{array}$ & $\mid \begin{array}{c}* \\
\infty \\
\infty\end{array}$ & 容 & 范 & \% & 范 \\
\hline
\end{tabular}




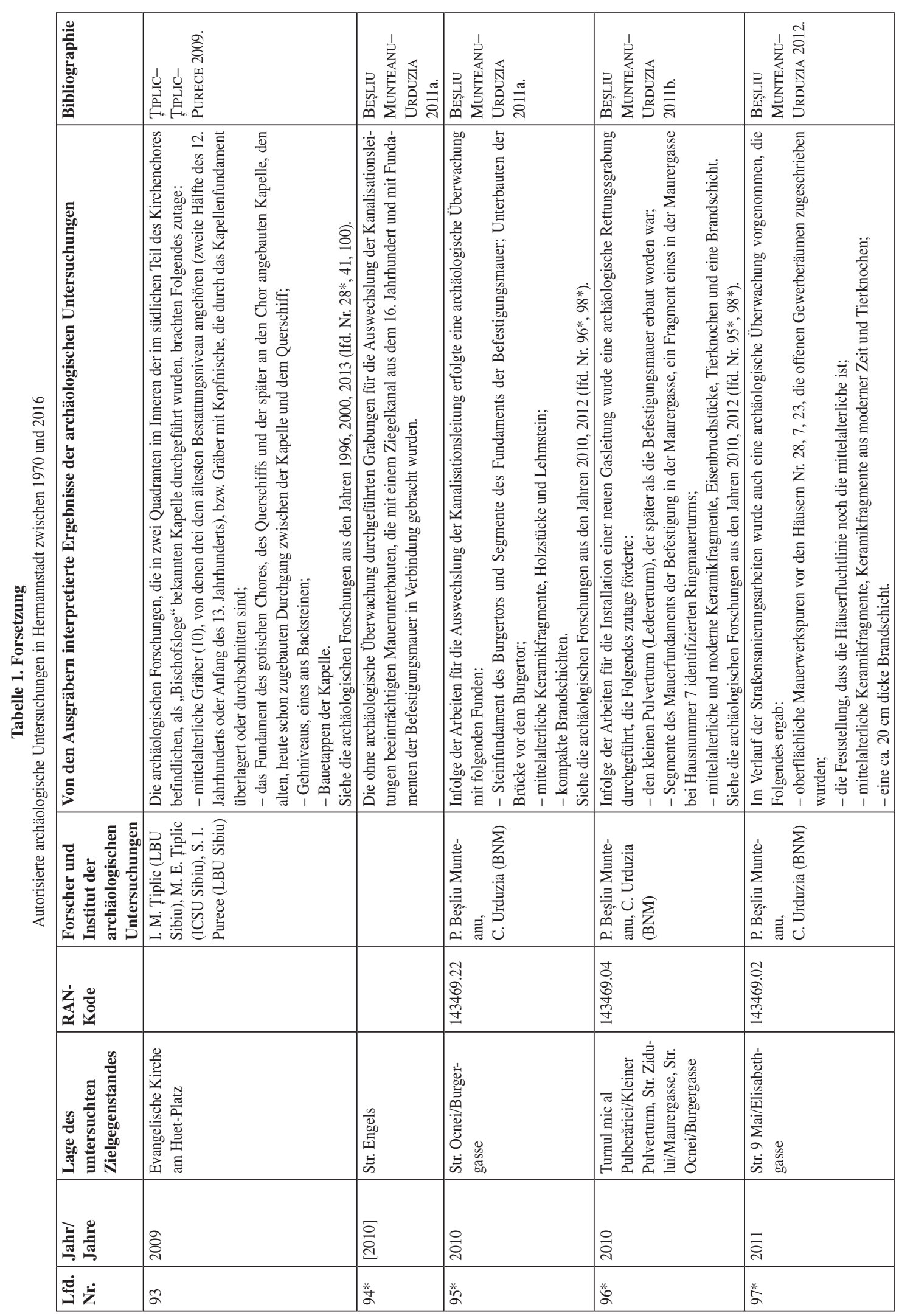

Acta Archaeologica Academiae Scientiarum Hungaricae 70, 2019 


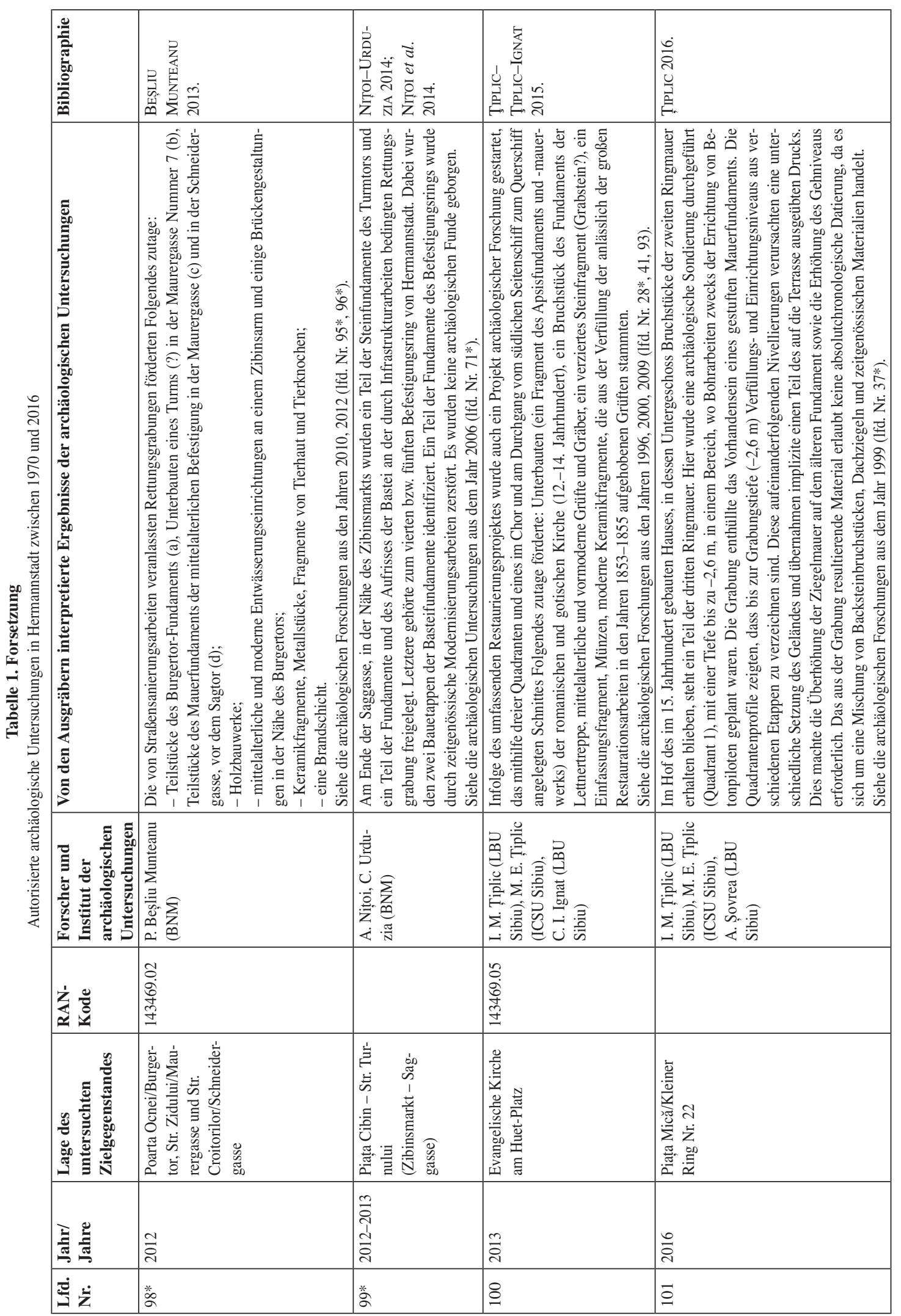

Acta Archaeologica Academiae Scientiarum Hungaricae 70, 2019 
Ergebnisse und präsentierten Auslegungen, der zahlreichen Artikel, Studien, Monographien und nicht zuletzt einer kurzgefassten Deutung derselben - im Rahmen des zur Verfügung stehenden Publikationsumfangs.

Im Folgenden werden wir eine Übersicht über die wichtigsten Ergebnisse der archäologischen Kampagnen bieten, über die geklärten Probleme oder diejenigen, die weiterhin Interpretationsschwierigkeiten bereiten - im Hinblick auf die grundlegenden Elemente, die das Bild der städtischen Besonderheiten Hermannstadts und des städtischen Erbes ausmachen: 1. Kirchen, Klöster und Kapellen; 2. mittelalterliche Friedhöfe; 3. Befestigungsanlagen der Stadt; 4. öffentliche Zivilgebäude (Sitz des Hermannstädter Rathauses); 5. Wohnhäuser; 6. Platz- und Straßengestaltungen; 7. Getreidelager; 8. materielle Kultur. Natürlich gibt es auch nicht berücksichtigte Aspekte, wie Brände und andere Zerstörungen, die die Stadt im Laufe der Zeit erlitten hatte und die archäologisch häufig in der Stratigraphie der Grabungsstätten identifiziert wurden.

\section{KIRCHEN, KLÖSTER UND KAPELLEN}

In der 1191 anlässlich der Kirchengründung der Deutschen Siebenbürgens als eine freie Propstei ecclesia Theutonicorum Ultrasilvanorum in praeposituram sit liberam institutam ${ }^{20}$ zum ersten Mal urkundlich erwähnten Ortschaft gelang es mithilfe von archäologischen Untersuchungen, ergänzt durch Dokumente, kartographische und/ oder architektonische Quellen, die erste Pfarrkirche romanischer Bauweise der deutschen Gäste, die dieselbe räumliche Lage wie die gotische Kirche am Huetplatz hatte, auf dem Gelände zu identifizieren (s. Ifd. Nr. 28 und 100 in der Tabelle bzw. auf der Karte 1 und 2; Abb. 1) - wie auch den Friedhof in ihrem direkten Umfeld, fünf mittelalterliche Klöster von den sechs, die im Gebiet Hermannstadts urkundlich nachgewiesen sind, drei Kapellen am Huetplatz (von den vier bis fünf urkundlich nachgewiesenen) und zwei in der Nähe des Großen Rings (s. auf der Karte 2). In der Fachliteratur herrscht weiterhin Unsicherheit in Bezug auf die Identität der Klöster und Kapellen und ihre Identifikation auf dem Gelände. Abgesehen von dem Prämonstratenserkloster, das 1234-1235 in Hermannstadt urkundlich erwähnt wurde ${ }^{21}$ und mit dem Mongoleneinfall verschwand, dessen Verortung auf dem Gelände nicht bekannt ist, wurden alle anderen fünf Klöster archäologisch auf dem Gelände identifiziert.

Das Dominikanerkloster von Hermannstadt ist die erste Ansiedlung, die die Predigerbrüder in Siebenbürgen errichtet hatten. Sie wurde erstmals 1241 erwähnt, als die Tataren die Stadt und das Kloster, das sich außerhalb der Ortschaft befand, in Brand setzten. ${ }^{22}$ Das Kloster war laut der zweiten urkundlichen Erwähnung 1282 bereits wiederhergestellt, ${ }^{23} 1300$ wurde auch der Schutzheilige attestiert (,Kirche zum Heiligen Kreuz“). ${ }^{24}$ Außerhalb der Stadtmauern errichtet, wurde das Kloster bei den Türkenangriffen von 1432, 1438 und 1442 schwer beschädigt und nicht wieder aufgebaut. ${ }^{25}$ Seine ungefähre Lage auf dem Gelände war bis zu der archäologischen Rettungsgrabung 2006 auf dem Bahnhofsplatz vermutet. Da gelang es, ein Mauerfragment aus massiven Flusssteinen freizulegen, in der Nähe der Kreuzkapelle (s. lfd. Nr. 74 in der Tabelle bzw. auf der Karte 1 und 2; Abb. 2). Da keine Artefakte, Gräber oder andere architektonische Elemente entdeckt wurden, war eine genauere Datierung im 13. Jahrhundert nicht möglich. ${ }^{26}$ Wegen der wiederholten Zerstörungen der türkischen Angriffe zog sich der Konvent 1474 hinter die Stadtmauern, wo es gelang, einen Platz für den Wiederaufbau des Klosters zu erhalten, das heute als Ursulinenkloster bekannt ist (Str. General Magheru/Sporergasse Nr. 38) (s. lfd. Nr. 31 auf der Karte 2; Abb. 3.a). Diese im letzten Viertel des 15. Jahrhunderts erbaute Dominikanerkirche wurde mit dem Einzug der Ursulinen in Hermannstadt zwischen 1728 und 1733 stark umgestaltet. ${ }^{27}$

\footnotetext{
${ }^{19}$ In diesem Sinn ist der Ansatz des angesehenen tschechischen Archäologen Jan Klápšté für den tschechischen Raum zu betrachten. J. KLÁPŠTÉ: The Archaeology of Prague and the Medieval Czech Lands, 1100-1600. Studies in the archaeology of medieval Europe. Sheffield-Bristol 2016. Auf diesem Weg möchten wir uns bei Dr. Florin Curta von der University of Florida dafür bedanken, dass er uns den Zugriff zu den von Jan Klápšté veröffentlichten Informationen erleichterte.

${ }^{20}$ ZIMMERMANN-WERNER 1892, 1-2, Nr. 1; M. ROLLER (red.): Documente privind istoria României. Veacul XI, XII şi XIIII. C. Transilvania [Urkunden zur Geschichte Rumäniers. C. Silbenkünrgen,
}

11., 12. und 13. Jahrhundert]. I: 1075-1250. Bucureşti 1951, 11, 360361; JAKÓ 1997, 129, Nr. 21.

${ }^{21}$ JAKÓ 1997, 180, Nr. 176.

${ }^{22}$ Ebenda, 186, Nr. 192.

${ }^{23}$ Zimmermann-Werner 1892, 144, Nr. 202; Roller 1952, 242-243, Nr. 274; JAKÓ 1997, 257-258, Nr. 394.

${ }^{24}$ ZiMMERMANN-WERNER 1892, 214-217, Nr. 286, 287;

Roller 1952, 478-481, Nr. 522, 523; JAKÓ 1997, 34, Nr. 597, 598.

${ }^{25}$ Avram-Bucur 1999, 37, 82-85; SAlontai 2002, 209-227.

${ }^{26}$ LuCA et al. 2007a.

${ }^{27}$ Avram-Bucur 1999，37，82-85; Salontai 2002,

209-227.

Acta Archaeologica Academiae Scientiarum Hungaricae 70, 2019 

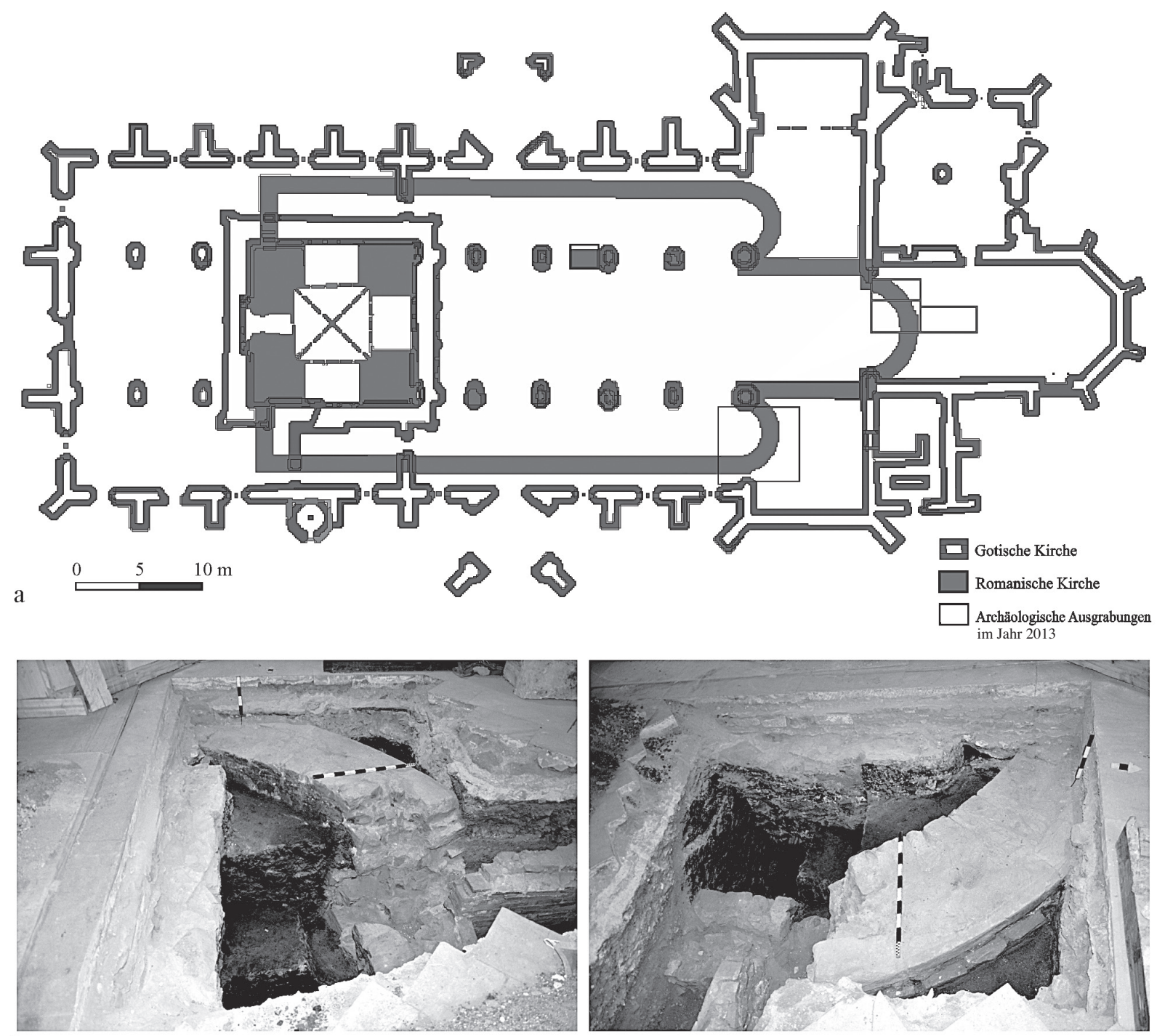

b

Abb. 1. Hermannstadt. Archäologische Ausgrabungen im Inneren der Evangelischen Kirche (durchgeführt im Jahr 2013).

a: Hypothetischer Grundriss der romanischen Kirche; b: romanisches Absisfundament (@ I. M. Țiplic und M. Crîngaci Țiplic)

In Hermannstadt gab es für eine kurze Periode ebenfalls ein dominikanisches Nonnenkloster, dessen Schutzheilige die Heilige Maria Magdalena war (Str. Șelarilor/Franziskanergasse) (s. lfd. Nr. 88 auf der Karte 2; Abb. 3.c). Es wurde zum ersten Mal am Anfang des 16. Jahrhunderts bescheinigt. Die Nonnen mussten dann mit dem Einsetzen der Reformation die Stadt verlassen, infolgedessen die Gebäude des Klosters in städtisches Eigentum übergingen. ${ }^{28}$ In der Historiographie herrschte lange Zeit Verwirrung über ihre Identität, wobei sie häufig dem Franziskanerorden zugeordnet wurden. Der Klausenburger Wissenschaftlerin Mihaela Sanda Salontai gelang es, ihre ursprüngliche Zugehörigkeit zu den dominikanischen Nonnen zu demonstrieren. Die Gebäude des Klosters wurden 1716 den Franziskanerobservanten überlassen, die sie nach der Mode der Zeit im Barockstil umbauen ließen und dem Schutzheiligen Franziskus neu weihten. Im Hinblick auf die Datierung ihrer Errichtung schwankt die Geschichtsschreibung zwischen dem 14. Jahrhundert und dem Beginn des 16. Jahrhunderts. ${ }^{29}$ Bei den vor der aktuellen Franziskanerkirche

$$
{ }^{28} \text { SALONTAI 2002, 224-225. }
$$

${ }^{29}$ Ebenda, 227. 


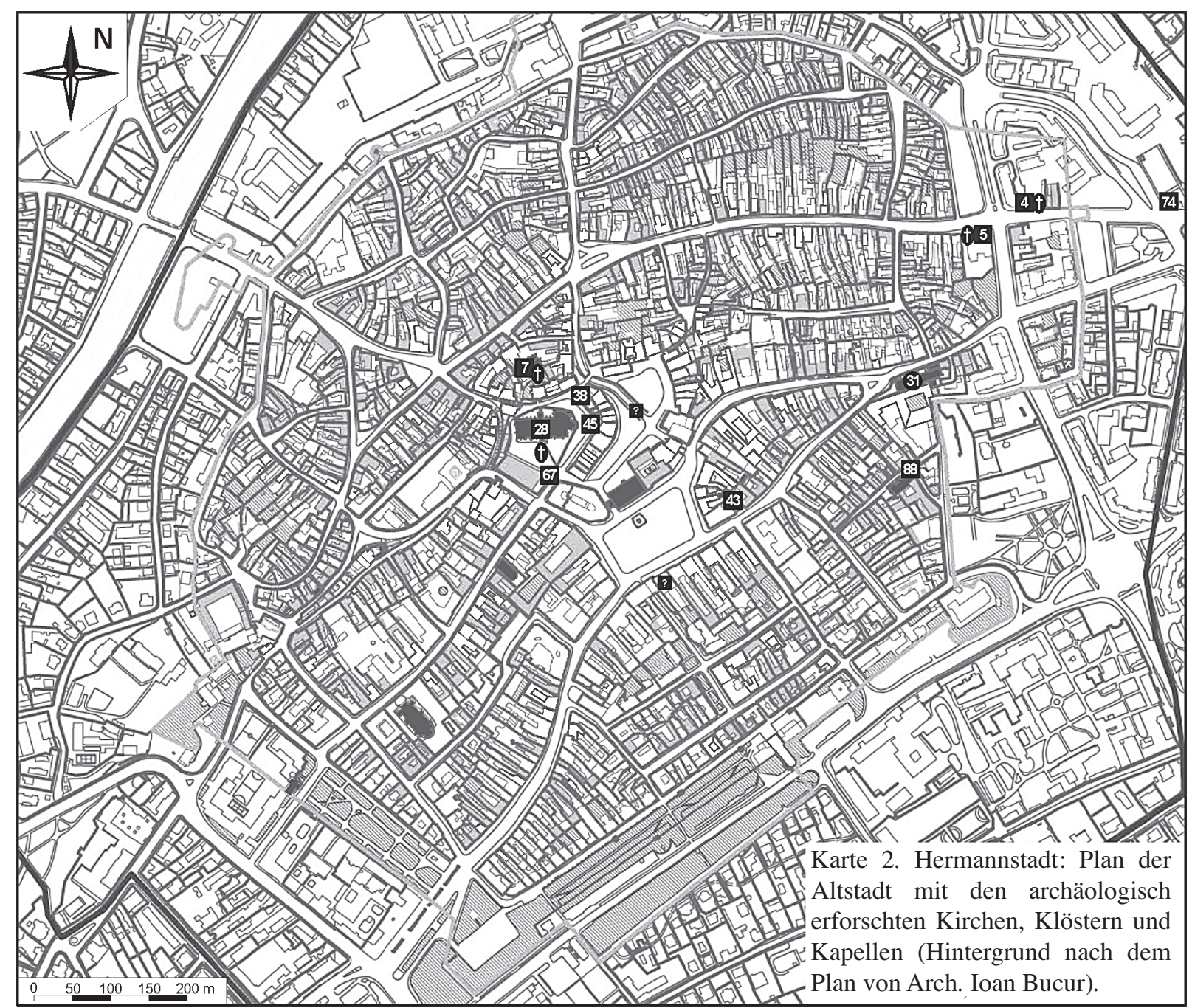

Karte 2. Hermannstadt: Plan der Altstadt mit den archäologisch erforschten Kirchen, Klöstern und Kapellen (Hintergrund nach dem Plan von Arch. Ioan Bucur)

in der Franziskanergasse durchgeführten archäologischen Untersuchungen wurden Fundamentfragmente der ins 15. Jahrhundert datierten Klosterkirche der Dominikanernonnen der Heiligen Maria Magdalena identifiziert. ${ }^{30}$

Ein anderes frühzeitiges Kirchengebäude Hermannstadts ist die Franziskanerkirche der Heiligen Elisabeth, deren erste urkundliche Erwähnung aus dem Jahr 1300 stammt $^{31}$ und die im Jahr 1868 abgerissen wurde. Was ihre Lokalisierung auf dem Gelände betrifft, herrscht auch in diesem Fall keine Übereinstimmung in der Historiographie: Einige optieren für ihre Lage an der Kreuzung der Salzgasse mit der Elisabethgasse oder im Bereich der Elisabethgasse und der Nasturelui-Straße (heute eine Gegend mit Wohnblocks, sie wurde 1987 aufgelöst). Die im Jahr 1300 attestierte und 1868 abgerissene Kirche befand sich - wie auch Hermann Fabini nachwies - an der Kreuzung der Salzgasse und Elisabethgasse (s. lfd. Nr. 5 und 42 in der Tabelle bzw. lfd. Nr. 5 auf der Karte 1 und 2). Archäologische Rettungsgrabungen identifizierten einen Teil der Unterbauten des gotischen Chors der Franziskanerkirche Heilige Elisabeth, ein Fragment der umgebenden Klostermauer und Skelettreste. ${ }^{32}$

\footnotetext{
${ }^{30}$ Beșliu Munteanu 2009b; Beșliu Munteanu et al. 2010.

${ }^{31}$ ZIMMERMANN-WERNER 1892, 214-217, Nr. 286, 287;
} Roller 1952, 478-481, Nr. 522, 523; JAKÓ 1997, 343, Nr. 597, 598.
${ }^{32}$ Munteanu Beșliu 2001, 31-41; Beșliu Munteanu $2014,125-135$ 

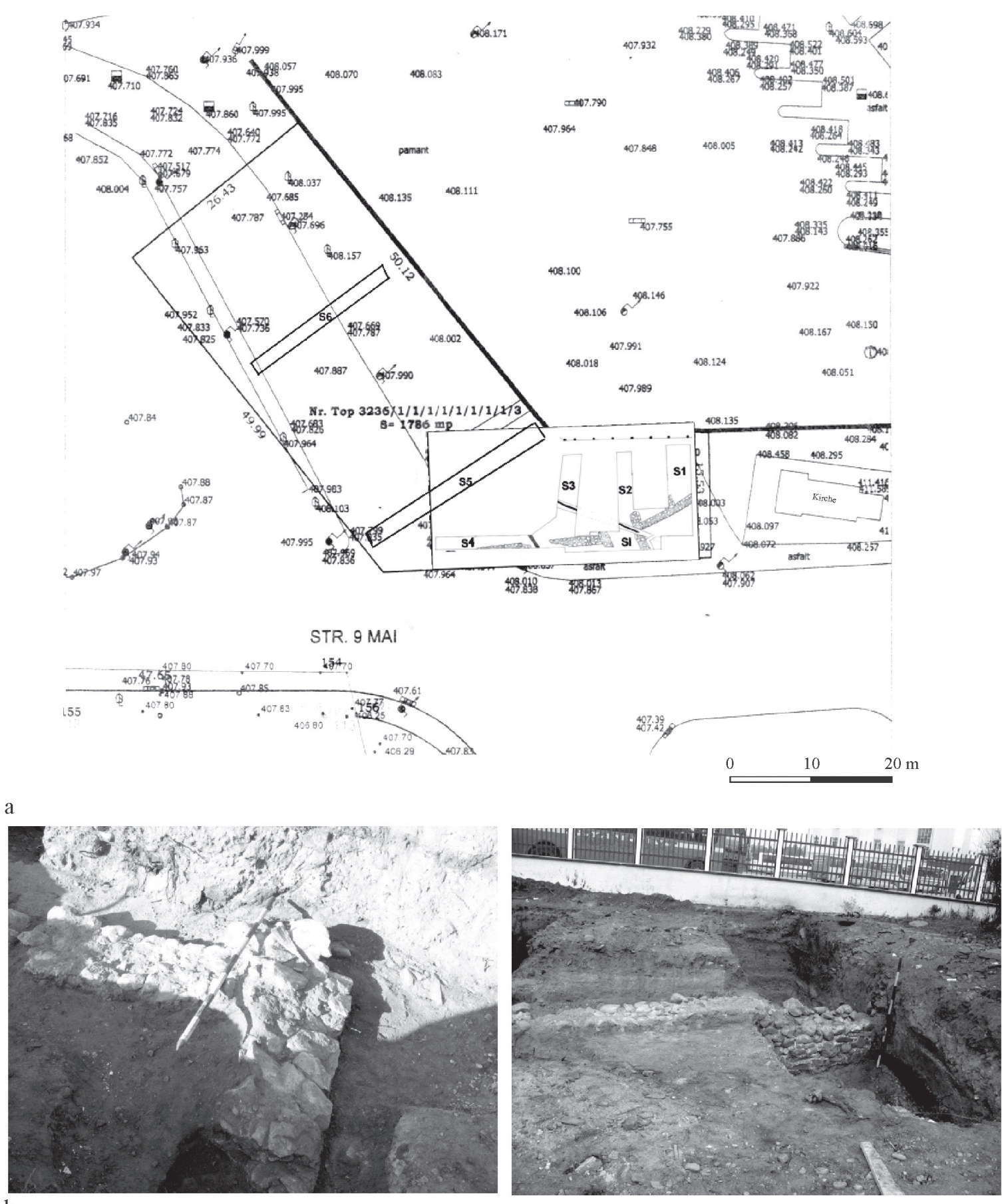

Abb. 2. Hermannstadt. Archäologische Ausgrabungen am Bahnhofsplatz, in der Nähe der Kreuzkapelle (durchgeführt im Jahr 2006). a: Umfassender Plan der Ausgrabung; b: Mauerfragment des Dominikanerklosters (C I. M. Țiplic und M. Crîngaci Țiplic) 


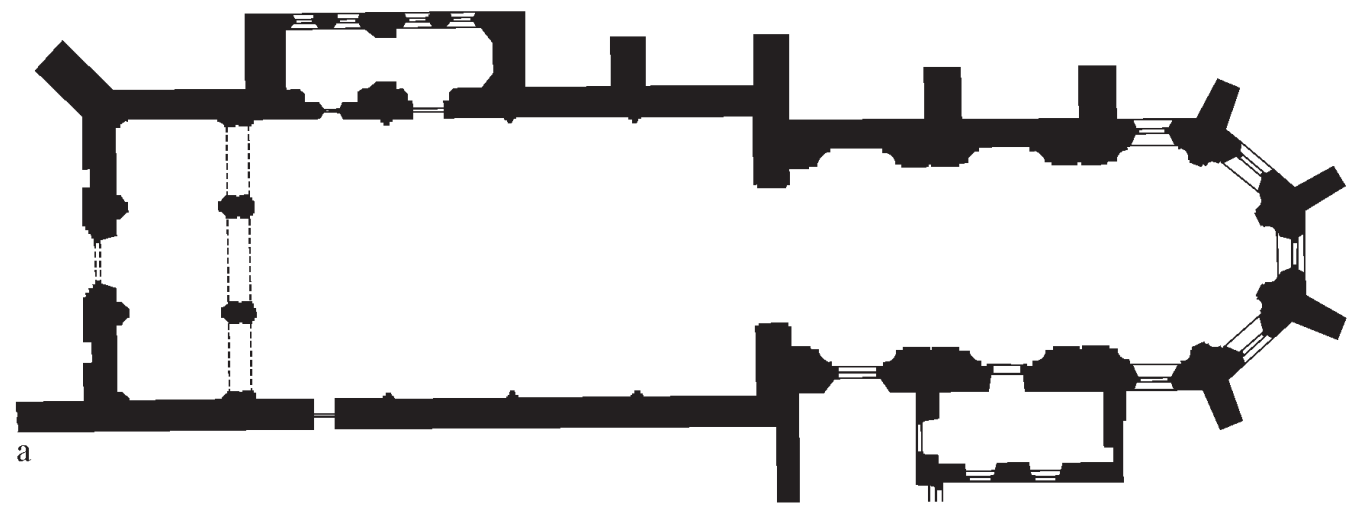

b
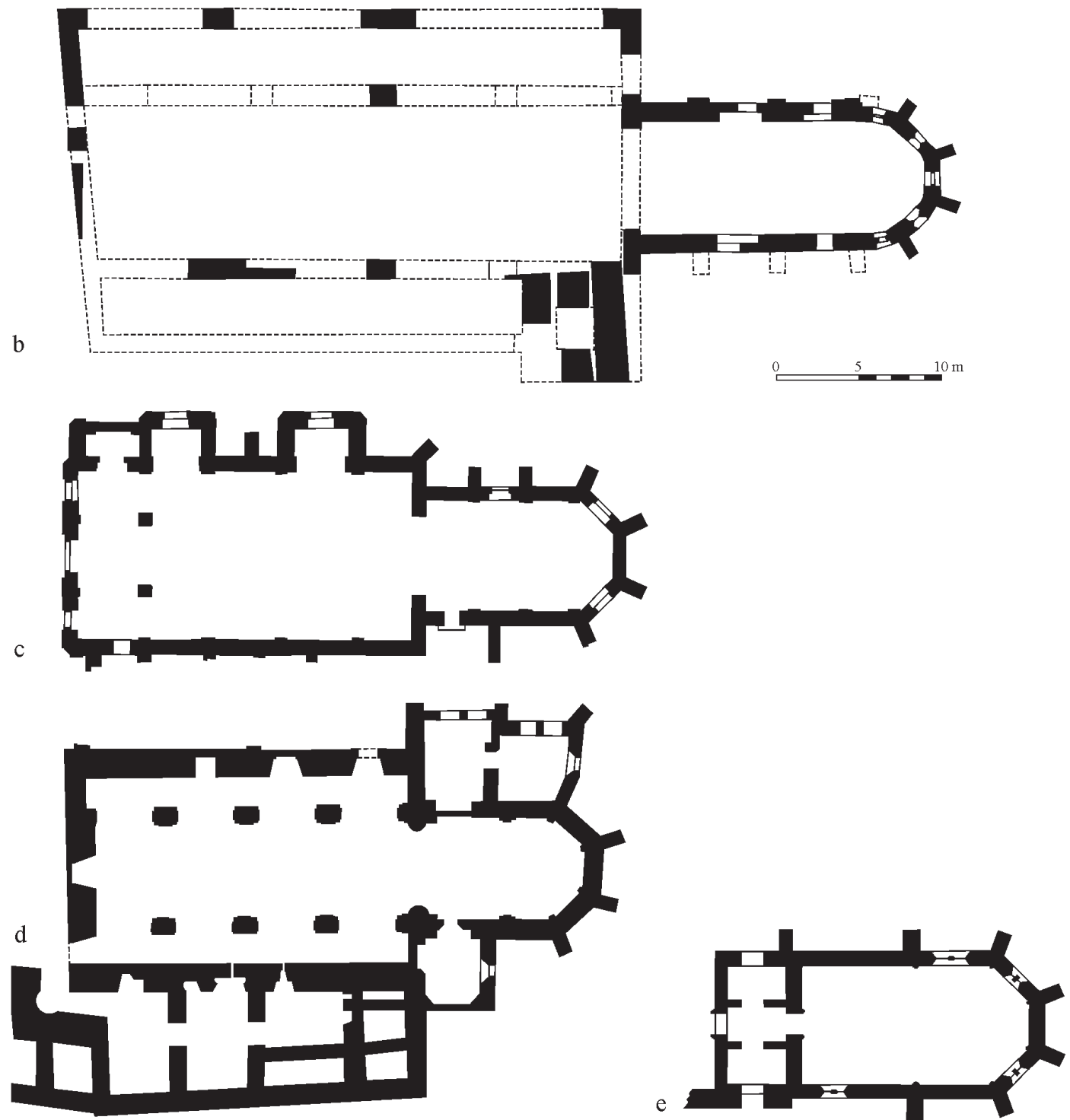

Abb. 3. Hermannstadt. Gotische Grundrisse. a: Ursulinenkirche; b: Klosterkirche der Franziskanernonnen;

c: Klosterkirche der Dominikanernonnen; d: Siechenhauskirche; e: Kapelle des Heiligen Ladislaus (gezeichnet von M. Crîngaci Tiplic und M. Vlad nach Avram-Bucur 1999, 83, 97, 89; Beșliu 1991; FABINI 1991 und MarCU Istrate 2007, 70-74) 
Ein anderes kirchliches Gebäude, das aus dem urbanen Erbe Hermannstadts verschwand, ist die Klosterkirche der Franziskanernonnen, die seit dem Ende des 15. Jahrhunderts urkundlich bescheinigt ist und deren Chor bis 1987 erhalten blieb, als er abgerissen wurde. Trotz der Tatsache, dass die Studie von Hermann Fabini unserer Meinung nach die Identität dieses Gebäudes, das erst kürzlich aus dem städtischen Erbe verschwand und das sich an der Kreuzung der Elisabethgasse mit der Nasturelui-Straße ${ }^{33}$ (s. lfd. Nr. 4 in der Tabelle bzw. auf der Karte 1 und 2; $A b b .3 . b$ ) befand, klärte, herrscht in der Fachliteratur immer noch ein Durcheinander. Archäologischen und historischen Untersuchungen gelang es, den Moment zu bestimmen, als der Bau der Kirche begann (zum Ende des 13. Jahrhunderts hin), die Bauetappen und die verschiedenen Zweckbestimmungen zu skizzieren, die sie nach dem Brand im Jahr 1556 innehatte (Getreidelager, Seidenmanufaktur, Bäckerei, Wohnraum) sowie die planimetrische Erfassung dieser Kirche mit einer Gesamtlänge von $51 \mathrm{~m}$ vorzunehmen und einen Friedhof zu identifizieren. ${ }^{34}$

Bis zu den konkreten Ergebnissen, die die jüngste Stadtarchäologie bat, nahmen viele Forscher eine mögliche Lage der ersten Pfarrkirche an der Stelle der heutigen Siechenhauskirche/Asylkirche (Spitalsgasse Nr. 4; s. lfd. Nr. 7 in der Tabelle bzw. auf der Karte 1 und 2; Abb. 3.d) als Hypothese an. Es wurde vermutet, dass die auf der oberen Terrasse des Zibins, am Huetplatz befindliche Pfarrkirche von einer zweiten Generation von Siedlern erbaut wurde, genauer am Ende des 12. Jahrhunderts. In urkundlicher Hinsicht lässt sich die Siechenhauskirche mit dem Haus identifizieren, das die Hermannstädter Gemeinde den „Kreuzbrüdern des Heilig-Geist-Ordens“ gestiftet hatte, ,zusammen mit allem, was dazugehört und das seit langer Zeit als Spital genutzt wurde und von weltlicher Hand verwaltet wurde“. ${ }^{35}$ Den in diesem Punkt über fast zwei Jahrzehnte hinweg durchgeführten archäologischen Untersuchungen - die erste Kampagne begann 1988 - gelang es nicht, eine Kirche oder Gräber aus dem 12. Jahrhundert freizulegen. Dafür entdeckten aber die Forscher Folgendes: durch die Kirchenmauern überlagerte Holzstrukturen aus dem 13. Jahrhundert, die „einem Holzbauwerk aus Holz und einem Hof" vom Anfang des 13. Jahrhunderts zugeordnet wurden; Steinfundamente, die von einem anderen Bauwerk stammen $(22 \times 11 \mathrm{~m})$, das vor die erste urkundliche Erwähnung im Jahr 1292 datiert werden kann und das durch die gotische Kirche überlagert wurde - da wurden die Unterbauten aus Stein dem 1292 attestierten Heiliggeistspital zugewiesen; des Weiteren einen Friedhof, der seit dem 13. Jahrhundert bis zu Beginn des 18. Jahrhunderts belegt war. ${ }^{36}$

In der Umgebung der Pfarrkirche am Huetplatz gab es laut Urkunden vier oder fünf Kapellen. Archäologische Untersuchungen machten drei Kapellen am Huetplatz aus: eine in romanischem und zwei in gotischem Baustil. Wegen fehlender Urkunden für die Anfangszeit Hermannstadts lassen sich die Identität der romanischen Rotunde, die kürzlich entdeckt und in die Mitte des 12. Jahrhunderts datiert wurde (s. Ifd. Nr. 45 in der Tabelle und auf der Karte 2; $A b b .4$ ), sowie ihre späteren Funktionen nur vermuten. So nimmt Zeno Karl Pinter an, dass diese Rotunde, die in vielerlei Hinsicht jener in Broos ähnelt, eine Doppelkapelle war, die zunächst die Funktion einer herrschaftlichen Kapelle erfüllte. Der Stifter könnte ein Ritter gewesen sein, der aus dem Abendland gekommen wäre und die Rolle des Lokators bei der sächsischen Ansiedlung übernahm. Diese Person könnte jener Hermann gewesen sein, der die Siedlung, die seinen Namen trägt, gründete: villa Hermanni, Hermannstadt. ${ }^{37}$ Daniela Marcu Istrate ist der Ansicht, dass diese romanische Kapelle im 13. Jahrhundert erbaut wurde. Sie identifiziert sie mit der Kapelle des Heiligen Johannes, die in den Jahren 1530-1531 in den Rechnungsbüchern Hermannstads urkundlich erwähnt wird. ${ }^{38}$ Die urkundliche Bescheinigung erfolgte aber viel später als der Zeitpunkt ihrer Errichtung, weshalb die Problematik ihrer Identität weiterhin offen bleibt.

Im Fall der anderen beiden gotischen Kapellen, der Kapelle des Heiligen Ladislaus und der des Heiligen Jakobs, klärten archäologische und historische Forschungen die Verortung. Die Kapelle des Heiligen Jakobs befand sich in der Nordecke des Huetplatzes, heute teilweise eingegliedert in das Gebäude auf dem Huetplatz Nr. $17^{39}$ (s. lfd. Nr. 38 in der Tabelle und auf der Karte 2). Die Kapelle des Heiligen Ladislaus, deren Planimetrie und topographische Angaben bei archäologischen Untersuchungen 2005 festgelegt wurden, befand sich in der südöstlichen Ecke des Huetplatzes, in der Nähe des Brukenthalgymnasiums (s. lfd. Nr. 67 in der Tabelle und auf der Karte 2;

\footnotetext{
${ }^{33}$ FABINI 1991, 74-77.

${ }^{34}$ Munteanu Beșliu 2001, 9-30.

${ }^{35}$ ZIMMERMANN-WERNER 1892, 191-192, Nr. 260; ROLLER 1952, 391-392, Nr. 432.

${ }^{36}$ Beșliu Munteanu 2008a; Beșliu Munteanu 2009a; Beșliu Munteanu 2012.
}

Acta Archaeologica Academiae Scientiarum Hungaricae 70, 2019

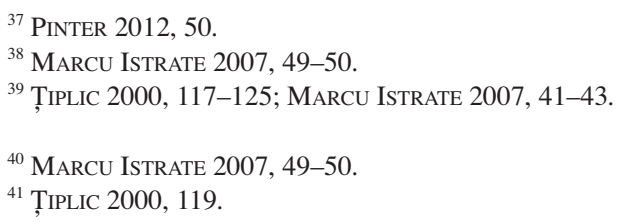

${ }^{37}$ PINTER 2012, 50.

${ }^{38}$ Marcu Istrate 2007, 49-50.

${ }^{40}$ Marcu Istrate 2007, 49-50.

${ }^{41}$ ȚIPLIC 2000, 119. 
Abb. 3.e). ${ }^{40}$ Die Existenz der Letzteren ist wohlbekannt sowohl aus Dokumenten als auch aus alten Fotografien. Sie wurde 1898 zusammen mit dem Priesterturm abgerissen.

Weitere urkundlich belegte Kapellen auf dem Huetplatz, die auf dem Gelände nicht identifiziert wurden, sind: die Kapelle des Heiligen Stefan, über die man annimmt, dass der ursprüngliche Schutzheilige der Kapelle zum Heiligen Jakob vom Huetplatz Nr. 17 der Heilige Stefan war, ${ }^{41}$ zweitens die Kapelle des Heiligen Nikolaus, die sich in extra cimiterium in via versus alumniam in mediio murt ${ }^{42}$ befand und bei der es nicht ausgeschlossen ist, dass sie am Großen Ring oberhalb des ehemaligen Zugangstunnels zur Unterstadt lag. In moderner Zeit (1747) war sie als Laubenkirche ${ }^{43}$ bekannt und sie ist auf dem Plan Hermannstadts von 1845 markiert. ${ }^{44}$ Sie wurde 1851 abgerissen. ${ }^{45}$

Eine weitere Kapelle, die archäologisch identifiziert wurde und auf dem Plan von G. M. Visconti von 1699 eingezeichnet ist, ist jene im Hof eines Hauses am Großen Ring bzw. im Hof des Lutsch-Hauses, heute der Sitz des Deutschen Forums (Str. General Magheru/Sporergasse Nr. 1-3; s. lfd. Nr. 43 in der Tabelle und auf der Karte 2). ${ }^{46}$ Es wird auch angenommen, dass es eine Privatkapelle im Hof eines Hauses am Großen Ring gab (Hecht-Haus, Piața Mare/Großer Ring Nr. 8). ${ }^{47}$

\section{FRIEDHÖFE}

Durch archäologische Forschungen wurden vier mittelalterliche Friedhöfe im Bereich des historischen Zentrums identifiziert (Karte 2).

1. Der Friedhof auf dem Huetplatz (s. lfd. Nr. 67), um die Pfarrkirche herum, wurde seit der zweiten Hälfte des 12. bis zum 16. Jahrhundert belegt. Im Unterschied zu den anderen drei zeichnet sich dieser durch eine sehr hohe Bestattungsdichte aus. Es wurden 1833 Gräber entdeckt, über die man annimmt, dass sie ungefähr ein Fünftel der Anzahl der im Laufe der Zeit in diesem Raum Beigesetzten darstellen. ${ }^{48}$

2. Der Friedhof der Siechenhauskirche/Spitalkirche (s. lfd. Nr. 7) wurde seit dem 13. Jahrhundert belegt. Die letzte Beisetzung wurde im 18. Jahrhundert registriert. Die Bestattungsdichte ist gering, es wurden 177 Gräber entdeckt. Die Beisetzungen wurden sowohl im Inneren der Kirche als auch an der Außenseite durchgeführt. Das älteste Bestattungsniveau datiert ins 13. Jahrhundert, es gibt auch hier Gräber mit Kopfnischen. Die jüngste Beisetzung fand Anfang des 18. Jahrhunderts statt. ${ }^{49}$

3. Der Friedhof der Klosterkirche der Franziskanernonnen (s. lfd. Nr. 4) gehörte zu den historischen Monumenten und wurde 1987 abgerissen. Der Friedhof wurde bis zur ersten Hälfte des 16. Jahrhunderts belegt. Angesichts des Umfangs der archäologischen Grabungsstelle und der 39 entdeckten Gräber, deren anthropologische Analysen nicht veröffentlicht wurden, ist es anzunehmen, dass der Friedhof sehr klein war. ${ }^{50}$

4. Archäologische Sondierungen wurden an der Franziskanerkirche Heilige Elisabeth (s. lfd. Nr. 5) durchgeführt, die 1868 abgerissen wurde. Da wurden Skelettreste, die das Vorhandensein eines Friedhofs auch an dieser Stelle anzeigen, zutage gefördert. ${ }^{51}$

\section{BEFESTIGUNGSANLAGEN DER STADT}

Infolge der archäologischen Rettungsgrabungen auf dem Verwaltungsgebiet der Stadt Hermannstadt können wir sagen, dass die Bilanz keinen wirklichen Aufschluss über die Anfangsphase der Befestigungen der Siedlung villa Hermanni gibt. Durch die auf dem Großen und Kleinen Ring und in den Untergeschossen der Gebäude um diese Plätze herum durchgeführten archäologischen Rettungsgrabungen wurden Segmente der Steinringmauer und

\footnotetext{
${ }^{42}$ SEIWERT $1874,362$.

${ }^{43}$ Sigerus 2006, 36; Avram-Bucur 1999, 39.

${ }^{44}$ Die Karte von 1845 „Grundriss der innern Stadt Hermannstadt" befindet sich in der Bibliothek des Nationalmusems Brukenthal, Hermannstadt, Kartensammlung Nr. 4928. Sie kann auch auf verschiedenen Websites im Internet angesehen werden.

${ }^{45}$ Sigerus 2006, 48.

${ }^{46}$ Munteanu BeșLiu 2001, 63-72.
}

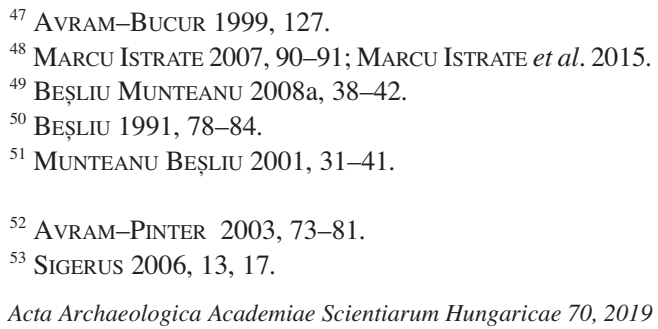


der Befestigungsgraben identifiziert. Allerdings kam man im Hinblick auf die ersten zwei Etappen der Siedlungsbefestigung zu keinen spektakulären Schlussfolgerungen oder zu einer engeren Chronologie.

Im gegenwärtigen Forschungsstadium und in Ermangelung von veröffentlichten Ergebnissen vollständiger archäologischer Untersuchungen sind wir weit davon entfernt, es verstehen zu können, wie die erste Ringmauer verlief. Man nimmt an, dass sie das erste kirchliche Gebäude, das auf der Fläche des heutigen Huetplatzes erbaut wurde, geschützt hatte. Gleichzeitig sind wir weit davon entfernt zu wissen, wie die Situation der Befestigungen Hermannstadts in der Mitte des 18. Jahrhunderts im Zusammenhang mit den Zerstörungen der Siedlung durch den Mongolenangriff war. Die bis in die Gegenwart durchgeführten archäologischen Forschungen waren konjunkturell und erlauben nicht die Gewinnung von wichtigen Angaben, was in der Konsequenz zum Ansammeln disparater Informationen führte.

Eine Neudeutung der Befestigungen Hermannstadts auf der Grundlage der archäologischen Entdeckungen, vor allem nach der Veröffentlichung der Ergebnisse der archäologischen Forschungen auf dem Kleinen Ring, die von S. A. Luca (s. lfd. Nr. 69) koordiniert wurden, verdient eine detaillierte Behandlung in einer selbstständigen Studie, da sich die vorliegende nur auf die Systematisierung der vorhandenen Informationen beschränkt (s. Tabelle 1). Diese könnte die Grundlage eines ausgearbeiteten Plans sein, der wesentlich konkretere Angaben im Zusammenhang mit dem Bau und der Entwicklung des Verteidigungssystems Hermannstadts vom 12. bis zum 16. Jahrhundert zu bieten vermag.

\section{ZIVILE ÖFFENTLICHE GEBÄUDE (SITZ DES HERMANNSTÄDTER RATHAUSES)}

Zu den öffentlichen Zivilgebäuden, die archäologischen Untersuchungen unterzogen wurden, gehören die drei sukzessiven Sitze des Rathauses von Hermannstadt. Im 14. und 15. Jahrhundert befand sich der Sitz des Rathauses in der unmittelbaren Nähe des Ratsturmes, östlich davon, an der Stelle, wo sich jetzt das Gebäude vom Großen Ring Nr. 31 - Str. Avram Iancu/Reispergasse Nr. 1-3 (s. Nr. 47) befindet. Durch die an dieser Stelle durchgeführten archäologischen Untersuchungen konnte ein Gebäude mit rechtwinkligem Grundriss, das sich in einer Entfernung von ungefähr acht Meter an der Innenseite der Ringmauer befand, identifiziert werden. Es wurde auch eine Struktur erkannt, die dem Sitz des Rathauses im 14. und 15. Jahrhundert zugeordnet wurde. Das Rathaus funktionierte hier bis $1470,{ }^{52}$ als Thomas Gulden das Haus neben dem Priesterturm als Rathaussitz für die Stadt stiftete, wo es bis 1549 verblieb. ${ }^{53}$ Kurz danach zog das Rathaus in das Altemberger Haus (Str. Mitropoliei/Fleischergasse Nr. 2; s. Ifd. Nr. 1), wo es bis 1948 tätig war. Die letztgenannte historische Stätte war eines der archäologisch am intensivsten untersuchten Denkmäler, wobei die erlangten Resultate die Entwicklung des Gebäudes im Verlauf des Mittelalters sowie Elemente der mittelalterlichen und nachmittelalterlichen materiellen Kultur aufzeigten. ${ }^{54}$

\section{HÄUSER}

Als komplexe Stadt hat Hermannstadt im Zentrum relativ viel von der mittelalterlichen Substanz der zivilen Architektur bewahrt. ${ }^{55}$ Deshalb beschränken wir uns darauf, daran zu erinnern, dass archäologische Forschungen Häuser und Strukturen aus Holz bestätigten, die aufgrund des geborgenen Keramikmaterials im Allgemeinen in die 12.-13. oder 13.-14. Jahrhunderte datiert wurden, sowohl in der Unterstadt im Bereich der Siechenhauskirche, der Elisabethkirche und der Saggasse als auch in der Oberstadt im Bereich Kleiner Ring, Großer Ring, Reispergasse, Fleischergasse Nr. 2 usw. (s. Tabelle 1). Archäologische Forschungen haben die Hypothese der Vorherrschaft von Holzkonstruktionen in der mittelalterlichen Siedlung bestätigt.

${ }^{54}$ Fabini 1997, 6-16; Munteanu Beșliu 2000a; Beșliu MunTeanu 2006a.
${ }^{55}$ Über dieses Thema hat Hermann Fabini ausführlich geschrieben. Siehe H. FABINI: Sibiul gotic [Das gotische Hermannstadt]. București 1982; AVRAM-BuCUR 1999, 127. 

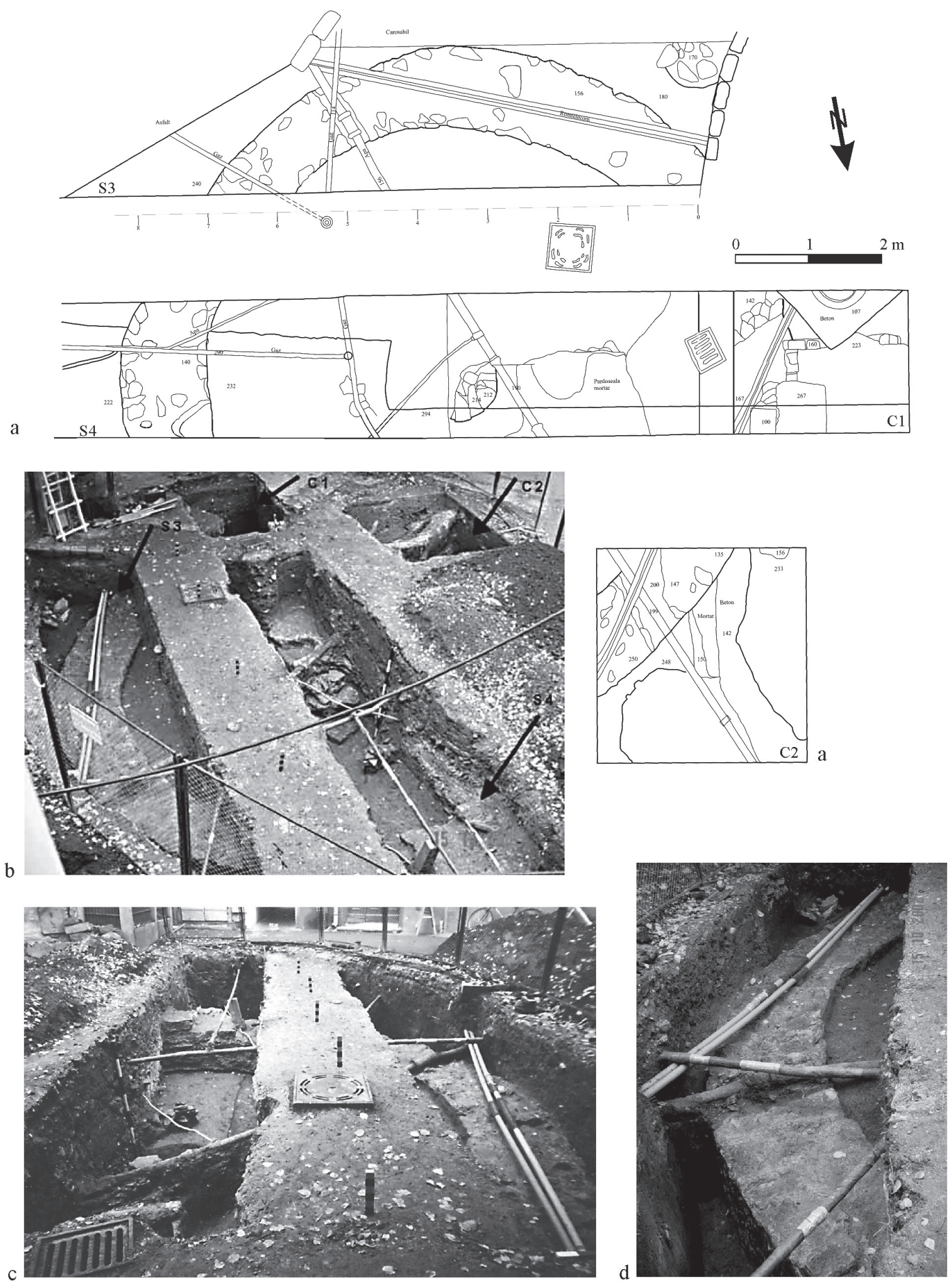

Abb. 4. Hermannstadt. Archäologische Ausgrabungen am Huetplatz (durchgeführt im Jahr 2002). a: Grundriss der romanischen Rotunde; b-d: Fundament der Rotunde ( Z. K. Pinter und I. M. Țiplic) 


\section{PLATZ- UND STRASSENGESTALTUNG}

Anlässlich der Sanierungs- und Modernisierungsarbeiten an den Plätzen und Straßen im historischen Zentrum Hermannstadts wurden verschiedene Typen von Straßenanlagen aus unterschiedlichen Perioden freigelegt: Elemente von Brücken (Str. Ocnei/Burgergasse; s. lfd. Nr. 98), Wasserzuleitungsanlagen, Brunnen, Abwasserkanäle und Elemente städtischen Mobiliars, wobei die Letztgenannten auf dem Großen Ring entdeckt wurden (der Sockel der Rolandstatue, das Fundament der Narrenkäfige, der geziegelte Standort der Statue des Heiligen Nepomuk). ${ }^{56}$

Im Hinblick auf die Straßenanlagen wurde die älteste Anlage, die durch eine Schicht von Zweigen und Brettern oder Baumstämmen charakterisierbar war ${ }^{57}$ (Str. Avram Iancu/Reispergasse; s. lfd. Nr. 62), an archäologischen Untersuchungen entdeckt. Es wurden auch Pflasterungen aus Flussstein freigelegt, die gemäß einem Dokument des Magistrats aus dem Jahr 1721 ins 18. Jahrhundert zu datieren sind (Str. Cetătii/Harteneckgasse, Str. Tipografilor/Wiesengasse, Str. Avram Iancu/Reispergasse, Str. Alexandru Odobescu/Pempflingergasse, Piața Gării/ Bahnhofsplatz, Piața Mare/Großer Ring, ${ }^{58}$ Piața Cibin/Bauholzplatz; s. Ifd. Nr. 62, 75, 51, 50, 61, 71). In diesem Dokument wurde der Arbeitsbeginn der Pflasterung der Straßen beschlossen und verlangt, dass ,,jeder Karren, der in die Stadt einfährt, am Stadttor drei bis sechs Steine übergeben muss““. 59

Im Zusammenhang mit den Anlagen der Wasserzuleitung, Brunnen und Abwasserkanälen förderten die archäologischen Aufsichten und Freilegungen folgende Fundtypen häufig zutage: Fragmente von Wasserleitungen aus Holz (Piaţa Mare/Großer Ring, Str. Avram Iancu/Reispergasse, Piaţa Aurarilor/Fingerlingsplatz, Str. Nicolae Bălcescu/Heltauergasse; s. lfd. Nr. 61, 62, 76), Brunnenfundamente (Piaţa Mare/Großer Ring, Str. Avram Iancu/ Reispergasse vor dem Haus Nr. 3, Piaţa Aurarilor/Fingerlingsplatz, Str. Filarmonicii/Kleine Erde; s. 1fd. Nr. 61, 62, 21, 76), ferner Wasserablaufkanäle aus Balken und Brettern (Str. Vopsitorilor/Färbergasse, Str. Moş Ion Roată/Entengasse) oder aus Ziegelsteinen (Piaţa Mică/Kleiner Ring, Piaţa Huet/Huetplatz, Piaţa Aurarilor/Fingerlingsplatz, Piaţa Mare/Großer Ring Nr. 2, Str. Avram Iancu/Reispergasse, Str. Cetăţii/Harteneckgasse, Biserica Azilului/Siechenhauskirche, Scările Fingerling/Fingerlingsstiege, Str. Argintarilor/Fingerlingsgasse, Str. Engels). Ihre Datierung erwies sich oft als schwierig, doch sie müssten mit urkundlichen Bescheinigungen verglichen werden. So stiftete zum Beispiel Graf Mathias Armbruster 1538 eine schöne Bronzeleitung für den Brunnen auf dem Großen Ring und im Jahr 1584 wird auf dem Großen Ring der erste Brunnen mit Rohren installiert. ${ }^{60}$ Das 18. Jahrhundert ist die Periode, als auf vielen Straßen Brunnen mit Rohren eingerichtet werden: Str. Avram Iancu/Reispergasse, Str. Mitropoliei/Fleischergasse, Str. Centumvirilor/Hundsrücken, Str. Tribunei/Quergasse, Str. Ocnei/Burgergasse, Str. 9. Mai/Elisabethgasse, Str. Nicolae Bălcescu/Heltauergasse. ${ }^{61}$

\section{GETREIDELAGER, VORRATSGRUBEN}

Wir wollen versuchen, die Bedeutung dieses Themas in ein paar Zeilen zu unterstreichen - umso mehr, weil dieses Thema in der Geschichtsschreibung anderer siebenbürgischer Städte nicht wiederzufinden ist. Erneut bildet Hermannstadt eine Ausnahme, nicht nur wegen der häufigen urkundlichen Erwähnungen dieser Getreidegruben, sondern auch wegen ihrer Auffindung auf dem Gelände durch archäologische Untersuchungen. ${ }^{62}$ Die erste Erwähnung der Korngruben auf dem Großen Ring stammt aus der ersten Hälfte des 15. Jahrhunderts. Diese befanden sich im Besitz der Hermannstädter Pfarrkirche. ${ }^{63}$ Bis zur Entdeckung der teilweise noch vollständig erhalten gebliebenen 23 Korngruben in den Jahren 2004 und 2005 wurde ihre Existenz von den Historikern nur vermutet (s. Ifd. Nr. 61). ${ }^{64}$ Laut der Urkunde besaß die Kirche eine weitere Getreidegrube unter dem Eingang des Heltauer

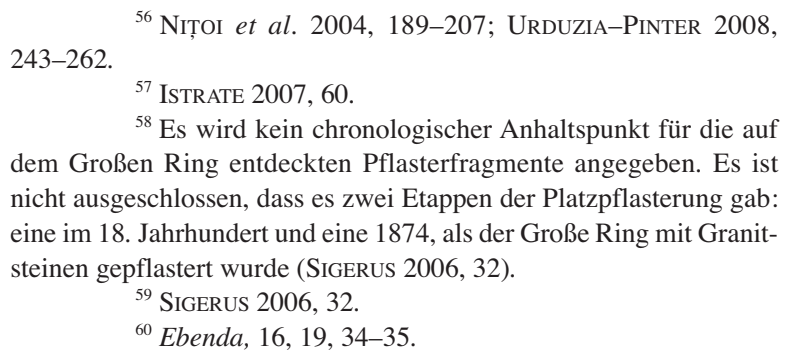

${ }^{58}$ Es wird kein chronologischer Anhaltspunkt für die auf dem Großen Ring entdeckten Pflasterfragmente angegeben. Es ist nicht ausgeschlossen, dass es zwei Etappen der Platzpflasterung gab: eine im 18. Jahrhundert und eine 1874, als der Große Ring mit Granitsteinen gepflastert wurde (SIGERUS 2006, 32).

${ }^{59}$ Sigerus 2006, 32.

${ }^{60}$ Ebenda, 16, 19, 34-35.

\footnotetext{
2010, 85-92

${ }^{61}$ Eine ausführlichere Darstellung findet sich bei URDUZIA

${ }^{62}$ Beșliu Munteanu-Blezu 2004, 139-142; UrduziaPINTER 2008, 244.

${ }^{63}$ SEIWERT 1874, 328

${ }^{64}$ Für eine Beschreibung und ihre Topographie s. URDUZIA-PinTER 2008, 244. Siehe auch die Beschreibung bei E. Sigerius (Sigerus 2003, 99), die bis ins Detail den Ergebnissen der Hermannstädter Archäologen gleicht.
} 
Tores, die archäologisch aber noch nicht identifiziert wurde. Archäologische Rettungsgrabungen und Aufsichten belegten die Existenz weiterer, mit Erde gefüllter Korngruben auf dem Kleinen Ring; aus einigen von ihnen wurden Keramikmaterial, Tierknochen, Eisenstücke und Münzen geborgen. Zudem wurde eine Korngrube in der Reispergasse/Str. Avram Iancu 11 und eine in der Pempflingergasse/Str. Al. Odobescu entdeckt. ${ }^{65}$

Eine Analyse der urkundlichen Quellen könnte interessante Informationen zu diesem Thema über die Häufigkeit dieser Getreidegruben und -lager bzw. die verschiedenen Lagertypen bieten - hier beziehen wir uns zum Beispiel auf die Klosterkirche der Franziskanernonnen, die nach dem Feuer 1556 und wegen der Vorherrschaft der Reformation in ein Kornlager umfunktioniert wurde -, des Weiteren über ihre Bedeutung im Leben der Gemeinschaft, ihre Instandhaltung und ihre Eigentümer/Verwalter. Sogar ihre Kartierung wäre vorstellbar, wenn man bedenkt, dass 1704 die Getreidereserven inventarisiert und 1705 die Kornreserven der Bewohner inspiziert wurden. ${ }^{66}$

\section{MATERIELLE KULTUR}

Das aus den archäologischen Freilegungen und Aufsichten stammende reiche Material wird in den Lagern des Brukenthal-Nationalmuseums aufbewahrt. Ein Teil davon gelangte auch in die wissenschaftlichen Kreise. Die meisten Artefakte sind Folgende: keramisches Material (wir erinnern an jene zwei mittelalterlichen Töpferöfen und an das dazu gehörige Keramikmaterial, die in der Harteneckgasse entdeckt wurden; s. lfd. Nr. 52), Kacheln, Glasstücke und -behälter (wir veranschaulichen hier nur das Material aus dem alten Rathaus Hermannstadts; s. lfd. Nr. 3), Eisenstücke und Tierknochen. Unter den aus archäologischen Forschungen stammenden Artefakten, die in Hermannstadt relativ selten sind, befinden sich die zwei ganzen Pilgermuscheln aus Santiago de Compostela, die in zwei Gräbern auf dem Huetplatz geborgen wurden, ${ }^{67}$ Münzen - die Hälfte einer byzantinischen Münze aus der Zeit Manuels I. (1143-1180), die im Bereich des Friedhofs am Huetplatz entdeckt wurde, einige arpadenzeitliche Münzen von Béla III., Andreas II., Béla IV. und Ladislaus -, Streitkolbenenden, eine Pfeilspitze, Talglampen, ein Knochenwürfel, ein Knochenkamm, ein Bronzemedaillon der Heiligen Ursula (1556) usw.

\section{SCHLUSSFOLGERUNGEN}

Durch die Präsentation der in Hermannstadt - einer der wichtigsten mittelalterlichen und modernen Städte Siebenbürgens - zutage geförderten archäologischen Funde haben wir versucht, die Bedeutung der Stadtarchäologie bei der Skizzierung der Geschichte und der Identität der Stadt zu umreißen. Im Vergleich zu anderen Städten Siebenbürgens verfügt Hermannstadt über eine reichhaltige Archäologie mit den entsprechenden Ergebnissen. Natürlich gibt es auch nicht veröffentlichte oder überarbeitete und nur teilweise veröffentlichte Ergebnisse archäologischer Grabungen, doch der fehlende Zugang zu den Informationen lässt weiterhin Raum für hypothetische Interpretationen - siehe zum Beispiel den Fall der ersten Etappe der Befestigung Hermannstadts. Obwohl mehr als dreißig Jahre seit den ersten archäologischen Forschungen in Hermannstadt vergangen sind, zeigen die von uns gesammelten und vorgestellten Angaben, dass wir uns erst am Anfang befinden, da dieser Bereich ein riesiges Potenzial hat. Zusätzlich stellt die Erfassung der registrierten archäologischen Informationen einen Indikator der Veränderungen und Veränderungsphänomene dar, die die Stadt sowohl in vorhergehenden Zeiten als auch in der Gegenwart durchgemacht hat und heute noch erlebt - ein Forschungsthema, das neue Horizonte eröffnen kann.

\footnotetext{
${ }^{65}$ Beșliu Munteanu-Blezu 2004, 139-140.

${ }^{66}$ Sigerus 2006, 28.
}

\author{
${ }^{67}$ Diese Art von Artefakt ist in ganz Siebenbürgen einzig- \\ artig; s. M. CRîNGACI ȚIPLIC: Obiecte speciale. In: MARCU IsTRATE \\ 2007, 109. \\ Acta Archaeologica Academiae Scientiarum Hungaricae 70, 2019
}


AVRAM-BUCUR 1999

Avram-PINTER 2003

AVRAM-RILL 1990

BELDIMAN-SONOC-SZTANCS 2007

BELDIMAN-SZTANCS 2006

BEȘLIU 1991

BEȘLIU 2003

Beșliu-Beșliu Munteanu 2006

BEŞLIU-NÄGLER 1989

Beșliu Munteanu 2005a

Beșliu Munteanu 2005b

Beșliu Munteanu 2005c

Beșliu Munteanu 2005d

Beșliu Munteanu 2006a

Beșliu Munteanu 2006b

Beșliu Munteanu 2007a

Beșliu Munteanu 2007b

Beșliu Munteanu 2007c

Beșliu Munteanu 2007d

Beșliu Munteanu 2007e

Beșliu Munteanu 2008a

\section{LITERATUR}

= A. Avram-I. Bucur: Denkmaltopographie Siebenbürgen. 5.1.1. Stadt Hermannstadt. Die Altstadt / Topografia monumentelor din Transilvania. 5.1.1. Municipiul Sibiu. Centrul istoric. Bearb. von A. Avram und I. Bucur, hrsg. von Chr. Machat. Köln 1999.

= A. Avram-Z. K. Pinter: Edificiul primăriei Sibiului în secolele XIV-XV (Piața Mică nr. 31 - str. Avram Iancu nr. 1-3) [Das Gebäude des Hermannstädter Rathauses im 14.-15. Jahrhundert (Kleiner Ring Nr. 31 - Reispergasse Nr. 1-3)]. In: Artă, istorie, cultură. Studii în onoarea lui Marius Porumb. Ed.: C. Firea, C. Opreanu. Cluj-Napoca 2003, 73-81.

= A. Avram-M. RiLl: Betrachtungen zum Gebäude des ersten Spitals in Hermannstadt. Zeitschrift für Siebenbürgische Landeskunde 13/1 (1990) 62-74.

= C. BELDIMAN-A. GH. SONOC-D.-M. SzTANCS: Artefacte provenind dintr-un atelier de confecționare a pieptenilor [Aus einer Kammwerkstatt stammende Artefakte]. Cronica cercetărilor arheologice. Campania 2006. A XLI-a ediţie a Sesiune Anuale de Rapoarte Arheologice, Tulcea 2007. Ed.: M. V. Angelescu, F. Vasilescu. Bucureşti 2007, 333-334, 470.

= C. BELdimAN-D.-M. SzTANCS: Sibiu, jud. Sibiu. Punct: Piața Mică. Cronica cercetărilor arheologice. Campania 2005. A XL-a Sesiune Naţională de Rapoarte Arheologice, Constanţa, 31 Mai - 3 Iunie 2006. Ed.: M. V. Angelescu, F. Vasilescu. Bucureşti 2006, 324-325.

= P. BEșLiu: Istoria unei biserici de mănăstire din Sibiu [The History of a Monastery Church in Sibiu]. Revista Monumentelor Istorice 60/1 (1991) 78-84.

= P. BEșLIU: Cercetarea arheologică a bisericii azilului din Sibiu [The archaeological research of the Hospital Church from Sibiu]. Corviniana 7 (2003) 129-158.

= O. Beșliu-P. Beșliu Munteanu: Catalogul pieselor provenite de la Biserica Azilului din Sibiu [The historical and archaeological objects from the Hospital Church in Sibiu]. Sargetia 34 (2006) 681-692.

= P. BeŞLIU-Th. NÄGLER: Die archäologischen Grabungen im Hermannstädter Alten Rathaus. Forschungen zur Volks- und Landeskunde 22/2 (1989) 28-40.

= P. Beșliu Munteanu: Sibiu, jud. Sibiu. Punct: Str. Avram Iancu, nr. 11. Cronica Cercetărilor Arheologice. Campania 2004. A XXXIX-a Sesiune Naţională de Rapoarte Arheologice, Jupiter-Mangalia, 25-28 Mai 2004. Ed.: M. V. Angelescu, I. Oberlănder-Târnoveanu, F. Vasilescu. Bucureşti 2005, 341-343.

= P. BeșLiu Munteanu: Sibiu, str. Avram Iancu, nr. 11 - Studiu arheologic [Sibiu, Avram Iancu Street No. 11 - Archaeological study]. Corviniana 9 (2005) 139-162.

= P. Beșliu Munteanu: Sibiu, jud. Sibiu. Punct: Casa din Piața Mare, nr. 2-4. Cronica cercetărilor arheologice. Campania 2004. A XXXIX-a Sesiune Naţională de Rapoarte Arheologice, JupiterMangalia, 25-28 Mai 2004. Ed. : M. V. Angelescu, I. Oberlănder-Târnoveanu, F. Vasilescu. Bucureşti 2005, 343-344.

= P. Beșliu Munteanu: Sibiu, jud. Sibiu. Punct: Piaţa Mică. Cronica cercetărilor arheologice. Campania 2004. A XXXIX-a Sesiune Naţională de Rapoarte Arheologice, Jupiter-Mangalia, 25-28 Mai 2004. Ed.: M. V. Angelescu, I. Oberlănder-Târnoveanu, F. Vasilescu. Bucureşti 2005, 344-347.

= P. BeșLiu Munteanu: Primăria veche din Sibiu. Casa, oamenii, muzeul (The Old Townhall in Sibiu. The Building, the People, the Museum). Bibliotheca Brukenthal 1. Sibiu 2006.

= P. BeŞLIU MunteAnu: O insulă de case demolate în Sibiu în perioada interbelică [Eine Insel abgerissener Häuser im Hermannstadt der Zwischenkriegszeit]. Transilvania 2006/1, 76-77.

= P. BeşLiu Munteanu: Sibiu, jud. Sibiu. Punct: str. Moş Ion Roată. Cronica cercetărilor arheologice. Campania 2006. A XLI-a ediţie a Sesiune Anuale de Rapoarte Arheologice, Tulcea 2007. Ed.: M. V. Angelescu, F. Vasilescu. Bucureşti 2007, 320-321.

= P. Beşliu Munteanu: Sibiu, jud. Sibiu. Punct: str. Ocnei, nr. 22. Cronica cercetărilor arheologice. Campania 2006. A XLI-a ediţie a Sesiune Anuale de Rapoarte Arheologice, Tulcea 2007. Ed.: M. V. Angelescu, F. Vasilescu. Bucureşti 2007, 321-323.

= P. Beşliu Munteanu: Le bâtiment - monument historique de Sibiu, Rue d'Ocnei, 22. Étude archéologique. Brukenthal Acta Musei 2/1 (2007) 165-187.

= P. Beşliu Munteanu: Sibiu, jud. Sibiu. Punct: strada Turnului, nr. 7. Cronica cercetărilor arheologice. Campania 2006. A XLI-a ediţie a Sesiunei Anuale de Rapoarte Arheologice, Tulcea 2007. Ed.: M. V. Angelescu, F. Vasilescu. Bucureşti 2007, 323-325.

= P. Beşliu Munteanu: Sibiu, jud. Sibiu. Punct: Teatrul Gong. Cronica cercetărilor arheologice. Campania 2006. A XLI-a ediţie a Sesiune Anuale de Rapoarte Arheologice, Tulcea 2007. Ed.: M. V. Angelescu, F. Vasilescu. Bucureşti 2007, 326-327.

= P. BeșLiu Munteanu: Spitalul medieval din Sibiu [Das mittelalterliche Spital und die Spitalkirche von Hermannstadt]. Sibiu 2008. 
Beșliu Munteanu 2008b

Beșliu Munteanu 2008c

Beșliu Munteanu 2008d

Beșliu Munteanu 2008e

Beșliu Munteanu 2009a

Beșliu MunTeAnu 2009b

Beșliu Munteanu 2009c

BeșLiu Munteanu 2010

Beșliu Munteanu 2012

Beșliu Munteanu 2013

BeșLiu Munteanu 2014

Beșliu Munteanu-Beșliu 2001-2002

Beșliu Munteanu-Blezu 2004

Beșliu Munteanu et al. 2000

Beșliu Munteanu et al. 2005a

Beșliu Munteanu et al. 2005b

Beșliu Munteanu et al. 2010

Beșliu Munteanu et al. 2015

Beșliu Munteanu-UrduZia 2011a

Beșliu Munteanu-UrduZia 2011b

Beșliu Munteanu-UrduZia 2012
= P. BeşLiu Munteanu: Cercetări arheologice din Sibiu, strada Turnului nr. 7 [Archaeological excavations on Turnului Street No. 7, Sibiu]. Brukenthal Acta Musei 3/1 (2008) 219-241.

= P. Beșliu Munteanu: Sibiu, jud. Sibiu. Punct: str. Azilului, nr. 4 (Spitalul de bătrâni). Cronica cercetărilor arheologice. Campania 2007. A XLII-a Sesiune Naţională de Rapoarte Arheologice, Iaşi, 14-17 Maie 2008. Ed.: M. V. Angelescu, F. Vasilescu. Bucureşti 2008, 276.

= P. Beșliu Munteanu: Sibiu, jud. Sibiu. Punct: scările Fingerling, str. Argintarilor. Cronica cercetărilor arheologice. Campania 2007. A XLII-a Sesiune Naţională de Rapoarte Arheologice, Iaşi, 14-17 Maie 2008. Ed.: M. V. Angelescu, F. Vasilescu. Bucureşti 2008, 275.

= P. Beșliu Munteanu: Sibiu, jud. Sibiu. Punct: str. A. D. Xenopol nr. 16. Cronica cercetărilor arheologice. Campania 2007. A XLII-a Sesiune Naţională de Rapoarte Arheologice, Iaşi, 14-17 Maie 2008. Ed.: M. V. Angelescu, F. Vasilescu. Bucureşti 2008, 274-275.

= P. BeșLiu Munteanu: Azilul de bătrâni din Sibiu. Raport de cercetare arheologică 2004-2008 [The rest homes from Sibiu. Report of archaeological research 2004-2008]. Brukenthal Acta Musei 4/1 (2009) 171-201.

= P. Beșliu Munteanu: Sibiu, jud. Sibiu. Punct: str. Manejului și Șelarilor (Biserica Franciscanilor). Cronica cercetărilor arheologice. Campania 2008. A XLIII-a ediţie a Sesiune Naţională de Rapoarte Arheologice, Târgovişte, 27-30 Mai 2009. Ed.: M. V. Angelescu et al. Valachia 21. Bucureşti 2009, 343-344.

= P. Beșliu Munteanu: Sibiu, jud. Sibiu. Punct: str. Manejului (zidul Cetății). Cronica cercetărilor arheologice. Campania 2008. A XLIII-a ediţie a Sesiune Naţională de Rapoarte Arheologice, Târgovişte, 27-30 Mai 2009. Ed.: M. V. Angelescu et al. Valachia 21. Bucureşti 2009, 342-343.

= P. Beșliu MunteAnu: Evoluția clădirii Bisericii Azilului și a Spitalului medieval (postmedieval) din Sibiu [The medieval (postmedieval) hospital and the Hospital Church in Sibiu: The evolution of the buildings]. Historia Urbana 18 (2010) 157-168.

= P. Beșliu Munteanu: Hermannstädter Spital und Spitalkirche, 13.-18. Jh. / Spitalul și Biserica Spitalului din Sibiu, secolele XIII-XVIII. Sibiu 2012.

= P. Beșliu Munteanu: Sibiu, jud. Sibiu. Punct: Poarta Ocnei, str. Zidului și str. Croitorilor. Cronica cercetărilor arheologice. Campania 2012. A XLVII-a ediţie a Sesiune Naţională de Rapoarte Arheologice, Craiova, 27-30 Mai 2013. Ed.: M. V. Angelescu. Bucureşti 2013, 178-180.

= P. BeșLiu Munteanu: Rescue archaeological excavations in Sibiu, Constituţiei Street, 2000. Brukenthal Acta Musei 9/1 (2014) 125-135.

= P. Beșliu Munteanu-O. Beșliu: Turnul Sfatului din Sibiu [The Town Hall tower from Sibiu]. Sargetia 30 (2001-2002) 269-284.

= P. BeȘLiU MunTEANU-F. BLEZU: Restituiri istorice: gropile de provizii de pe terasa de sus a orașului medieval Sibiu [Historische Restitutionen: Die Vorratsgruben auf der Oberterrasse der mittelalterlichen Stadt Hermannstadt]. Transilvania 2004/2-3, 139-142.

= P. Beșliu Munteanu-A. Georgescu-N. Rodean: Cercetări arheologice de salvare în Piața Huet din Sibiu [Rescue archaeological excavation in Sibiu, Huet Square]. Apulum 37/1 (2000) 471-484.

= P. Beșliu Munteanu-A. Nițoi-R. Pop: Sibiu, jud. Sibiu. Punct: Piața Huet. Cronica cercetărilor arheologice. Campania 2004. A XXXVIII-a Sesiune Naţională de Rapoarte Arheologice, ClujNapoca, 26-29 Mai 2004. Ed.: M. V. Angelescu, I. Oberlănder-Târnoveanu, F. Vasilescu. Bucureşti 2005, 335-341.

= P. Beșliu Munteanu-A. Nițoi-R. Pop-C. Urduzia: Sibiu, jud. Sibiu. Punct: Biserica Azilului. Cronica cercetărilor arheologice. Campania 2004. A XXXIX-a Sesiune Naţională de Rapoarte Arheologice, Jupiter-Mangalia, 25-28 Mai 2004. Ed.: M. V. Angelescu, I. Oberlănder-Târnoveanu, F. Vasilescu. Bucureşti 2005, 335.

= P. Beșliu Munteanu-A. Georgescu-C. Munteanu: Sibiu, jud. Sibiu. Punct: Consiliul Județean Sibiu, str. Gen. Magheru nr. 14. Cronica cercetărilor arheologice. Campania 2009. A XLIV-a ediţie a Sesiune Anuale de Rapoarte Arheologice, Suceava 2010. Ed.: M. V. Angelescu, C. Bem, I. Oberlănder-Târnoveanu, F. Vasilescu. Bucureşti 2010, 306-307.

= P. BeșLiu Munteanu et al.: Groapa cu Lei. Istorie și arheologie (Die Löwengrube. Geschichte und Archäologie). Sibiu 2015.

= P. Beșliu Munteanu-C. UrduZia: Sibiu, jud. Sibiu. Punct: Str. Ocnei. Cronica cercetărilor arheologice. Campania 2010. A XLIII-a ediţie a Sesiune Naţională de Rapoarte Arheologice, Sibiu, 22-26 Mai 2011. Ed.: M. V. Angelescu et al. Sibiu 2011, 232-234.

= P. Beșliu Munteanu-C. Urduzia: Sibiu, jud. Sibiu. Punct: Turnul mic al Pulberăriei, Str. Zidului, str. Ocnei. Cronica cercetărilor arheologice. Campania 2010. A XLV-a ediţie a Sesiune Naţională de Rapoarte Arheologice, Sibiu, 22-26 Mai 2011. Ed.: M. V. Angelescu et al. Sibiu 2011, 234-235.

= P. Beșliu Munteanu-C. Urduzia: Sibiu, jud. Sibiu. Punct: str. 9 Mai. Cronica cercetărilor arheologice. Campania 2011. A XLVI-a ediţie a Sesiune Naţională de Rapoarte Arheologice, Târgu Mureş, 23-26 Mai 2012. Ed.: M. V. Angelescu. Bucureşti 2012, 254. 
Ciobanu-IacoB 2017

FABINI 1991

FABINI 1997

Fulga-Munteanu Beşliu 1997

GALEA 1997

ISTRATE 2007

ISTRATE-ROMAN-URDUZIA 2006

ISTRATE-URDUZIA 2006

ITTU 1998

JAKÓ 1997

KLUSCH 1997

LAZĂR-BEŞLIU MunTEANU 2007

LUCA-BOROFFKA 1997

LUCA et al. 2003

LuCA et al. 2007a

LUCA et al. 2007b

LUCA et al. 2007c

MARCU IsTRATE 2007

MARCU ISTRATE et al. 2006

MARCU IstRATE et al. 2015

Marcu Istrate-Roman 2007a
= V. CiobanU-D. D. IAcOB (Hrsg.): Studii de istorie a orașelor. In honorem Paul Niedermaier [Studien zur Städtegeschichte. In honorem Paul Niedermaier]. București-Brăila 2017.

= H. FABINI: Un monument medieval din Sibiu, astăzi dispărut [A medieval monument of Sibiu, Nonexistent today]. Revista Monumentelor Istorice 60/1 (1991) 74-77.

$=$ H. FABINI: Vechea primărie sibiană (The Ancient Town Hall from Sibiu). Buletinul Comisiei Monumentelor Istorice 8/1-4 (1997) 6-16.

= L. Fulga-P. Munteanu BeşLiu: Sticla transilvăneană de la Primăria Veche din Sibiu (The Transylvanian glass from Old Town Hall from Sibiu). Buletinul Comisiei Monumentelor Istorice 8/1-4 (1997) 67-74.

= S. GALEA: Ceramică modernă descoperită la Primăria Veche, Sibiu - Analiza statistică (Modern pottery discovered at the Old Town Hall from Sibiu - Statistical analysis). Buletinul Comisiei Monumentelor Istorice 8/1-4 (1997) 66.

= A. Istrate: Piața Mare. Cercetări arheologice 1-2. (Sibiu [Hermannstadt], Great Square. The Archaeological Research). Alba Iulia 2007.

= A. Istrate-C. Roman-C. Urduzia: Sibiu, jud. Sibiu. Punct: Centrul istoric, turnul bisericii catolice si colegiul iezuit. Cronica cercetărilor arheologice. Campania 2005. A XL-a Sesiune Naţională de Rapoarte Arheologice, Constanţa, 31 Mai - 3 Iunie 2006. Ed.: M. V. Angelescu, F. Vasilescu. Bucureşti 2006, 321-323.

= A. Istrate-C. Urduzia: Sibiu, jud. Sibiu. Punct: Centrul istoric, str. Avram Iancu, nr. 1-3. Cronica cercetărilor arheologice. Campania 2005. A XL-a Sesiune Naţională de Rapoarte Arheologice, Constanţa, 31 Mai -3 Iunie 2006. Ed.: M. V. Angelescu, F. Vasilescu. Bucureşti 2006, 320-321.

= F. ITTU: Contributii la cunoașterea ceramicii din zona Sibiului: Descoperirile arheologice din curtea Palatului Brukenthal [Beiträge zur Kenntnis der Keramik aus der Hermannstädter Gegend: Die archäologischen Entdeckungen aus dem Hof des Brukenthal-Palais]. Revista Monumentelor Istorice 57/1-2 (1998) 127-132.

= Zs. JAKÓ (ed.): Codex Diplomaticus Transsylvaniae. Diplomata, epistolae et alia instrumenta litteraria res Transsylvanas illustrantia I. 1023-1300. / Erdélyi okmánytár. Oklevelek, levelek és más írásos emlékek Erdély történetéhez I. 1023-1300. A Magyar Országos Levéltár kiadványai II. Forráskiadványok 26. Budapest 1997.

$=$ H. KLUSCH: Keramikfunde aus dem 17. und 18. Jahrhundert im Alten Rathaus von Hermannstadt. Buletinul Comisiei Monumentelor Istorice 8/1-4 (1997) 59-65.

= M. D. LAZĂR-P. BeŞLIU MunteAnu: Sibiu, jud. Sibiu. Punct: Piața Aurarilor. Cronica cercetărilor arheologice. Campania 2006. A XLI-a ediţie a Sesiune Anuale de Rapoarte Arheologice, Tulcea 2007. Ed.: M. V. Angelescu, F. Vasilescu. Bucureşti 2007, 317-320.

= S. A. LuCA-N. G. O. BorofFKA: Noi descoperiri preistorice din Sibiu (New prehistorical discoveries in Sibiu). Buletinul Comisiei Monumentelor Istorice 8/1-4 (1997) 75-78.

$=$ S. A. LuCA-Z. K. PINTER-A. GEORGESCU: Repertoriul siturilor arheologice şi monumentelor istorice din judeţul Sibiu [Verzeichnis der archäologischen Stätten und historischen Denkmäler im Kreis Hermannstadt]. Bucureşti 2003.

= S. A. Luca-A. Dragotă-D. Popa-S. Istrate Purece-A. Sonoc-I. Suciu-I. M. Ţiplic: Sibiu, jud. Sibiu. Punct: Piața Gării (1 Decembrie), C.F. 51.216, nr. topo 3236/1/1/1/1/1/1/1/1/3. In: Cronica cercetărilor arheologice. Campania 2006. A XLI-a ediţie a Sesiune Anuale de Rapoarte Arheologice, Tulcea 2007. Ed.: M. V. Angelescu, F. Vasilescu. Bucureşti 2007, 332-334.

= S. A. LuCA et al.: Sibiu, jud. Sibiu. Punct: Piața Gării (Piața 1 Decembrie 1918, turnul Porții Elisabeta). Cronica cercetărilor arheologice. Campania 2006. A XLI-a ediţie a Sesiune Anuale de Rapoarte Arheologice, Tulcea 2007. Ed.: M. V. Angelescu, F. Vasilescu. Bucureşti 2007, 314-316.

= S. A. LucA et al.: Sibiu, jud. Sibiu. Punct: Piața Unirii (Cazarma '90 și turnul Porții Cisnădiei). Cronica cercetărilor arheologice. Campania 2006. A XLI-a ediţie a Sesiune Anuale de Rapoarte Arheologice, Tulcea 2007. Ed.: M. V. Angelescu, F. Vasilescu. Bucureşti 2007, 328-332.

= D. Marcu Istrate: Sibiu. Piața Huet. Monografie arheologică 1 [Hermannstadt. Huet-Platz. Archäologische Monographie]. Alba Iulia 2007.

= D. Marcu Istrate-A. Istrate-C. Roman-M. ȚiPlic-D. TĂnase-A. Nițoi: Sibiu, jud. Sibiu. Punct: Piața Huet. Cronica cercetărilor arheologice. Campania 2005. A XL-a Sesiune Naţională de Rapoarte Arheologice, Constanţa, 31 Mai - 3 Iunie 2006. Ed.: M. V. Angelescu, F. Vasilescu. Bucureşti 2006, 323.

= D. Marcu Istrate-M. Constantinescu-A. Soficaru: The Medieval Cemetery from Sibiu (Hermannstadt). Huet Square: Archaeology, Anthropology, History. Erlangen 2015.

= D. Marcu Istrate-T. C. Roman: Sibiu, jud. Sibiu. Punct: Străzile Cetății și Tipografilor. Cronica cercetărilor arheologice. Campania 2006. A XLI-a ediţie a Sesiune Anuale de Rapoarte Arheologice, Tulcea 2007. Ed.: M. V. Angelescu, F. Vasilescu. Bucureşti 2007, 316-317. 
MARCU Istrate-Roman 2007b

MunTEANU 2006

Munteanu BeşLiu 1991

Munteanu BeşLiu 1993a

Munteanu BeşLiu 1993b

Munteanu BeşLiu 1994a

MunteAnu BeșLiu 1994b

Munteanu Beșliu 1995

MunteAnu BeȘLiU 1996

Munteanu Beșliu 1997a

Munteanu Beșliu 1997b

Munteanu BeşLiu 1998a

Munteanu Beșliu 1998b

Munteanu Beșliu 1998c

Munteanu BeșLiU 2000a

Munteanu Beșliu 2000b

Munteanu BeșLiu 2001

Munteanu BeșLiu 2002

Munteanu Beșliu 2003a

Munteanu Beșliu 2003b

Munteanu BeșLiu 2003c

Munteanu BeșLiu 2003d

Munteanu Beșliu 2004a
= D. Marcu Istrate-T. C. Roman: Sibiu, jud. Sibiu. Punct: Piaţa Mare, nr. 2 (Gimnaziul iezuit). Cronica cercetărilor arheologice. Campania 2006. A XLI-a ediţie a Sesiune Anuale de Rapoarte Arheologice, Tulcea 2007. Ed.: M. V. Angelescu, F. Vasilescu. Bucureşti 2007, 327-238.

= C. Munteanu: Despre sediul breslei croitorilor din Sibiu [Über den Sitz der Schneiderzunft in Hermannstadt]. Corviniana 10 (2006) 213-226.

= P. MunteAnU BeşLiu: Archäologische Forschungen im „Hermeshaus“ (Gewerbeverein) von Hermannstadt. Zeitschrift für Siebenbürgische Landeskunde 14/2 (1991) 151-163.

= P. MunteAnu BeșLiu: Zur Geschichte einer Hermannstädter Klosterkirche aus der zweiten Hälfte des 13. Jahrhunderts. Zeitschrift für Siebenbürgische Landeskunde 16/1 (1993) 12-31.

= P. MunteAnu BeşLIU: Cercetări arheologice la Casa Hermes din Sibiu (Archäologische Forschungen im „Hermeshaus“ von Hermannstadt). Buletinul Comisiei Monumentelor Istorice 4/1-2 (1993) 43-50.

= P. Munteanu Beșliu: Sibiu, jud. Sibiu. Punct: Centru istoric. http://cronica.cimec.ro/detaliu. asp?k=152\&d=Sibiu-Centru-istoric-1994 (21.8.2017.).

= P. MunTEANU BeșLiU: Vase din lut și sticlă descoperite la săpătura arheologică Sibiu, Piața Huet nr. 3 [Vessels of clay and glass find in the archaeological digging in Sibiu, Huet Market 3]. Anuarul Institutului de Cercetări Socio-Umane Sibiu 1 (1994) 55-68.

= P. Munteanu BeșLiu: Sibiu, jud. Sibiu. Punct: Turnul Sfatului, CCA. Campania 1995. http://cronica. cimec.ro/detaliu.asp?k=308\&d=Sibiu-Turnul-Sfatului-1995 (22.8.2017.).

= P. Munteanu Beșliu: Sibiu, jud. Sibiu. Punct: Biserica Azilului, Biserica Evanghelică, str. Avram Iancu și Blănarilor. Cronica cercetărilor arheologice. Campania 1996, 56-57. http://cronica.cimec. ro/detaliu.asp?k=460\&d=Sibiu-Biserica-Azilului-Biserica-Evanghelica-str-Avram-Iancu-si-Blanarilor-1996 (22.8.2017.).

= P. Munteanu Beșliu: Cercetările arheologice de la Primăria veche din Sibiu (Archaeological research at the Old Town Hall from Sibiu). Buletinul Comisiei Monumentelor Istorice 8/1-4 (1997) 39-49.

= P. Munteanu Beșliu: Groapa cu gunoaie arse de la Primăria Veche (The incinerated garbage hollow from Old Town Hall). Buletinul Comisiei Monumentelor Istorice 8/1-4 (1997) 55-58.

= P. Munteanu BeșLiu: Cercetări de arheologie medievală în perimetrul oraşului Sibiu efectuate în ultimul deceniu [The medieval archaeological excavations in Sibiu during the last ten years]. Arheologia Medievală 2 (1998) 87-102.

= P. Munteanu Beșliu: Arheologia Palatului Brukenthal [The Brukenthal Palace from Sibiu Archaeological excavations]. Revista Monumentelor Istorice 57/1-2 (1998) 109-126.

= P. Munteanu Beșliu: Sibiu, jud. Sibiu. Punct: Biserica Azilului. Cronica cercetărilor arheologice. Campania 1997 (1998). http://cronica.cimec.ro/detaliu.asp?k=559\&d=Sibiu-Biserica-Azilului-1997 (22.8.2017.).

= P. BeșLiu Munteanu: Primăria veche din Sibiu (Das Alte Rathaus in Hermannstadt). ConstanțaSibiu 2000.

= P. Munteanu Beșliu: Sibiu, jud. Sibiu. Punct: Biserica Azilului. Cronica cercetărilor arheologice. Campania 1999. Bucureşti 2000, 94-95.

= P. Munteanu BeșLiu: Biserici dispărute - biserici regăsite [Verschwundene Kirchen - wiedergefundene Kirchen]. Sibiu 2001.

= P. Munteanu Beșliu: Spitalul din Sibiu în secolul al XIII-lea [Das Hermannstädter Spital im 13. Jahrhundert]. Cumidava 25 (2002) 97-103.

= P. Munteanu Beșliu: Sibiu, jud. Sibiu. Punct: Piața Mică nr. 16. Cronica cercetărilor arheologice. Campania 2002. A XXXVII-a Sesiune Naţională de Rapoarte Arheologice, Covasna, 2-6 Iunie 2003. Ed.: M. V. Angelescu, B. Borş, F. Vasilescu. Bucureşti 2003, 285-287.

= P. Munteanu Beșliu: Sibiu, jud. Sibiu. Punct: Biserica Azilului. Cronica cercetărilor arheologice. Campania 2002. A XXXVII-a Sesiune Naţională de Rapoarte Arheologice, Covasna, 2-6 Iunie 2003. Ed.: M. V. Angelescu, B. Borş, F. Vasilescu. Bucureşti 2003, 283-284.

= P. Munteanu BeșLiu: Sibiu, jud. Sibiu. Punct: str. Avram Iancu, nr. 11. Cronica cercetărilor arheologice. Campania 2002. A XXXVII-a Sesiune Naţională de Rapoarte Arheologice, Covasna, 2-6 Iunie 2003. Ed.: M. V. Angelescu, B. Borş, F. Vasilescu. Bucureşti 2003, 287-289.

= P. Munteanu Beșliu: Sibiu, str. Avram Iancu, nr. 11 - Studiu arheologic. Cronica cercetărilor arheologice. Campania 2002. A XXXVII-a Sesiune Naţională de Rapoarte Arheologice, Covasna, 2-6 Iunie 2003. Ed.: M. V. Angelescu, B. Borş, F. Vasilescu. Bucureşti 2003, 139-162.

= P. Munteanu Beșliu: Sibiu, jud. Sibiu. Punct: Piața Gării, Strada Alexandru Odobescu - Sala de Sport, Strada Cetății. Cronica cercetărilor arheologice. Campania 2003. A XXXVIII-a Sesiune Naţională de Rapoarte Arheologice, Cluj-Napoca, 26-29 Mai 2004. Ed.: M. V. Angelescu, I. Oberlănder·Târnoveanu, F. Vasilescu. Bucureşti 2004, 301-308. 
Munteanu BeșLiu 2004b

Munteanu BeșLiU-Guttmann 1995

NÄGLER-RILL-MunTEANU-BEŞLIU 1997

NIEDERMAIER 2005

NiȚOI et al. 2004

NiȚOI et al. 2014

NiţOI-PoP 2005

NiȚOI-URDUZIA 2014

PINTER 2003

PINTER 2004

PINTER 2012

PINTER 2013

PINTER-T, TIPLIC 2003

PINTER et al. 2000

ROLLER 1952

RoMAN 2007

SALONTAI 2002

SEIWERT 1874

SIGERUS 2003

SigerUS 2006

T,IPLIC 2000

T,IPLIC 2006a

T,IPLIC 2006b

TiPLIC 2016
= P. Munteanu BeșLiu: Casa Schasser (Sibiu, Piața Mică, nr. 12). Raport arheologic [Schasser-Haus (Hermannstadt, Kleiner Ring Nr. 12). Archäologischer Bericht]. Corviniana 8 (2004) 167-182.

= P. Munteanu Beșliu-Sz. Guttmann: Cercetările arheologice de la sala Thalia din Sibiu [The archaeological investigation of the Thalia Hall in Sibiu]. Anuarul Institutului de Cercetări SocioUmane Sibiu 2 (1995) 59-75.

= Th. NÄGLER-M. RiLl-P. MunTEAnU-BeșLiu: Primăria veche - Turnul de locuit (The Old Town Hall - The Inhabited Tower). Buletinul Comisiei Monumentelor Istorice 8/1-4 (1997) 50-54.

= P. NiEdERMAIER (Hrsg.): Elenchus Fontium Historiae Urbanae - Quellensammlung zur Frühgeschichte der Stadt in Rumänien (bis 1301) / Izvoare privind istoria timpurie a oraşelor din România (până în anul 1301). București 2005.

= A. Nițoi-C. Munteanu-R. C. Pop-E. Penciu: Elementele de „mobilier urban” în Piața Mare din Sibiu: statuia Sf. Nepomuk (Elemente städtischer Mobiliar auf dem Großen Ring in Hermannstadt/ Sibiu. Die Statue des heiligen Nepomuk). Corviniana. Acta Musei Corviniensis 8 (2004) 189-207.

= A. Nițoi-C. UrduZia-V. Palaghie-Gh. V. Natea: Rescue archaeological excavations on Turnului Street from Sibiu. Brukenthal Acta Musei 9/1 (2014) 109-124.

= A. NiţoI-R. PoP: Observații privind cercetările arheologice din centrul Sibiului - Casa Parohială Romano-Catolică - Piața Mare nr. 2 [Bemerkungen zu den archäologischen Forschungen im Zentrum von Hermannstadt - Das Römisch-Katholische Pfarrhaus - Großer Ring Nr. 2]. Corviniana 9 (2005) 195-209.

= A. NițOI-C. URduZIA: Elements of fortification of the medieval and early modern city of Sibiu. The Tower Gate and the Gate's Bastion. Historical and archaeological considerations. Ziridava 28 (2014) 243-258.

= Z. K. PinTER: Rotonda de la Orăștie [Die Brooser Rotunde (Rundkapelle)]. In: D. MARCU IstrateA. IstRATE-C. GAIU (coord.): In memoriam Radu Popa. Temeiuri ale civilizației românești în context european. Biblioteca Muzeului Bistrița Ser. Historica 7. Cluj-Napoca 2003, 263-286.

= Z. K. PINTER: Casa din strada Vopsitorilor nr. 13 (Sibiu). Sondaje arheologice [Das Haus in der Färbergasse Nr. 13 (Hermannstadt). Archäologische Forschungen]. Studia Universitatis Cibiniensis Ser. Historica 1 (2004) 55-64.

= Z. K. PINTER: Die mittelalterliche Rotunde am Huet-Platz in Hermannstadt/Sibiu. Forschungen zur Volks- und Landeskunde 55 (2012) 32-57.

= Z. K. PINTER: The Rotunda from Huet Square in Sibiu. Brukenthal Acta Musei 8/1 (2013) 79-98.

= Z. K. PINTER-I. M. TiPlic: Sibiu, jud. Sibiu. Punct: Piața Huet - Rotondă. Cronica cercetărilor arheologice. Campania 2002. A XXXVII-a Sesiune Naţională de Rapoarte Arheologice, Covasna, 2-6 Iunie 2003. Ed.: M. V. Angelescu, B. Borş, F. Vasilescu. Bucureşti 2003, 284-285.

= Z. K. Pinter-I. M. ŢiPliC-M. CRÎNGaCI-A. Niţoi: Sibiu, jud. Sibiu. Punct: str. Vopsitorilor nr. 13. Cronica cercetărilor arheologice. Campania 1999 (2000). http://cimec.ro/Arheologie/newcronica2000 (22.8.2017.).

= M. Roller (red.): Documente privind istoria României. Veacul XIII. C. Transilvania [Urkunden zur Geschichte Rumäniens. C. Siebenbürgen, 13. Jahrhundert]. II.: 1251-1300. Bucureşti 1952.

= T. C. RomAn: Cercetările arheologice de la colegiul iezuit [Die archäologischen Forschungen am Jesuitenkolleg]. In: IsTRATE 2007, 43-52.

= M. S. SALONTAI: Mănăstiri dominicane din Transilvania [The houses of the Dominican Order in Transylvania]. Bibliotheca Ars Transilvaniae. Cluj-Napoca 2002.

$=$ G. SEIWERT: Das älteste Hermannstädter Kirchenbuch. Archiv des Vereins für Siebenbürgische Landeskunde 11/3 (1874) 323-410.

= E. SigERUS: Vom alten Hermannstadt (Nachdruck der Ausgabe Hermannstadt 1922). Heilbronn 2003.

= E. SigERUS: Cronica orașului Sibiu 1100-1929 [Chronik der Stadt Hermannstadt 1000-1929]. Sibiu 2006.

= I. M. ȚIPLIC: Identificarea unei capele gotice din Sibiu (Piața Huet, nr. 17) [Identifizierung einer gotischen Kapelle in Hermannstadt, Huet-Platz Nr. 17]. Arheologia Medievală 3 (2000) 117-126.

= I. M. ȚIPLIC: Raport privind supravegherea arheologică: Traseu canalizare și cabluri de curent electric. Piața agro-alimentară Cibin, Sibiu, septembrie 2006 [Bericht über die archäologische Überwachung: Trasse der Kanalisation und Stromkabel. Lebensmittelmarkt Zibin, Hermannstadt]. (Unveröffentlicht.)

= I. M. ȚiPLIC: Sibiu, jud. Sibiu. Punct: Piața 1 Decembrie 1918. Cronica cercetărilor arheologice. Campania 2005. A XL-a Sesiune Naţională de Rapoarte Arheologice, Constanţa, 31 Mai - 3 Iunie 2006. Ed.: M. V. Angelescu, F. Vasilescu. Bucureşti 2006, 325-326.

= I. M. ȚiPLIC: Raport de cercetare arheologică: Sibiu - Piața Mică nr. 22, 22. Februar 2016 [Archäologischer Forschungsbericht: Hermannstadt - Kleiner Ring Nr. 22]. (Unveröffentlicht.) 
ȚIPLIC o. J.

TुIPLIC-CRÎNGACI 2000

ŢIPLIC-CRîNGACI 2002

TुIPLIC-PURECE-SUCIU 2007

ȚIPLIC-ȚIPLIC-IGNAT 2015

ȚiPLIC-ȚiPLIC-PuRECE 2009

URDUZIA 2010

URDUZIA-PINTER 2006

URDUZIA-PINTER 2008

ZIMMERMANN-WERNER 1892
= I. M. ȚIPLIC: Raport de cercetare arheologică. Sibiu - str. Movilei nr. 1 [Archäologischer Forschungsbericht. Hermannstadt - Neustift Nr. 1]. (Unveröffentlicht.)

= I. M. TुIPLIC-M. CRîngACI: Sibiu, jud. Sibiu. Punct: Piața Huet nr. 17. Cronica cercetărilor arheologice. Campania 1999 (2000). http://cimec.ro/Arheologie/newcronica2000 (22.8.2017.).

= I. M. TIPLIC-M. E. CRÎNGACI: Sondajul arheologic din interiorul Bisericii Parohiale Evanghelice din Sibiu [Die archäologischen Probegrabungen in der Evangelischen Stadtpfarrkirche von Hermannstadt]. Ziridava 23 (2002) 75-84.

= I. M. ŢIPLIC-S. I. PURECE-C. I. SUCIU: Raport privind supravegherea arheologică: Îmbunătătire sistem de alimentare cu gaze naturale Piața Unirii - Sibiu, 8. Mai 2007. Sibiu [Bericht über die archäologische Überwachung: Trasse der Kanalisation und Stromkabel. Lebensmittelmarkt Zibin]. (Unveröffentlicht.)

= I. M.Țiplic-M. E. ŢipLic-C. I. Ignat: Biserica Evanghelică, Sibiu, jud. Sibiu. Punct: Biserica evanghelică. Cronica cercetărilor arheologice în Romania. Campania 2014. A XLIX-a ediţie a Sesiune Naţională de Rapoarte Arheologice, Piteşti, 28-30 Mai 2015. Red.: D. Mihai. Bucureşti 2015, 241-242.

= I. M. ȚIPLIC-M. E. ȚIPLIC-S. I. PuRECE: Raport arheologic Biserica parohială evanghelică - Bischofsloge, 15. Juli 2009, Sibiu [Archäologischer Bericht: Evangelische Stadtpfarrkirche Bischofsloge]. (Unveröffentlicht.)

= C. URDUZIA: Mărturii arheologice de civilizație urbană transilvăneană (secolele XIII-XV.) [Archäologische Belege siebenbürgischer Stadtzivilisation (13.-15. Jahrhundert)]. Dissertation an der Lucian-Blaga-Universität Sibiu. Sibiu 2010.

= C. URduZiA-Z. K. PINTER: Cercetări arheologice la o casă medievală din Sibiu, Piața Mică, nr. 24 [Archaeological diggings in a medieval house in Sibiu, 24, Small Square]. Corviniana 10 (2006) 195-212.

= C. URduZia-Z. K. Pinter: Vechi piese de mobilier urban din Piața Mare din Sibiu [Alte Stücke städtischen Mobiliars auf dem Großen Ring in Hermannstadt]. Brukenthal Acta Musei 3/1 (2008) 243-262.

$=$ Fr. ZiMMERMANN-C. WERNER (Hrsg.): Urkundenbuch zur Geschichte der Deutschen in Siebenbürgen. I.: 1191 bis 1342. Nummer 1 bis 582. Hermannstadt 1892. 